\title{
Building Safe Lithium-Ion Batteries for Electric Vehicles: A Review
}

\author{
Jian Duan ${ }^{1} \cdot$ Xuan Tang ${ }^{2} \cdot$ Haifeng Dai $^{2} \cdot$ Ying Yang $^{1} \cdot$ Wangyan $\mathrm{Wu}^{1} \cdot$ Xuezhe Wei $^{2} \cdot$ Yunhui Huang $^{1}$
}

Received: 8 April 2019 / Revised: 13 June 2019 / Accepted: 5 December 2019 / Published online: 28 December 2019

(C) The Author(s) 2019

\begin{abstract}
Lithium-ion batteries (LIBs), with relatively high energy density and power density, have been considered as a vital energy source in our daily life, especially in electric vehicles. However, energy density and safety related to thermal runaways are the main concerns for their further applications. In order to deeply understand the development of high energy density and safe LIBs, we comprehensively review the safety features of LIBs and the failure mechanisms of cathodes, anodes, separators and electrolyte. The corresponding solutions for designing safer components are systematically proposed. Additionally, the in situ or operando techniques, such as microscopy and spectrum analysis, the fiber Bragg grating sensor and the gas sensor, are summarized to monitor the internal conditions of LIBs in real time. The main purpose of this review is to provide some general guidelines for the design of safe and high energy density batteries from the views of both material and cell levels.
\end{abstract}

Keywords Electric vehicles $\cdot$ Lithium-ion battery $\cdot$ Safety $\cdot$ Batteries design $\cdot$ Real-time monitoring

\section{Introduction}

Nowadays, lithium-ion batteries (LIBs) are important energy storage devices because of their high energy/power density, long cycle life and environmental friendliness [1,2]. Having dominated as the power sources for consumer electronics, LIBs are advancing into the field of transportation, especially electric vehicles (EVs) [3]. One important parameter of EVs is driving range per charge, which is closely related to energy density and the weight ratio of the LIB system to the whole car, etc. Since the energy density is the most important factor to fulfill a long driving range $\mathrm{EV}$, many countries have set goals to design the LIBs with high energy density in the near

Jian Duan, Xuan Tang and Haifeng Dai have contributed equally to this work.

\footnotetext{
Ying Yang

yingyang@tongji.edu.cn

$\triangle$ Xuezhe Wei

weixzh@tongji.edu.cn

Yunhui Huang

huangyh@tongji.edu.cn

1 School of Materials Science and Engineering, Tongji University, 4800 Caoan Road, Shanghai 201804, China

2 Clean Energy Automotive Engineering Center, School of Automotive Studies, Tongji University, 4800 Caoan Road, Shanghai 201804, China
}

future. For example, the objective of energy density is set to be $350 \mathrm{Wh} \mathrm{kg}^{-1}$ for the cell and $250 \mathrm{Wh} \mathrm{kg}^{-1}$ for the pack by 2020 , and the driving range of EVs is set to be $400 \mathrm{~km}$ for one charge in China [4]. Presently, in order to achieve the above energy density goals, many efforts have been focused on developing high-capacity cathode and anode materials of LIBs [5-7]. For cathode materials, Ni-rich ternary materials $\mathrm{Li}\left(\mathrm{Ni}_{x} \mathrm{Co}_{y} \mathrm{Mn}_{z}\right) \mathrm{O}_{2}(x>0.5)$ or $\mathrm{Li}\left(\mathrm{Ni}_{0.85} \mathrm{Co}_{0.1} \mathrm{Al}_{0.05}\right) \mathrm{O}_{2}(\mathrm{NCA})$ and Mn-based Li-rich metal-oxide $x \mathrm{Li}_{2} \mathrm{MnO}_{3} \cdot(1-x) \mathrm{LiMO}_{2}$ $(\mathrm{M}=\mathrm{Mn}, \mathrm{Co}, \mathrm{Ni})$ have been considered as the most promising candidates with high capacity $[8,9]$, while on the anode side, major efforts have been devoted to constructing siliconbased [10] or tin-based carbon composites with high capacity and good cycling stability [11]. However, higher-capacity materials tend to show lower thermal stability. For instance, Ni-rich materials $\left[\mathrm{Li}\left(\mathrm{Ni}_{1-x-y} \mathrm{Co}_{x} \mathrm{Mn}_{y}\right) \mathrm{O}_{2}\right]$ with a higher $\mathrm{Ni}$ content could offer higher capacity, but their thermal stability would be reduced [12].

Apart from energy density, safety is another main concern for LIBs widespread application [13]. Several burning accidents of portable electronics and EVs have been reported and drawn lots of public attention. Researchers have paid more attention to the essence of unsafe behavior of LIBs, showing that the exothermic reactions inside batteries are the main reasons. In general, these exothermic reactions include: (1) excessive delithiation of cathodes would result in irreversible structure change of cathodes, oxygen release and oxidization of 
organic solvents [14]; (2) lithium dendrites formed on anodes react with electrolytes to generate a large amount of gas, heat and continuous growth of lithium dendrites, which could further penetrate separator and hence result in internal short circuit of batteries [15]; (3) the melting of PE-based separators when temperature increases to above $130^{\circ} \mathrm{C}$, which also leads to internal short circuit [16]; (4) the electrolyte is easily decomposed at high temperature $\left(>200{ }^{\circ} \mathrm{C}\right)$ and high voltage (about 4.6 V) due to the carbonate organic solvents with low flash points and low boiling points, which will generate large amount of heat $[17,18]$. When the amount of heat generation is higher than its dissipation in a battery, the exothermic reactions will cause fast increase in internal temperature and pressure of batteries, which may result in thermal runaways, burning or even explosion of LIBs [19, 20]. Nowadays, with the help of advanced characterization and electrochemical analysis techniques, the researchers are trying to get a deeper understanding of safety issues of LIBs and then design novel, safe and high-capacity cathode and anode materials, as well as stabler electrolytes and separators for better batteries with high energy density for EVs. In practical application, LIBs are assembled in series and parallels into a battery module with high voltage and energy, and the safety issue of the battery system is different from a single cell [21]. Rather than just focusing on safer materials for LIBs, it is necessary to develop real-time internal state monitoring methods to keep track of the cell's state of charge (SOC) [22] and state of health ( $\mathrm{SOH})$ [23], electrolyte leakage [24], dendrite growth [25], etc., to ensure the safety of the running cells at the same time. For example, in situ ultrasonic detection for tracking SOC [26], neutron diffraction for dendrite detection [27] and a gas sensor for electrolyte leakage detection [24] can be used to monitor the internal state of the battery during operation, thus ensuring that the battery is working within the safety range. In this review, we aim to provide guidance toward reasonable materials design and effective cell monitoring methods for the practical application of high energy density LIBs in EVs. We systematically discuss the safety features of LIBs and give a brief summary of certification standards before LIBs applied in EVs and failure mechanisms of cathodes and anodes. Based on the failure mechanisms, we collect and discuss the corresponding methods for fabricating applicable electrode materials for high-quality LIBs. To ensure LIBs working within the safety range, advanced monitoring methods for the cells are summarized. Finally, we present a prospect for the future development of safer LIBs in EVs.

\section{Safety Issue of LIBs}

Due to high energy density, high voltage and long cycle life, LIBs have been applied extensively in the fields such as consumer electronics and transportation since their invention in
1991 by Sony Ltd. [28]. The safety of LIBs is long regarded as one of the important issues due to the serious consequence. Even for the small cell phones, once the explosion accident happens, it will draw much public attention to the safety issues, cause maybe millions of dollars loss and bring damage to the extensive application [29, 30]. Compared with consumer electronics, EVs are driven by high-energy and power battery systems that contain a large number of cells connected in series and parallels [21]. For example, the Tesla Model S ( $99 \mathrm{kWh}$ battery pack) is powered by 8256 cylindrical cells packed together in series and parallels. The safety issue becomes more important and also more complicated. Due to the special working condition of EVs, the battery system will suffer different kinds of vibration, extreme temperature, water soak, fast charging and so on, which are big challenges for LIBs [29, 31, 32]. The triggering conditions of the failures for EVs include car crash, hard object intrusion, overcharge, overdischarge, water soak, overheat, battery leakage and electrical system failure, etc. In order to design a safer and more reliable LIB-based energy system for EVs $[29,31]$, it is important to gain a deep and comprehensive understanding of LIBs safety issue behind these accidents.

\section{Safety Features of LIBs and Certification Standards}

As we know, a LIB contains two electrodes, the cathode and the anode, separated by the ion-conductor and electroninsulator nonaqueous electrolyte. The electrode materials usually have a layered structure with lithiation/delithiation ability. LIBs have high cell voltage, high volumetric, gravimetric and power density, which have gradually become principal energy sources in our daily life. However, $\mathrm{Li}$ is an active element, and the LIBs always work at various voltages, temperatures and other conditions; thus, their safety issues should be especially concerned.

In general, LIBs are temperature- and voltagesensitive products. Figure 1 shows the behaviors of $\mathrm{Li}\left(\mathrm{Ni}_{0.5} \mathrm{Co}_{0.2} \mathrm{Mn}_{0.3}\right) \mathrm{O}_{2} /$ graphite-based LIBs at various voltages and temperatures [33]. There is a comfortable zone with a voltage range from 2.5 to $4.2 \mathrm{~V}$ and a temperature range from -30 to $55{ }^{\circ} \mathrm{C}$, which is the design index formulated by the battery plant. As temperature increases, the batteries possess better rate capability due to fast ion migration both in the electrolyte and in electrode materials, and quick electrochemical reaction, but the side reactions become severe, resulting in a fast capacity decay. If the temperature continues increasing, hazards may occur due to the decomposition of the solid electrolyte interface (SEI) as well as electrode materials and continues intensified side reactions. On the other hand, low temperature will lead to lithium plating on the anode and poor rate capability. Overcharge will result in 
Fig. 1 The behaviors of $\mathrm{Li}\left(\mathrm{Ni}_{0.5} \mathrm{Co}_{0.2} \mathrm{Mn}_{0.3}\right) \mathrm{O}_{2} /$ graphitebased LIBs at various voltages and temperatures. Reproduced with permission from Ref. [33]. Copyright 2018, Science Publishing Group

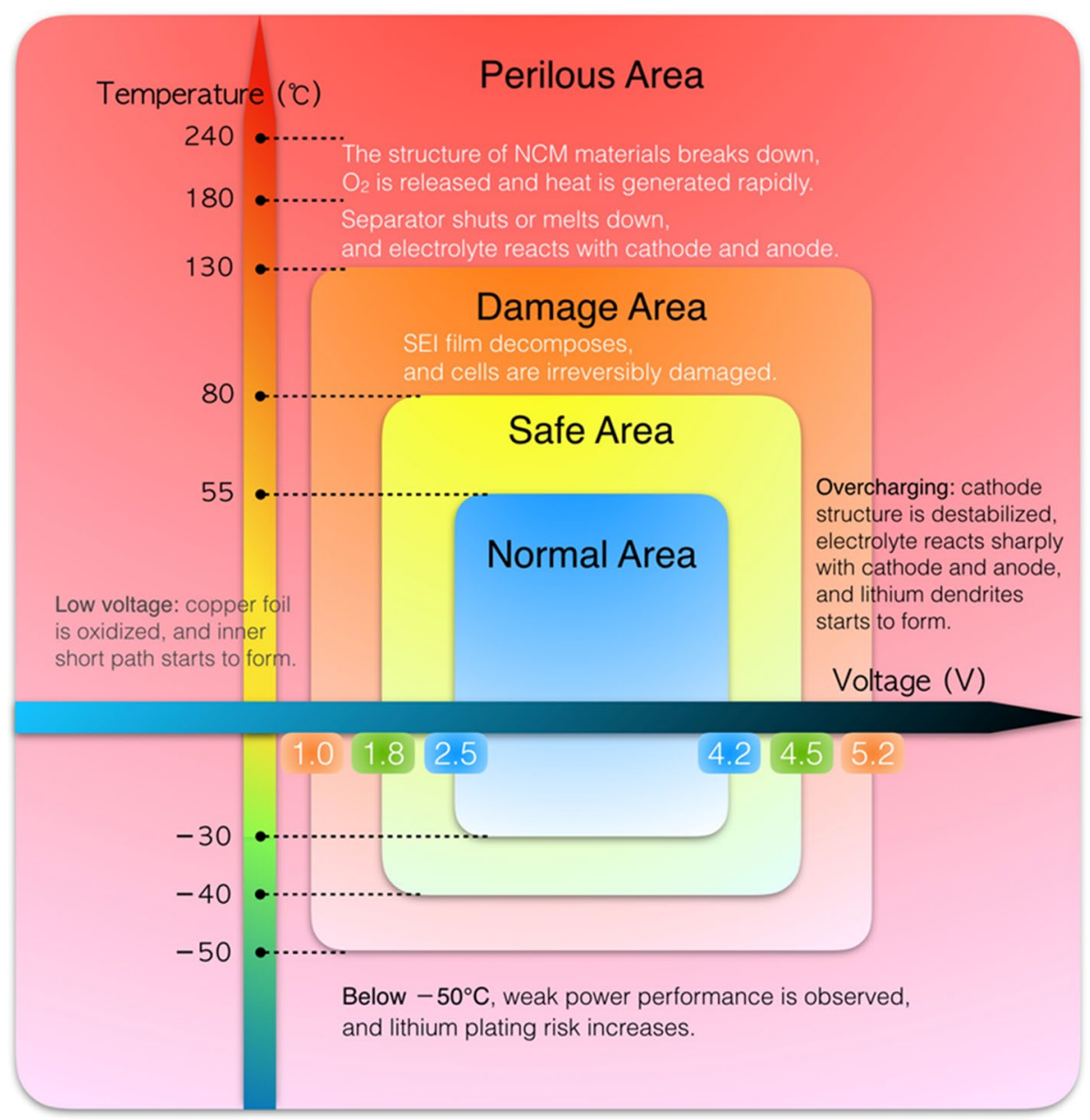

the decomposition of cathode materials and the oxidization of the electrolyte due to depleted lithium ion of the cathode. Overdischarge will lead to the decomposition of SEIs on the anode and may even cause copper foil oxidization. More details are analyzed as below.

\subsection{Safety Features of LIBs}

\subsubsection{LIB Behaviors at Various Voltages}

Overcharge Overcharge often happens when the battery is charged forcedly after reaching cutoff voltage [32]. Generally, once the battery is overcharged, over much lithium will be delithiated from the cathode and plate on the anode [15, 34]. It is a common viewpoint that overcharge will cause a collapse of cathode materials and exacerbate exothermic side reactions, which will generate a lot of heat and hence rapidly increase the battery internal temperature [32, 35]. According to public data, overcharge is one major reason for EV failures. Deeply understanding the overcharge is critical for designing safe and reliable EV batteries.

On the cathode side, the olivine-type $\mathrm{LiFePO}_{4}$ (LFP) cathode has the best overcharge performance due to its stabler structure after full delithiation. Iriyama's experiments indicate that LFP could keep its structure stable even if charged to $5.0 \mathrm{~V}$ (vs. $\mathrm{Li} / \mathrm{Li}^{+}$) [36]. On the contrast, overdelithiation of the layered oxide cathode often leads to the collapse of material structure, the decomposition of active materials and severe side reactions [37-39], and may even lead to the molecular oxygen release, resulting in severe oxidation of the electrolyte [35, 38]. Although the ohmic heat increases with internal resistance, the rapid temperature increase inside the cell is mainly due to the serious side reactions between the cathode and the electrolyte [35, 40]. Zeng et al. [35] reported that $\mathrm{Li}_{x} \mathrm{CoO}_{2}$ could be deeply charged to oxidative $\mathrm{CoO}_{2}$, but $x=0.16$ is a critical point. If the value $x$ is less than $0.16, \mathrm{Li}_{x} \mathrm{CoO}_{2}$ will react with electrolytes violently, releasing a lot of gases and heat. The critical point for the cell with $\mathrm{LiNi}_{0.33} \mathrm{Co}_{0.33} \mathrm{Mn}_{0.33} \mathrm{O}_{2}$ as the cathode is at $180 \%$ SOC $[40,41]$. Once the cell is charged over $180 \%$ SOC, the cathode reacts violently with the electrolyte, and the internal temperature goes up rapidly [40].

Overcharge will also be much easy to cause the dissolution of transition metal into the electrolyte, which will deeply deteriorate the electrochemical performance of the graphite anode [41]. In the $\mathrm{LiMn}_{2} \mathrm{O}_{4}$ /graphite battery, the 
solvated $\mathrm{Mn}^{2+}$ from the cathode will deposit on the carbon anode surface and cause a significant impedance rise and capacity fade of the anode [42, 43].

For the anode side, metallic lithium will deposit on the anode surface due to too much lithium for anode acception $[34,44]$. The deposited lithium will react with the electrolyte, leading to impedance increase and a lot of heat generation at the same time [34]. In the worst case, the deposited lithium will form dendrites that could puncture the separator and lead to self-short, which may trigger the thermal runaway [45-47]. Optimizing the cutoff voltage is an effective way to maintain low cell impedance and prolong the cycle life without sacrificing the energy output. Improving the structure stability of the cathode and the electrochemical stability of the electrolyte at high voltage is effective for the batteries to endure the overcharge.

Overdischarge Overdischarge means that the cell is discharged to the voltage below the lowest limit, which depends on the chemistry of the battery. Overdischarge will deteriorate the performance of LIBs or even lead to serious safety problems, such as internal short circuit.

Overdischarge of the anode will cause decomposition of the SEI, generating gases like carbon dioxide, methane and carbon monoxide, thus inducing the cell swell [48]. Once the battery is recharged, new SEIs will be formed, consuming active lithium ions and electrolytes. And the new SEI will change the electrochemical properties of the anode, leading to capacity degradation [49]. In the case of deep overcharge, once the anode potential reaches the oxidation potential of copper around $3.5 \mathrm{~V} \mathrm{(vs.} \mathrm{Li}^{+} / \mathrm{Li}$ ), the copper current collector will be oxidized and $\mathrm{Cu}^{2+}$ ions will be dissolved into the electrolyte and migrate across the separator [50, 51]. Then the $\mathrm{Cu}^{2+}$ ions will be reduced during the subsequent charging process, leading to the deposition of $\mathrm{Cu}$ dendrites on the cathode [50]. With the growth of $\mathrm{Cu}$ dendrites, the separator will be penetrated, resulting in self-short and even triggering a thermal runaway [49].

Besides that, the morphology of the cathode material also changes during the overdischarge process [51, 52]. Shu et al. investigated the structural change of $\mathrm{LiCoO}_{2}$ during the overdischarge process. They noticed the irreversible formation of the metastable phase $\mathrm{Li}_{1+x} \mathrm{Co}^{\mathrm{II}}{ }^{\mathrm{III}} \mathrm{O}_{2-y}$ when the voltage goes under $1.0 \mathrm{~V}$ (vs. $\mathrm{Li}^{2} / \mathrm{Li}^{+}$), the $\mathrm{Li}_{1+x} \mathrm{Co}^{\mathrm{IIIII}} \mathrm{O}_{2-y}$ will decompose into $\mathrm{Li}_{2} \mathrm{O}$ and $\mathrm{Co}$ as the final products [53]. For LFP, it could be overdischarged to $1.0 \mathrm{~V}$ (vs. $\mathrm{Li} / \mathrm{Li}^{+}$) without any damage. With further overdischarging to $0 \mathrm{~V}$ (vs. $\mathrm{Li} / \mathrm{Li}^{+}$), the olivine structure will collapse, forming amorphous compounds [52]. In other words, LFP will be destroyed completely with the insertion of $3.78 \mathrm{Li}$ ions. For spinel $\mathrm{LiMn}_{2} \mathrm{O}_{4}$ (LMO), with overdischarging, the tetragonal $\mathrm{Li}_{2} \mathrm{Mn}_{2} \mathrm{O}_{4}$ is produced at $1.0 \mathrm{~V}$ (vs. $\mathrm{Li} / \mathrm{Li}^{+}$), and the process is reversible. If the voltage drops to $0.33 \mathrm{~V}$ (vs. $\left.\mathrm{Li} / \mathrm{Li}^{+}\right), \mathrm{LMO}$ will be destroyed to irreversible solid-state amorphization $[52,54]$. The layered Ni-rich $\mathrm{LiNi}_{x} \mathrm{Mn}_{y} \mathrm{Co}_{z} \mathrm{O}_{2}$ $(x+y+z=1)$ now becomes hot cathode materials to meet the increasing demand of high energy density, and their overdischarging performances are even poorer than those of LFP and LMO.

\subsubsection{LIB Behaviors at Various Temperatures}

Low-temperature performance At freezing temperature, LIBs will suffer from capacity fade, power attenuation and charge difficulty, etc. [55, 56], which is ascribed to the low electrolyte conductivity [57], poor kinetics of charge transfer $[58,59]$, increased SEI resistance $[55,60]$ and low solidstate lithium diffusivity in graphite [61]. The aforementioned low diffusivity of $\mathrm{Li}$ ions will result in a decrease in the intercalation rate, leading to lithium plating at the graphite surface during the charge process [55, 59]. Most of the deposited lithium will turn into "dead lithium," and it no longer participates in the later electrode reaction, which is the major reason for capacity fading [55]. Even worse, the growing dendrites could pierce the separator membrane and induce an internal short circuit, which could result in fearful safety problems [62].

Overheat Overheat will result in serious consequences. As the temperature increases, normally, the battery undergoes the following reactions: SEI decomposition, reactions between the anode-/cathode-active materials and the electrolyte, electrolyte decomposition and the reaction between the anode-active materials and the binder, etc. [63, 64], eventually resulting in the thermal runaway of the battery system. These reactions may not happen in an exactly given order; some of them may be occurring simultaneously.

When the temperature is above $60^{\circ} \mathrm{C}$, the SEI starts to decompose and the exposed lithiated anode materials $\left(\mathrm{LiC}_{6}\right.$ as an example) will rapidly react with the electrolyte. And the high temperature will enhance the dissolution of the transition-metal ions into the electrolyte. The capacity degradation becomes fast at elevated temperature. As the temperature goes up to $90^{\circ} \mathrm{C}$, the SEI will completely decompose and side reactions will intensify, generating a lot of gases and heat. At this moment, the battery may lose most of its capacity. As temperature goes higher to the melting point of the polymer separator, the battery will lose all of the functions. The high pressure may even burst the cell, and poison gas and electrolyte solvents will be leaked out. During the overheating process, if the generated heat is more than what can be dissipated, the exothermic processes would proceed and the cell's temperature will increase rapidly. The rising temperature will further accelerate the chemical reactions, rather than the desired galvanic reactions, generating even larger amount of heat, and may eventually result in thermal runaways. Efficient thermal control of battery is vital for safe and reliable operation in the lifetime. In recent years, many 
coolants have been used in battery thermal management systems, such as liquid, air, phase change materials, hydrogel and so on $[65,66]$. The improvement of battery thermal management systems greatly depends on optimizing the heat capacity and the heat transfer rate of the coolants. Optimizing the thermal management structure to avoid the hot spot suffering overtemperature is also an effective remedy [21].

\subsection{Certification Standards of LIBs for EVs}

Accidents of EVs occurred frequently in recent years, drawing a lot of public concerns about LIB safety. In order to improve the safety of EVs, many compulsory testing standards have been formulated for the LIBs before assembling the batteries in cars. Some typical compulsory testing standards formulated by each region of the world such as SAE J2464-2009, SAE J2929-2011, QT/T 743-2006, GB/T 31485, SAND 3123-2005, UN 38.3-2011 and IEC 626602:2010 are summarized in Table 1 [67]. The tests are strived to simulate how LIBs would react in real accidents.

According to Table 1, we can see that all of the testing standards focus on mechanical abuse, thermal abuse and electrical abuse with a slight difference. For mechanical abuse, the principal items are vibration, drop, penetration, immersion and crush tests. For thermal abuse, the main issue is thermal stability. For electrical abuse, the most focused ones are external short circuit, overcharge and overdischarge tests. Nowadays, some new test subjects such as rotation, thermal shock cycles and partial short circuit have been proposed to add to the compulsory test standards. However, the reasons for EV failures are diversiform. The battery safety issue is a complex subject, which should be paid more efforts. We need to get more information from the in-depth analysis.

The European Council for Automotive Research and Development (EUCAR) assigns the hazard into 8 levels as shown in Table 2 [68]. To meet the requirement of automobile safety, the LIB failures should be suppressed at least to level 4 [69]. To alleviate the hazardous level, many works have been done, such as modifying active materials and strengthening separators. Due to the lack of cognition on the complicated failure mechanisms about LIBs, it is urgent to establish a clear and quantitative relationship among materials, electrodes and cell levels.

\section{Design for Safe LIBs on the Cell Level}

\subsection{Cathode Materials}

Presently, as shown in Table 3 [33], three types of cathode materials are widely used, which are LFP, LMO and layered

Table 1 Summary of the compulsory test standards for LIBs. Reproduced with permission from Ref. [67]. Copyright 2018, Elsevier

\begin{tabular}{|c|c|c|c|c|c|c|c|c|}
\hline No. & Standard & $\begin{array}{l}\text { SAE } \\
\text { J2464- } \\
2009\end{array}$ & $\begin{array}{l}\text { SAE } \\
\text { j2929- } \\
2011\end{array}$ & QC/T 743-2006 & GB/T 31485 & $\begin{array}{l}\text { SAND } \\
2005- \\
3123\end{array}$ & UN 38.3-2011 & $\begin{array}{l}\text { IEC } \\
62660- \\
2: 2010\end{array}$ \\
\hline \multirow[t]{8}{*}{1} & Mechanical abuse & & & & & & & \\
\hline & Vibration & N/A & $\sqrt{ }$ & $\sqrt{ }$ & $\sqrt{ }$ & N/A & $\sqrt{ }$ & $\sqrt{ }$ \\
\hline & Shock & $\sqrt{ }$ & $\sqrt{ }$ & N/A & N/A & $\sqrt{ }$ & N/A & N/A \\
\hline & Drop & $\sqrt{ }$ & $\sqrt{ }$ & $\sqrt{ }$ & $\sqrt{ }$ & $\sqrt{ }$ & N/A & N/A \\
\hline & Penetration & $\sqrt{ }$ & N/A & $\sqrt{ }$ & $\sqrt{ }$ & $\sqrt{ }$ & N/A & N/A \\
\hline & Rotation & $\sqrt{ }$ & N/A & N/A & N/A & $\sqrt{ }$ & N/A & $\mathrm{N} / \mathrm{A}$ \\
\hline & Immersion & $\sqrt{ }$ & $\sqrt{ }$ & N/A & $\sqrt{ }$ & $\sqrt{ }$ & N/A & N/A \\
\hline & Crush & $\sqrt{ }$ & $\sqrt{ }$ & $\sqrt{ }$ & $\sqrt{ }$ & $\sqrt{ }$ & $\sqrt{ }$ & $\sqrt{ }$ \\
\hline \multirow[t]{5}{*}{2} & Thermal abuse & & & & & & & \\
\hline & High-temperature hazard/vehicle fire & $\sqrt{ }$ & $\sqrt{ }$ & N/A & N/A & $\sqrt{ }$ & N/A & $\sqrt{ }$ \\
\hline & Thermal stability & $\sqrt{ }$ & N/A & N/A & N/A & $\sqrt{ }$ & N/A & N/A \\
\hline & $\begin{array}{l}\text { Thermal stability cycling (without } \\
\text { thermal management) }\end{array}$ & $\sqrt{ }$ & N/A & N/A & N/A & N/A & N/A & N/A \\
\hline & Thermal shock cycling & $\sqrt{ }$ & $\sqrt{ }$ & N/A & $\sqrt{ }$ & $\sqrt{ }$ & $\sqrt{ }$ & $\sqrt{ }$ \\
\hline \multirow[t]{6}{*}{3} & Electrical abuse & & & & & & & \\
\hline & External short circuit & $\sqrt{ }$ & $\sqrt{ }$ & $\sqrt{ }$ & $\sqrt{ }$ & $\sqrt{ }$ & $\sqrt{ }$ & $\sqrt{ }$ \\
\hline & Partial short circuit & N/A & N/A & N/A & N/A & $\sqrt{ }$ & N/A & N/A \\
\hline & Overcharge & $\sqrt{ }$ & $\sqrt{ }$ & $\sqrt{ }$ & $\sqrt{ }$ & $\sqrt{ }$ & $\sqrt{ }$ & $\sqrt{ }$ \\
\hline & Overdischarge & $\sqrt{ }$ & $\sqrt{ }$ & $\sqrt{ }$ & $\sqrt{ }$ & $\sqrt{ }$ & N/A & $\sqrt{ }$ \\
\hline & Forced discharge & N/A & N/A & N/A & N/A & N/A & $\sqrt{ }$ & N/A \\
\hline
\end{tabular}

$\sqrt{ }$-with requirement to take such a test; N/A - without requirement to take such a test 
Table 2 The EUCAR hazard levels. Reproduced with permission from Ref. [68]. Copyright 2015, American Chemical Society

\begin{tabular}{|c|c|c|}
\hline Hazard level & Description & Classification criteria and effect \\
\hline 0 & No effect & No effect. No loss of functionality \\
\hline 1 & Passive. Protection activated & $\begin{array}{l}\text { No defect; no leakage, no venting, fire or flame; no rupture, no explosion; no exothermic reaction or } \\
\text { thermal runaway; cell reversibly damaged; repair of protection device needed }\end{array}$ \\
\hline 2 & Defect/damage & $\begin{array}{l}\text { No leakage; no venting, fire, or flame; no rupture; no explosion; no exothermic reaction or thermal } \\
\text { runaway; cell irreversibly damaged; repair needed }\end{array}$ \\
\hline 3 & Leakage, $\Delta_{\text {mass }}<50 \%$ & $\begin{array}{l}\text { No venting, fire, or flame; no rupture; no explosion; weight loss }<50 \% \text { of electrolyte weight (elec- } \\
\text { trolyte ="solvent + salt") }\end{array}$ \\
\hline 4 & Venting, $\Delta_{\text {mass }} \geqslant 50 \%$ & $\begin{array}{l}\text { No fire or flame; no rupture; no explosion; weight loss } \geq 50 \% \text { of electrolyte weight (electro- } \\
\text { lyte="solvent + salt") }\end{array}$ \\
\hline 5 & Fire or flame & No rupture; no explosion (i.e., no flying parts) \\
\hline 6 & Rupture & No explosion, but flying parts of the active mass \\
\hline 7 & Explosion & Explosion (i.e., disintegration of the cell) \\
\hline
\end{tabular}

Table 3 Comparison of electrochemical properties and price for cathode materials. Reproduced with permission from Ref. [33]. Copyright 2018, Science publishing group

\begin{tabular}{|c|c|c|c|c|c|}
\hline Material & $\mathrm{LiFePO}_{4}$ & $\mathrm{LiMn}_{2} \mathrm{O}_{4}$ & $\mathrm{LiCoO}_{2}$ & $\mathrm{Li}\left(\mathrm{Ni}_{x} \mathrm{Co}_{y} \mathrm{Mn}_{z}\right) \mathrm{O}_{2}$ & $\mathrm{LiNi}_{0.8} \mathrm{Co}_{0.15} \mathrm{Al}_{0.05} \mathrm{O}_{2}$ \\
\hline Average voltage (V) & 3.4 & 3.8 & 3.7 & 3.6 & 3.6 \\
\hline Specific capacity $\left(\mathrm{mAh} \mathrm{g}^{-1}\right)$ & $130-140$ & $100-120$ & $135-150$ & $160-220$ & $180-200$ \\
\hline Cycle number & $2000-5000$ & $500-2000$ & $500-1000$ & $800-2000$ & $800-2000$ \\
\hline Safety performance & Excellent & Good & Poor & Poor & Poor \\
\hline Price (thousand $\$$ ton $^{-1}$ ) & $7.4-14.7$ & $4.4-8.8$ & $50-57$ & $22-29$ & $26-35$ \\
\hline
\end{tabular}

oxide of $\mathrm{LiMO}_{2}(\mathrm{M}=\mathrm{Ni}, \mathrm{Co}, \mathrm{Mn}$ and $\mathrm{Al})$. Among them, LFP is commonly used for its low cost, the highest thermal stability and long cyclability. It could keep stable at a temperature of $350^{\circ} \mathrm{C}$ [70], which is attributed to its strong $\mathrm{P}=\mathrm{O}$ covalent bond in $\mathrm{PO}_{4}{ }^{3-}$ octahedral structure [71]. The equation shows the decomposition for the delithiated $\mathrm{Li}_{0} \mathrm{FePO}_{4}$ [72].

$2 \mathrm{Li}_{0} \mathrm{FePO}_{4} \rightarrow \mathrm{Fe}_{2} \mathrm{P}_{2} \mathrm{O}_{7}+0.5 \mathrm{O}_{2}$

However, it shows a low theoretical specific capacity of $170 \mathrm{mAh} \mathrm{g}^{-1}$ and low volume energy density due to its low tap density of about $2.2 \mathrm{~g} \mathrm{~cm}^{-3}$.

In contrast to LFP, LMO possesses better manufacturing performance. However, it suffers from low energy density and poor cycling stability due to Mn dissolution during the charge/discharge process, especially at evaluated temperature. Compared with other cathode materials, Nibased layered oxides have been widely investigated because of their higher specific energy. Among them, pure $\mathrm{LiNiO}_{2}$ suffers from poor electrochemical properties and thermal stability [73-75]. By replacing $\mathrm{Ni}$ with $\mathrm{Mn}, \mathrm{Co}$ or $\mathrm{Al}$ into lattice structure, typical $\mathrm{LiNi}_{x} \mathrm{Co}_{y} \mathrm{Mn}_{z} \mathrm{O}_{2}(0<x<1,0<y<1$, $0<z<1, x+y+z=1)$ including NCM333 ( $x: y: z=3: 3: 3)$, NCM433 (4:3:3), NCM532 (5:3:2), NMC622 (6:2:2) and NCM811 (8:1:1), has been developed to enhance electrochemical properties [76, 77]. Among these materials, higher utilization of lithium at the same voltage range would be obtained with the increasing Ni content. Thus, the cathode materials with a higher $\mathrm{Ni}$ content such as $\mathrm{LiNi}_{0.8} \mathrm{Co}_{0.15} \mathrm{Al}_{0.05} \mathrm{O}_{2}$ (NCA) and $\mathrm{NCM} 811$ have been regarded as promising candidates to meet requirements of energy, power and cost for application of EVs [78, 79]. However, it is reported that these materials with larger specific energy would present a lower onset temperature of phase transition and are easy to release a large amount of oxygen during phase transition. Figure 2 shows the guidelines for the temperature ranges of phase transitions for the four charged NMC433, NMC532, NMC622 and NMC811 [76]. It could be seen that the onset temperature of NMC111 is about $260{ }^{\circ} \mathrm{C}$, but the first phase transition of NMC 811 starts at about $135{ }^{\circ} \mathrm{C}$ [76]. It was reported that the onset temperature of $\mathrm{NCA}$ is around $170{ }^{\circ} \mathrm{C}$ [80].

$\mathrm{Li}_{0.36} \mathrm{Ni}_{0.8} \mathrm{Co}_{0.15} \mathrm{Al}_{0.05} \mathrm{O}_{2} \rightarrow 0.18 \mathrm{Li}_{2} \mathrm{O}+0.8 \mathrm{NiO}+0.05 \mathrm{Co}_{3} \mathrm{O}_{4}+0.025 \mathrm{Al}_{2} \mathrm{O}+0.372 \mathrm{O}_{2}$ 
Fig. 2 a Onset temperature and b the corresponding temperature region of the phase transition for NMC. Reproduced with permission from Ref. [76]. Copyright 2014, American Chemical Society

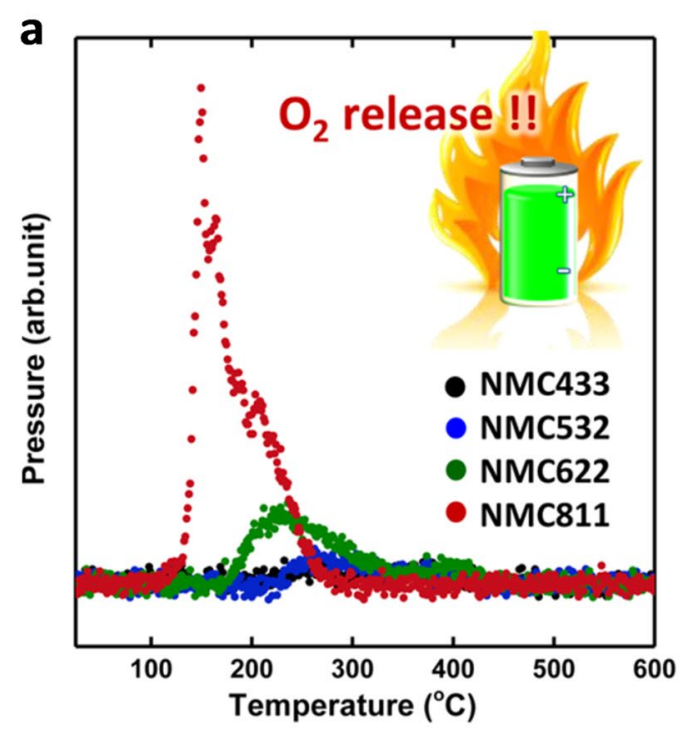

To effectively enhance the safety and electrochemical performances of LIBs, the mechanism of capacity degradation and poor thermal stability for these cathode materials should be deeply understood. With the aids of various advanced characterization tools, it is convenient for us to explore and optimize cathode materials of safe LIBs for EVs.

\subsubsection{Failure Mechanism of Cathode}

In general, poor thermal stability and cycle performance of nickel-rich layered oxide mainly stem from chemical reactions between delithiated cathodes and nonaqueous electrolytes at elevated temperature, which cause decomposition of cathode material and oxidation of electrolytes. The overdelithiated cathode would release oxygen from its lattice due to its high oxidability. Further, the electrolyte could react with oxygen to generate heat. If the heat generation and accumulation are more than its dissipation, a catastrophic failure of the cell will happen [81]. For the sake of designing safe cathode materials with high capacity, mechanisms of structure evolution, thermal stability and oxygen release in cathode materials during cycling should be thoroughly demonstrated. For example, some researchers investigated the structure evolution mechanism of NCM111 during cycling by in situ high-resolution synchrotron radiation diffraction and neutron powder diffraction. As shown in Fig. 3a and b, when the charge voltage is below 4.2 V, NCM111 maintains layered hexagonal phase $\mathrm{H} 1$ structure with slightly increased $c$ and decreased $a$ lattice parameters. When the voltage region is from 4.2 to $4.4 \mathrm{~V}$, a new hexagonal phase $\mathrm{H} 2$ is detected and gradually intensified. When it is charged to a high voltage above $4.6 \mathrm{~V}$, irreversible structure change appears from the original layered structure phase to a layered hexagonal phase H3 and a cubic spinel phase. After full lithiation, lattice parameters do not go back to its original ones, indicative of an irreversible structure evolution after charging to high voltage [82].

Besides structure degradation of cathode materials, the parasitic reaction arising from interactions between electrolytes and highly reactive delithiated cathodes is also one main reason of failure for $\mathrm{Ni}$-rich cathodes during cycling above 4.2 V. Chen et al. [83] developed an in situ highenergy X-ray diffraction (HEXRD) technique as an alternative to differential scanning calorimetry (DSC) and used it to investigate the chemical reactions between electrode materials and electrolytes during thermal ramping. Figure $3 \mathrm{c}-\mathrm{e}$ shows the in situ XRD patterns of pure delithiated $\mathrm{Li}_{1.1}\left(\mathrm{Ni}_{1 / 3} \mathrm{Mn}_{1 / 3} \mathrm{Co}_{1 / 3}\right)_{0.9} \mathrm{O}_{2}$ (NMC), the delithiated cathode in the presence of EC/EMC (3:7, by weight) and mixed delithiated NMC with an equivalent amount of $1.2 \mathrm{M} \mathrm{LiPF}_{6}$ in $\mathrm{EC} / \mathrm{EMC}$ (3:7, in weight ratios) during thermal ramping. Compared to pure NMC, the mixed one in the presence of electrolytes decomposed much earlier with the onset temperature reducing from 278 to $197{ }^{\circ} \mathrm{C}$. This result indicates that the thermal decomposition pathway of delithiated cathode materials, $\mathrm{Li}_{1-x}\left(\mathrm{Ni}_{1 / 3} \mathrm{Mn}_{1 / 3} \mathrm{Co}_{1 / 3}\right)_{0.9} \mathrm{O}_{2}$, strongly depends on the exposed chemical environment, revealing the necessity of precise surface design.

In the microlevel, Ni-rich cathode materials consist of some secondary micrometer particles, which is aggregated by primary micrometer particles. The microstructural evolution of the single $\mathrm{Li}\left(\mathrm{Ni}_{0.8} \mathrm{Co}_{0.15} \mathrm{Al}_{0.05}\right) \mathrm{O}_{2}$ particle during electrochemical cycling was further demonstrated by using in situ electron microscopy (Fig. 3f, g). Compared with the 

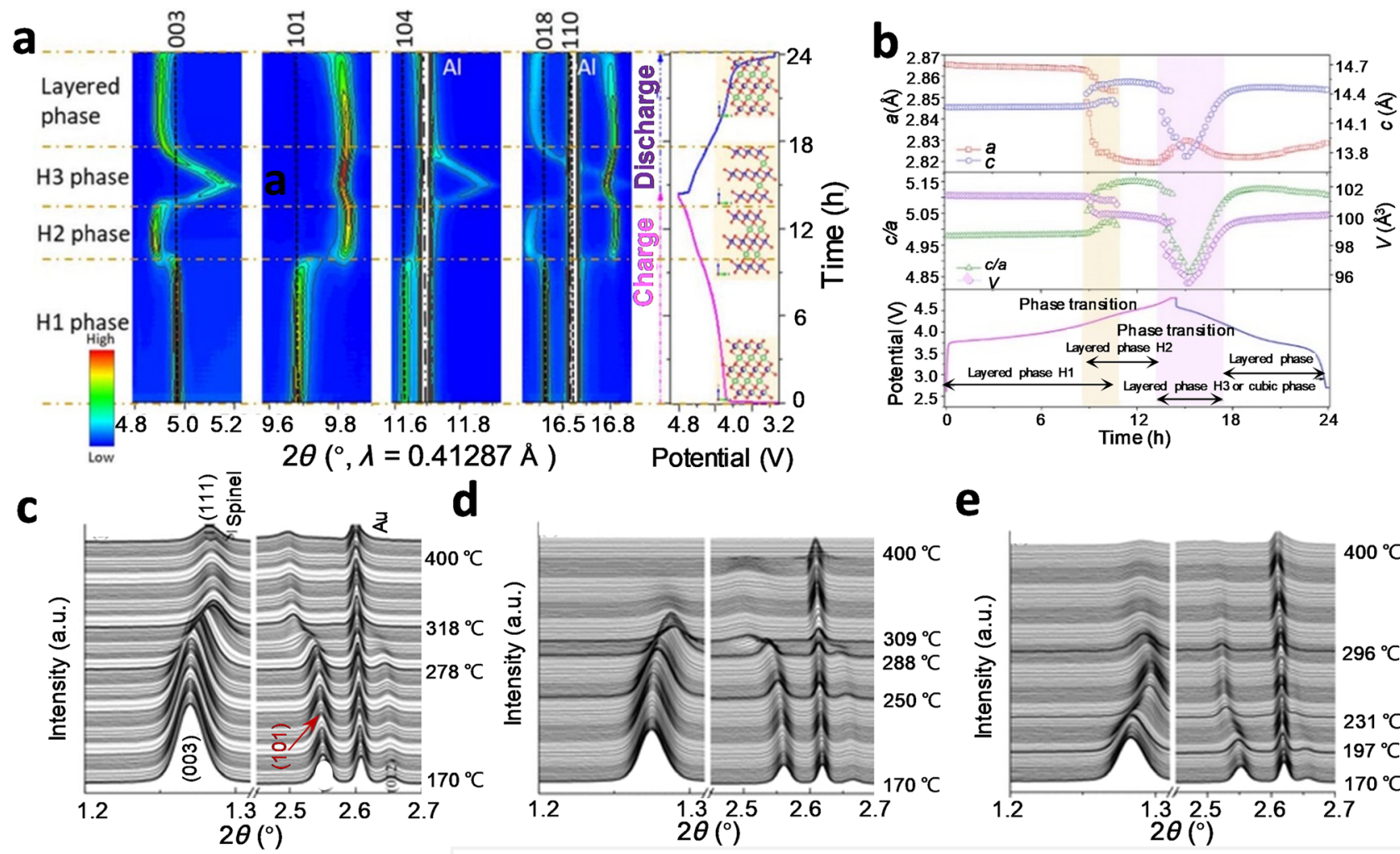

d

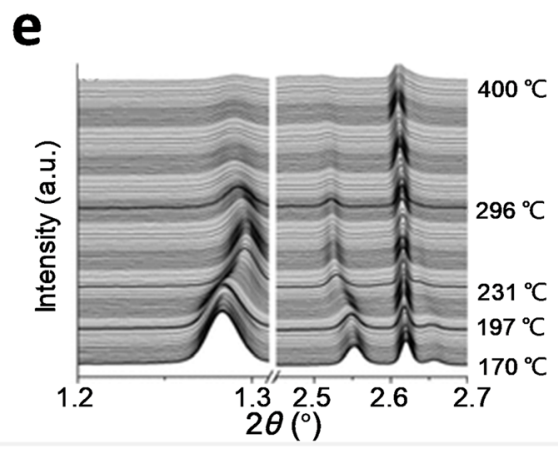

f
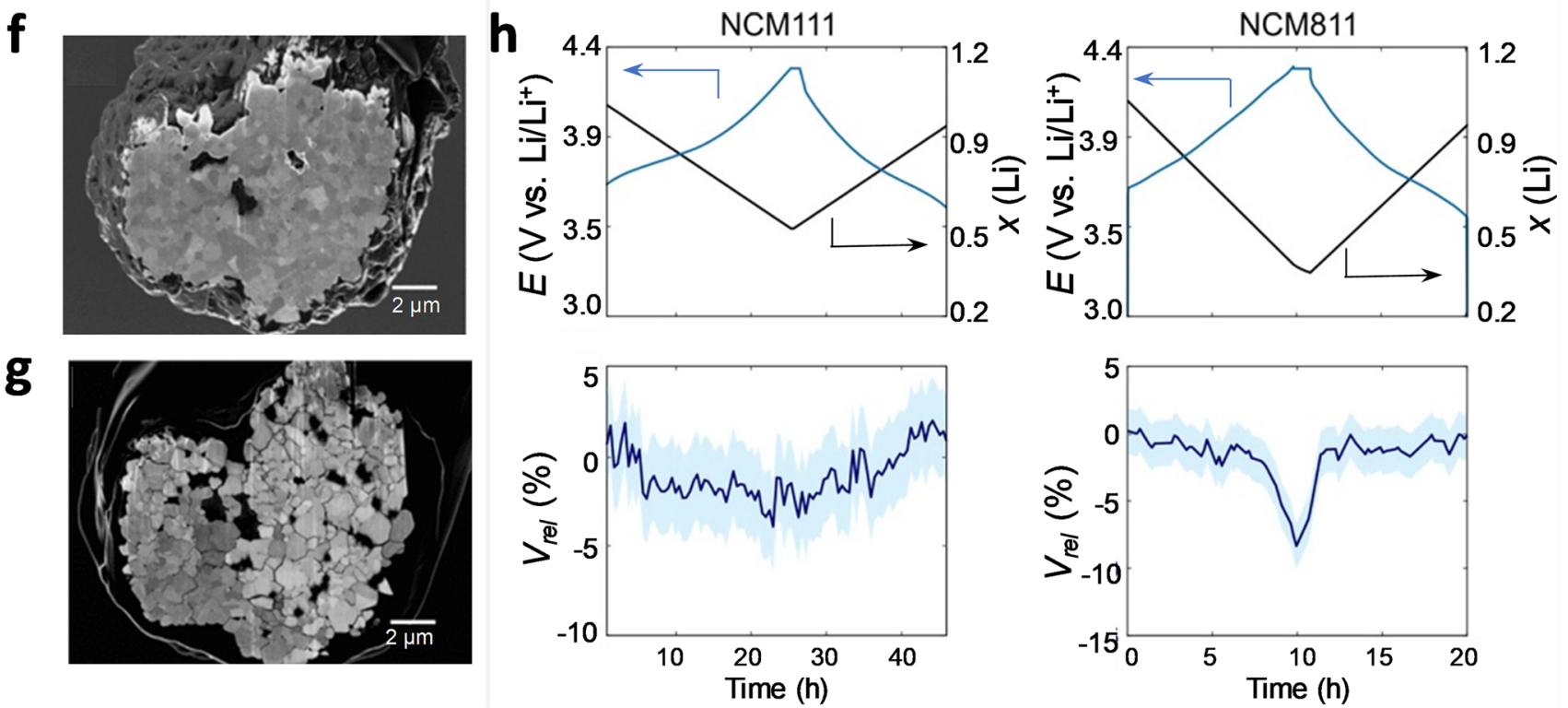

Fig. 3 In situ/operando techniques for the in-depth understanding of LIBs. a In situ synchrotron radiation powder diffraction (SRD) of the NCM111 electrode: the contour plot of reflection evolution of 003 , 101, 104, 018 and 110 during the first delithiation-lithiation. b Lattice parameter changes of NCM111 during the first charge-discharge process. Reproduced with permission from Ref. [82]. Copyright 2019, The Electrochemical Society. In situ HEXRD patterns of delithiated $\mathrm{Li}_{1-x}\left(\mathrm{Ni}_{1 / 3} \mathrm{Mn}_{1 / 3} \mathrm{Co}_{1 / 3}\right)_{0.9} \mathrm{O}_{2}$ during thermal abuse for $\mathbf{c}$ the dry delithiated cathode and $\mathbf{d}$ the delithiated cathode with the presence of EC/EMC (3:7, in weight ratios). e The delithiated cathode with the presence of $1.2 \mathrm{M} \mathrm{LiPF}_{6}$ in EC/EMC (3:7, in weight ratios). Reproduced with permission from Ref. [83]. Copyright 2013, Wiley-
VCH. In situ SEM image for showing the progression of particle fracture and fragmentation during cycles of $\mathbf{f}$ the as-prepared sample and $\mathbf{g}$ the sample after three complete charge/discharge cycles. Reproduced with permission from Ref. [84]. Copyright 2013, Wiley-VCH. h Changes in secondary particle volume from in situ light microscopy for (left) NCM111 and (right) NCM811 cathodes cycled against metallic lithium anodes. Only the second cycle is shown for clarity. Shaded areas represent the error margin. The corresponding voltage profiles and the evolution of the lithium content $[x(\mathrm{Li})]$ with cycling time are shown as well. Reproduced with permission from Ref. [85]. Copyright 2017, American Chemical Society 
as-prepared particles, the particles after three cycles showed obvious cracks, which allow penetration of electrolytes between primary particles. The above result suggests that loss of grain-to-grain connectivity between particles would result in capacity fading and performance degradation [84]. Furthermore, more exposed cathode surface during cycling will intensify reactions between cathodes and electrolytes, which would aggravate capacity fade.

The generation of cracks between micrometer-sized secondary particles is due to anisotropic lattice change of primary nanoparticles during repeated $\mathrm{Li}^{+}$insertion/extraction [85]. Kondrakov et al. [85] compared volumetric changes between NCM111 and NCM811 during cycling from 3.0 to $4.3 \mathrm{~V}$ versus $\mathrm{Li} / \mathrm{Li}^{+}$via in situ $\mathrm{XRD}$, which were $1.2 \%$ and $5.1 \%$, respectively (Fig. 3h). The Ni-rich cathode with a higher Ni content will utilize more lithium than a lower one, which means a deeper delithiated state. Volume change of NCM811 secondary particles $(7.8 \% \pm 1.5 \%)$ is even larger than that of NCM111 $(3.3 \% \pm 2.4 \%)$, which could be attributed to obvious decrease in the interlayer lattice parameter $c$ from 14.467 to $14.030 \AA$.

Above all, with the aid of advanced characterization techniques, the reasons, for structure evolution as well as side reaction between the electrolytes and the primary particles of cathode materials, have been deeply understood in the microlevel, which would guide us to design safe cathodes.

\subsubsection{Cathode Material Design for Safe LIBs}

As mentioned above, overlithiated cathodes will lead to irreversible structure change to nonelectrochemically active structure, large volumetric expansion and oxygen release during cycling. To solve these problems, many efforts have been made by controlling cation mixing [86], doping [87], surface coating [88], constructing core-shell structure and designing concentration-gradient composition with a decreasing Ni content and an increasing Mn content from the inner part to the outer part of cathode particles [89].

Doping Introducing extrinsic cations or anions into layered structure has proved to be an effective way to address structural instability of Ni-rich cathode materials. In general, doping in cathode materials can suppress the order-disorder transition by preventing $\mathrm{Ni}^{2+}$ ions migration to the undesired Li slab during cycling, stabilize structure and avoid oxygen release by increasing the bonding strength between anions and transition-metal ions. The effective dopant ions include $\mathrm{Al}, \mathrm{Mg}, \mathrm{Zr}$, Ti, Ga and $\mathrm{F}$ [87]. Kam et al. [90] used $\mathrm{Ti}^{4+}$ to partially substitute $\mathrm{Co}^{3+}$ at transition-metal sites. The valence difference between $\mathrm{Ti}^{4+}$ and $\mathrm{Co}^{3+}$ is compensated by the reduction of $\mathrm{Mn}$ from +4 to +3 to stabilize the layered structure. $\mathrm{Ti}^{4+}$ substitution can prevent phase change during cycling by restricting Ni migration to the Li slab, which is helpful to improve structural stability even with cycling to high voltage. With increasing the amount of cation dopants in transition layered structure, the specific capacity of the cathode material will generally decrease due to inert properties of the dopants. Thus, an ideal dopant would largely improve the structure stability but at the same time not lower specific capacity with a small amount of doping. The Albased dopant is a good example. The cathode material with less than 5\% $\mathrm{Al}$ doping almost remains unchanged specific capacity as compared with the original one [91].

For anion doping, F-doping has been considered as a promising approach for stabilizing the layered structure and optimizing cycle stability, since $\mathrm{F}$ is the most electronegative element and can form strong bonding with transition metals in the layered cathodes [92]. With the partial replacement of oxygen-metal bonds by the fluorine-metal bond, the initial Columbic efficiency, cycle performance and voltage degradation have been effectively improved, for example, in $\mathrm{Li}$ ( $\left.\mathrm{Li}_{0.133} \mathrm{Mn}_{0.467} \mathrm{Ni}_{0.2} \mathrm{Co}_{0.2}\right) \mathrm{O}_{1.95} \mathrm{~F}_{0.05}$ (LMR). Additionally, the structure stability of LMR is improved upon heating, which is confirmed by in situ X-ray diffraction [93].

Surface/structure modification During charge/discharge, side reactions between cathodes and electrolytes would be accelerated by reactive $\mathrm{Ni}^{4+}$ and $\mathrm{Co}^{4+}$ ions, which will deteriorate the cathode surface and make the cathode electrolyte interface (CEI) become thicker. Surface/structure modification is effective to solve the above problem of cathodes. To date, three typical methods have been widely used to achieve high-capacity Ni-rich cathodes, which are summarized in Table 4, including surface coating, core-shell and concentration-gradient cathode fabrications [89]. In the following section, recent advances are discussed in detail by describing the representative examples.

(1) Surface coating Surface coating is an effective way to suppress the side reactions between cathode materials and electrolytes without sacrificing capacity. The surface coating layer could act as a physical protection barrier to reduce side reactions between electrolytes and active cathode materials, especially at highly lithiated states. Additionally, the coating layer could serve as the scavenger of hydrogen fluoride (HF). Without the proper coating, HF will attack the cathode surface, making the transition-metal ions dissolved into electrolytes. Taking the $\mathrm{TiO}_{2}$ coating layer as an example, as metal fluorides present much lower Gibbs formation energy than the corresponding metal oxides, acidic $\mathrm{HF}$ will react with $\mathrm{TiO}_{2}$ as $\mathrm{TiO}_{2}+4 \mathrm{HF} \rightarrow \mathrm{TiF}_{4}+2 \mathrm{H}_{2} \mathrm{O}$. The formed $\mathrm{TiF}_{4}$ layer will further prevent the surface from being attacked by the acidity of electrolyte. Furthermore, the coating layer could help to suppress the phase transition of cathodes from a layer structure to a rock-salt phase during lithiation/delithiation.

Recently, many efforts have been focused on constructing a coating layer. The layers of $\mathrm{TiO}_{2}[94,95], \mathrm{Al}_{2} \mathrm{O}_{3}$ [96], $\mathrm{MgO}$ [97] and $\mathrm{ZrO}_{2}$ [98] are generally much stable but exhibit low 
Table 4 A summary of surface/structure modification methods for Ni-rich cathodes [89]

\begin{tabular}{|c|c|c|c|c|}
\hline Methods & Key points & Advantages & Disadvantages & Safety comparison \\
\hline Surface coating & $\begin{array}{l}\text { Chemical and electrochemical stabil- } \\
\text { ity of surface layers } \\
\text { Uniformly coating for effective pas- } \\
\text { sive physical protection } \\
\text { Ultra-thin for fast } \mathrm{Li}^{+} \text {conductivity } \\
\text { Good mechanical stability }\end{array}$ & $\begin{array}{l}\text { Easy manipulation } \\
\text { Low costs } \\
\text { Variety (the choice of coating materi- } \\
\text { als) }\end{array}$ & $\begin{array}{l}\text { Hard to obtain uniform } \\
\text { coating with proper } \\
\text { thickness } \\
\text { Poor rate capability } \\
\text { Limited improvement } \\
\text { for both cycling and } \\
\text { safety performance }\end{array}$ & Good \\
\hline Core-shell cathode & $\begin{array}{l}\text { Electrochemical active of shell } \\
\text { materials } \\
\text { High thermal stability of shell materi- } \\
\text { als } \\
\text { Well compatibility between core and } \\
\text { shell materials }\end{array}$ & $\begin{array}{l}\text { Uniform encapsulation with high } \\
\text { thermal stability shell materials } \\
\text { Shell materials provide additional } \\
\text { capacity } \\
\text { Improved cycling and thermal stabil- } \\
\text { ity }\end{array}$ & $\begin{array}{l}\text { Incompatible volume } \\
\text { change between } \\
\text { cores and shells } \\
\text { Complex production } \\
\text { processes }\end{array}$ & Excellent \\
\hline $\begin{array}{l}\text { Concentration-gra- } \\
\text { dient cathode }\end{array}$ & $\begin{array}{l}\text { Precisely controlling of the concen- } \\
\text { tration-gradient shell }\end{array}$ & $\begin{array}{l}\text { Well combination of thermal stability } \\
\text { and high capacity } \\
\text { Improved cycling and thermal stabil- } \\
\text { ity }\end{array}$ & $\begin{array}{l}\text { Difficult to manipulate } \\
\text { High costs }\end{array}$ & Excellent \\
\hline
\end{tabular}

Li-ion conductivity. The thickness and homogeneity of the coating layer is vital to balance stability and rate capability. One of the promising techniques for achieving uniform thin coating layers on cathode materials is atomic layer deposition (ALD), which features low growth temperature, atomic-scale/ stoichiometric deposition and excellent uniformity [99]. Xie et al. took advantage of ALD to construct a uniform, thin, stable and $\mathrm{Li}$-ion conductive $\mathrm{LiAlF}_{4}$ interfacial coating layer on an NCM811 electrode and obtained improved stability and comparable rate performance. Zhang et al. employed ALD to coat the layered oxide cathode with $\mathrm{Al}_{2} \mathrm{O}_{3}$ and significantly improved the cycle ability of cathodes. Systematic STEM atomic-level imaging and nanoscale chemical composition analysis reveals that uniform $\mathrm{Al}_{2} \mathrm{O}_{3}$ coating acts as a physical barrier between cathodes and electrolytes, prevents surface structure transformation and suppresses Mn dissolution in the electrolyte [100]. However, the ALD method is not efficient enough for large-scale production.

Among the coating materials, inorganic species have different kinds of crystal structure as compared with transition layered oxides, which makes them difficult to realize uniform coating. Further, the adhesion between coating materials and cathodes is relatively weak. During repeat cycling, the coating layer might detach from cathode particles. At this point, organic conductive polymers are attractive since they possess better elasticity, which can buffer the volume change of cathodes during cycling. However, polymers show poor thermal stability and good porosity, which will decrease the thermal stability of cathodes. A combination of organic conductive polymers and inorganic materials might be a good choice.

(2) Core-shell cathode Compared with doping and coating with inert materials, coated materials with electrochemically active and fast $\mathrm{Li}^{+}$insertion/delithiation properties are used, which would not sacrifice the high capacity of Ni-rich cathode. As shown in Fig. 4a, b, transition layered oxides with a higher Ni content show worse thermal stability [101]. In order to effectively increase thermal stability and maintain high capacity at the same time, constructing "core-shell" structured materials with a higher Mn content in the shell and a higher $\mathrm{Ni}$ content in the core, is proven effective (Fig. 4c) [102]. For example, a material with a $\mathrm{Li}\left(\mathrm{Ni}_{0.8} \mathrm{Co}_{0.2}\right)$ $\mathrm{O}_{2}$ Ni-rich core encapsulated by a $1-\mu \mathrm{m}$-thick Mn-rich $\mathrm{Li}\left(\mathrm{Ni}_{0.5} \mathrm{Mn}_{0.5}\right) \mathrm{O}_{2}$ shell was prepared (Fig. 4d) [103]. The Mn-rich shell shows good thermal and structural stability, while the Ni-rich core contributes to high specific capacity. The primary exothermic temperature of $\mathrm{Li}_{1-\delta}\left(\mathrm{Ni}_{0.5} \mathrm{Mn}_{0.5}\right) \mathrm{O}_{2}$ began at approximately $300{ }^{\circ} \mathrm{C}$ [104], which is about $100{ }^{\circ} \mathrm{C}$ higher than that of $\mathrm{Li}_{1-\delta}\left(\mathrm{Ni}_{0.8} \mathrm{Co}_{0.2}\right) \mathrm{O}_{2}$. The core material delivers a capacity of $220 \mathrm{mAh} \mathrm{g}^{-1}$, much higher than that of the shell material (140 $\left.\mathrm{mAh} \mathrm{g}^{-1}\right)$. Compared with pure $\mathrm{Li}\left(\mathrm{Ni}_{0.8} \mathrm{Co}_{0.2}\right) \mathrm{O}_{2}$ (Fig. 4e), the core-shell $\mathrm{Li}\left[\left(\mathrm{Ni}_{0.8} \mathrm{Co}_{0.2}\right)_{0}\right.$. ${ }_{8}\left(\mathrm{Ni}_{0.5} \mathrm{Mn}_{0.5}\right)_{0.2} \mathrm{O}_{2}$ material exhibits improved thermal stability. The pouch cell with core-shell $\mathrm{Li}\left[\left(\mathrm{Ni}_{0.8} \mathrm{Co}_{0.2}\right)_{0.8}\left(\mathrm{Ni}_{0.5}\right.\right.$ $\left.\left.\mathrm{Mn}_{0.5}\right)_{0.2}\right] \mathrm{O}_{2}$ as the cathode shows excellent nail penetration performance [103]. Sun et al. further explored the effect of shell thickness on the thermal stability based on core-shell $\mathrm{Li}\left[\left(\mathrm{Ni}_{0.8} \mathrm{Co}_{0.1} \mathrm{Mn}_{0.1}\right)_{1-x}\left(\mathrm{Ni}_{0.5} \mathrm{Mn}_{0.5}\right)_{x}\right] \mathrm{O}_{2}$ particles. With the increasing thickness of the shell layer, the thermal stability of the core-shell material is enhanced (Fig. 4f) [105]. However, due to the mismatch of the crystal structure of shell and core materials, volume change during repeated charge/ discharge is different, which will create voids between cores and shells, even leading to primary partial cracks. The voids between the core and the shell may hinder the Li-ion migration, and the cracks will make the fresh surface being exposed to the electrolyte, causing severe side 

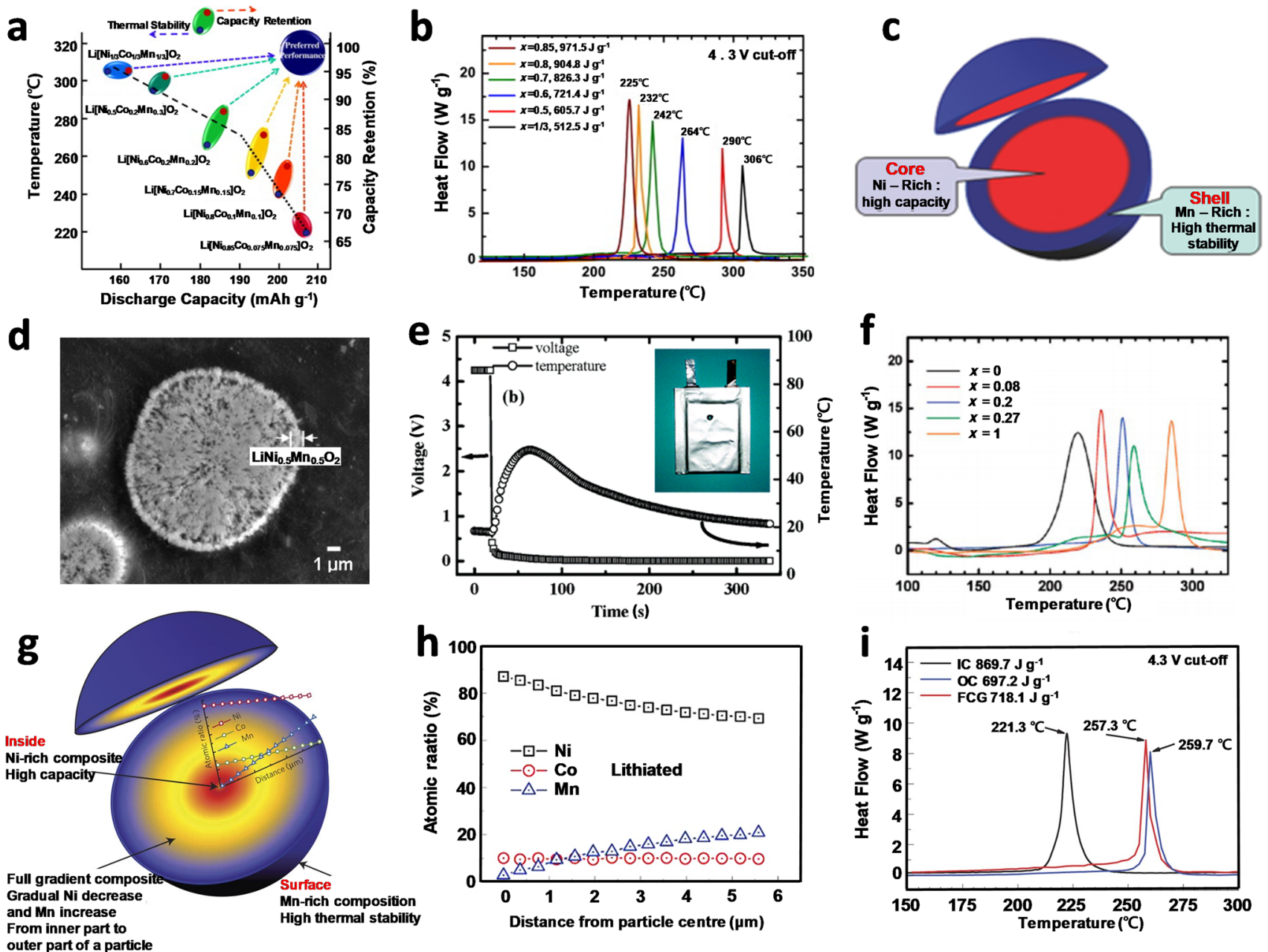

Fig. 4 a A map of the relationship between discharge capacity, thermal stability and capacity retention. b The DSC data of Ni-rich materials charged to $4.3 \mathrm{~V}$. Reproduced with permission from Ref. [101]. Copyright 2015, Wiley-VCH. c Schematic drawings of Ni-rich core and Mn-rich shell structure. Reproduced with permission from Ref. [102]. Copyright 2016, Wiley-VCH. d SEM images of core-shell Li[ $\left.\left(\mathrm{Ni}_{0.8} \mathrm{Co}_{0.2}\right)_{0.8}\left(\mathrm{Ni}_{0.5} \mathrm{Mn}_{0.5}\right)_{0.2}\right] \mathrm{O}_{2}$ powders after 150 cycles. e Voltage versus cell surface temperature plots in the Li-ion cells of core-shell $\mathrm{C} / \mathrm{Li}\left[\left(\mathrm{Ni}_{0.8} \mathrm{Co}_{0.2}\right)_{0.8}\left(\mathrm{Ni}_{0.5} \mathrm{Mn}_{0.5}\right)_{0.2}\right] \mathrm{O}_{2}$ cells during nail penetration tests at $4.3 \mathrm{~V}$. Insets show the Li-ion cell images of spherical C/coreshell $\mathrm{Li}\left[\left(\mathrm{Ni}_{0.8} \mathrm{Co}_{0.2}\right)_{0.8}\left(\mathrm{Ni}_{0.5} \mathrm{Mn}_{0.5}\right)_{0.2}\right] \mathrm{O}_{2}$ cells after nail penetration at 4.3 V. Reproduced with permission from Ref. [103]. Copyright 2006, American Chemical Society. f DSC profiles of $\mathrm{Li}\left[\left(\mathrm{Ni}_{0.8} \mathrm{Co}_{0.1} \mathrm{Mn}_{0.1}\right.\right.$

reaction. And the low-capacity shell materials will decrease the whole capacity.

(3) Concentration-gradient cathode In order to eliminate the large difference between cores and shells, concentrationgradient structure is introduced to further enhance the capacity of cathode materials. With chemical composition continuously varying from the core/shell interface to the outermost surface of the shell, the structural inconsistency of the interface is eliminated. A full concentration-gradient (FCG) cathode, in which the concentration of the main species is fully gradient changeable, is developed for ideal performance. Unlike
)$\left._{1-x}\left(\mathrm{Ni}_{0.5} \mathrm{Mn}_{0.5}\right)_{x}\right] \mathrm{O}_{2}(x=0-1)$ electrodes charged to $4.5 \mathrm{~V}$ versus $\mathrm{Li}$. Reproduced with permission from Ref. [105]. Copyright 2006, American Chemical Society. $\mathbf{g}$ Schematic diagram of the FCG lithium transition-metal-oxide particle with the Ni concentration decreasing from the center toward the outer layer and the concentration of Mn increasing accordingly. $\mathbf{h}$ EPMA line scan of the integrated atomic ratio of transition metals as a function of the distance from the particle center to the surface for the lithiated FCG material. i DSC profiles of the delithiated FCG material, the delithiated $\mathrm{Li}_{1-x} \mathrm{Ni}_{0.86} \mathrm{Co}_{0.10} \mathrm{Mn}_{0.04} \mathrm{O}_{2}$ and the delithiated $\mathrm{Li}_{1-x} \mathrm{Ni}_{0.7} \mathrm{Co}_{0 \cdot 1} \mathrm{Mn}_{0.2} \mathrm{O}_{2}$ with a scanning rate of $1{ }^{\circ} \mathrm{C} \mathrm{min}{ }^{-1}$. Reproduced with permission from Ref. [106]. Copyright 2012, Nature Publishing Group

the core-shell materials with concentration gradients, the FCG cathode shows more flexibility in adjusting gradients (Fig. 4g). A pioneering work was reported by Amine et al. [106] on a Ni-rich layered oxide with a nominal composition of $\mathrm{LiNi}_{0.75} \mathrm{Co}_{0.10} \mathrm{Mn}_{0.15} \mathrm{O}_{2}$. As shown in Fig. 4h, the concentrations of $\mathrm{Ni}$ and $\mathrm{Mn}$ vary continuously from central to surface areas within a primary particle of $\sim 5 \mu \mathrm{m}$, with $\mathrm{LiNi}_{0.9} \mathrm{Co}_{0.1} \mathrm{O}_{2}$ in the core and $\mathrm{LiNi}_{0.7} \mathrm{Co}_{0.1} \mathrm{Mn}_{0.2} \mathrm{O}_{2}$ on the surface. Due to a large distance for gradient change, the structural inconsistency is minimized. This advanced FCG material delivers a specific capacity up to $215 \mathrm{mAh} \mathrm{g}^{-1}$ with outstanding cycling stability 
in a full-cell configuration and maintains $90 \%$ capacity even after 1000 cycles. These results reveal that the chemical compositions of outer shells play a vital role in both electrochemical performance and thermal stability of Ni-rich materials (Fig. 4i). Sun et al. recently designed a Ni-rich concentration-gradient $\mathrm{Li}\left(\mathrm{Ni}_{0.865} \mathrm{Co}_{0.12} \mathrm{Al}_{0.015}\right) \mathrm{O}_{2}$ (NCA) cathode, with a Ni-rich core and a Co-rich particle surface. With a much more stable surface shell, this gradient NCA cathode showed improved high-temperature cycle performance and maintained $90 \%$ of its initial capacity after 100 cycles at $60^{\circ} \mathrm{C}$ and excellent thermal stability. The Co-rich surface provides a physical barrier between Ni-rich core materials and electrolytes. With the concentration-gradient shell, the inherent internal strain is largely reduced, ensuring a stable particle during lifetime [107]. The concentration-gradient-type materials are promising for practical application, but they still face many challenges such as controlling coverage and the consistent gradient of batches when extending to a 1000-fold and even larger scale.

Design better particles The layered oxide materials are commonly prepared by the co-precipitation method with round-shape primary particles randomly aggregating into large secondary particles. Anisotropic lattice volume expansion or contraction between the primary particles during cycling will result in microcracks, and electrolytes will penetrate into microcracks, causing severe side reaction.

Another way to eliminate cracks in the secondary particles is directly using single-crystal cathodes. Dahn et al. compared single-crystal and polycrystalline NCM523-positive electrode materials for high-voltage LIBs. The results show that single-crystal materials yield to longer lifetime for LIBs at both 40 and $55^{\circ} \mathrm{C}$ when tested at an upper cutoff potential of $4.4 \mathrm{~V}$. The reasons for superior performance of the single-crystal-based cells were explored by using thermogravimetric analysis/mass spectrometry experiments on the charged electrode materials, showing that single-crystal materials are extremely resistant to oxygen loss below $100{ }^{\circ} \mathrm{C}$ compared with the polycrystalline materials [108].

Kim et al. [109] reported a new concept to overcome the crack problem in the secondary particles of Ni-rich cathode materials via the nanoscaled surface treatment of the primary particles. As presented in the schematic diagram (Fig. 5a), NCM622 cathode materials with the surface treatment of its primary particles were prepared with the solution of lithium acetate and cobalt acetate (final products marked as STNCM). The surface of ST-NCM primary particles consists of the cation-mixing layer as a pillar layer, which effectively improves the structural stability and electrochemical performance of the cathode by suppressing the microcracks in the particles during cycling. As shown in Fig. 5b, c, compared with bare materials, the ST-NCM second particles remain tightly bound after 150 cycles. On the contrary, the untreated cathode materials appear obvious microcracks. Moreover, due to the cation-mixing layer on the surface with strong $\mathrm{Mn}-\mathrm{O}$ bonding, oxygen release would be prevented at elevated temperatures in ST-NCM. Such a creative treating method of primary particles provides us a way to improve both the electrochemical properties and thermal stability of cathodes.

Sun et al. [110] synthesized micrometer-sized Ni-rich NCM811 secondary cathode materials consisting of radially aligned single-crystal primary particles to address the issue of particle cracks during cycles (Fig. 5d). The aligned single-crystal secondary particles packed tightly (Fig. 5e), achieving coordinated charge-discharge volume change, which could alleviate the volume change-induced intergrain stress. This material with unique structure exhibits excellent cycling performance without any degradation after 300 cycles. The primary particles maintain origin shapes without obvious cracks (Fig. 5f). Sun et al. [111] applied this method into concentration-gradient-type cathodes with $\mathrm{Ni}$ concentration decreasing linearly and Co concentration increasing from the center to the outer surfaces (Fig. 5g). The primary particles are composed of the rod-shaped secondary particles of $\sim 2.5 \mu \mathrm{m}$ grown in the radial direction (Fig. 5h). This cathode is paired with mesocarbon microbead graphite to assemble into an aluminum pouch-type full cell ( $\sim 35 \mathrm{mAh})$. The full cell shows excellent cycle performance and maintains $70.3 \%$ capacity after 1000 cycles even at $55{ }^{\circ} \mathrm{C}$ (Fig. 5i). Such good cycle performance is mainly attributed to the stable surface and well-combined second particles, which can reduce the internal stress.

\subsection{Anode Materials}

Based on the lithiation/delithiation mechanism, anode materials can be classified into three types. (1) Intercalation anodes include carbon-based materials and lithium titanium oxide (LTO), in which lithium ions are inserted into crystals with low volume expansion [112, 113]. Graphite has been commercially used as LIB anode for about 20 years due to its low costs, high electrical conductivity and low-potential plateau [112]. LTO has also been used in LIB markets for its high rate charge/discharge and long cycle life [114]. However, the shortcomings of LTO are its high lithiation/delithiation plateau $\left(\approx 1.55 \mathrm{~V}\right.$ vs. $\left.\mathrm{Li}^{\prime} / \mathrm{Li}^{+}\right)$and low specific capacity (175 $\mathrm{mAh} \mathrm{g}^{-1}$ ) [113]. (2) Conversion reaction anodes consist of MX, where $\mathrm{M}$ would be transition metals such as $\mathrm{Fe}$, Co and $\mathrm{Cu}$, and $\mathrm{X}$ may be $\mathrm{O}, \mathrm{F}$ or even $\mathrm{H}$. Hence, MX could be compounds like $\mathrm{Fe}_{2} \mathrm{O}_{3}, \mathrm{Co}_{2} \mathrm{O}_{3}$ and $\mathrm{CuO}$. During charge/ discharge, these materials show higher specific capacity than intercalation anodes. However, their poor electronic conductivity may result in large irreversible capacity and voltage hysteresis and low rate performance [115]. (3) Alloyingtype anode materials mainly refer to the IV and V groups, including $\mathrm{Si}, \mathrm{Ge}, \mathrm{Sn}, \mathrm{Sb}$ metal and metal oxides, sulfides or phosphides. The alloying-type anodes could theoretically alloy with $x \mathrm{Li}^{+}$to be $\mathrm{Li}_{x} \mathrm{M}$ and offer discharge capacity 
a

a

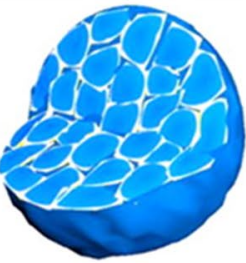

$\operatorname{LiNi}_{0.6} \mathrm{CO}_{0.2} \mathrm{O}_{2}$
Mixing with Li and Co acetate in ethanol

b

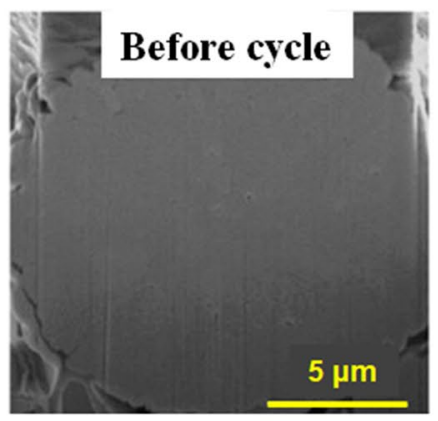

d

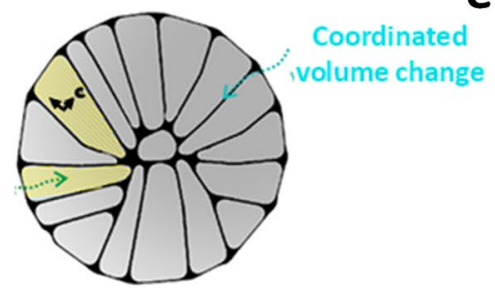

Radially aligned primary particles

g

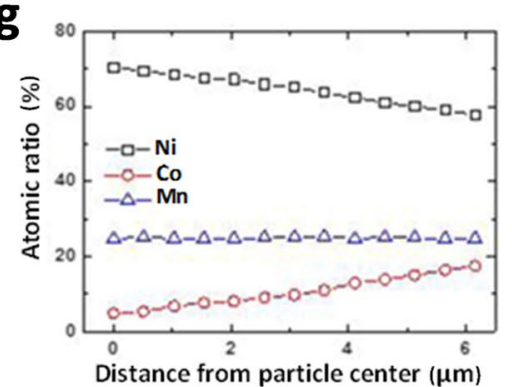

C

h

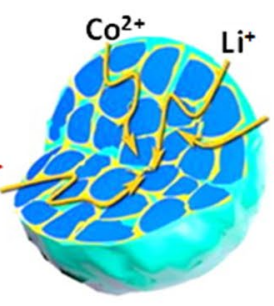

Calcination

$\left(800^{\circ} \mathrm{C}\right)$

$\mathrm{LiNi}_{0.6} \mathrm{Co}_{0.2} \mathrm{Mn}_{0.2} \mathrm{O}_{2}$

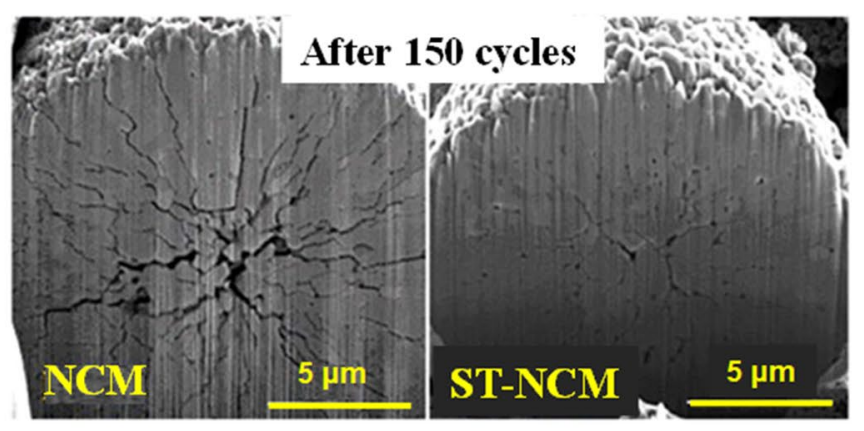

e
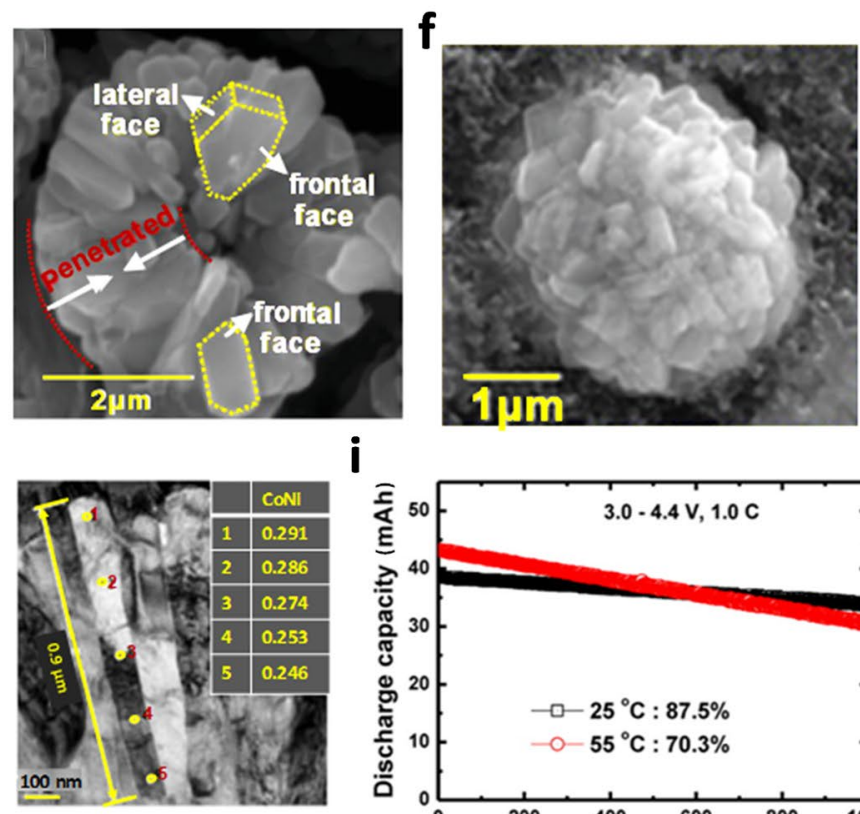

i

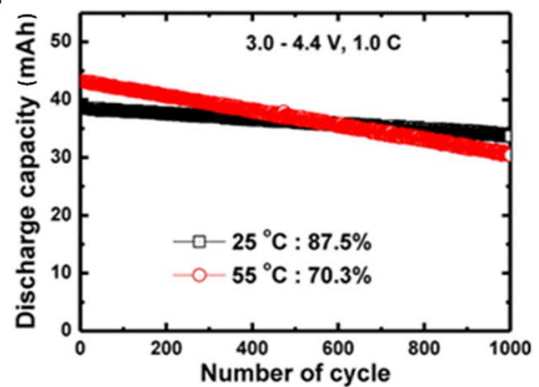

Fig. 5 a Schematic diagram of a coating method for alleviating the surface degradation of $\mathrm{LiNi}_{0.6} \mathrm{Co}_{0.2} \mathrm{Mn}_{0.2} \mathrm{O}_{2}$ cathode materials and the comparison of particle cross sections. b Before and $\mathbf{c}$ after 150 cycles before and after the modification. Reproduced with permission from Ref. [109]. Copyright 2015, American Chemical Society. d Schematic illustration of the structure of radially aligned primary particles. SEM images of radially aligned primary particles e before and $\mathbf{f}$ after cycle. Reproduced with permission from Ref. [110]. Copyright 2019, Wiley-VCH. g Integrated atomic ratio of transition metals

almost four times higher than that of graphite. However, the huge volume change (>300\%) during alloying and dealloying would result in serious pulverization and poor cycle life, which severely restricts their practical application [116]. as a function of the distance from the center of the particle for the lithiated FCG-Mn-F material. h TEM image, along with EDS data along the single elongated FCG-Mn-F primary particle. i Cycling performance of the laminated-type Al-pouch cell ( $35 \mathrm{mAh})$ by using mesocarbon microbead (MCMB) graphite as the anode and FCG$\mathrm{Mn}-\mathrm{F}$ as the cathode at a rate of $1 \mathrm{C}$, corresponding to $200 \mathrm{~mA} \mathrm{~g}^{-1}$ (an upper cutoff voltage of $4.4 \mathrm{~V}$ ). Reproduced with permission from Ref. [111]. Copyright 2013, American Chemical Society

Although alternative anode materials such as the conversion type and the alloying type have been explored for high energy density, many researchers focus on how to improve reversible capacity, effectively alleviate large 
volume expansion and control capacity fading [117]. Hence, the safety issues of these materials have not received much concern [118]. Therefore, we only concentrate on the safety problems of the commercial graphite anode in this review.

\subsubsection{Failure Mechanism of Anodes}

As shown in Fig. 6 [119], during the initial charging process of a fresh LIB in the carbonate-based nonaqueous electrolyte, the SEI is firstly formed in a potential window range of $0.6-1.3 \mathrm{~V}$ versus $\mathrm{Li} / \mathrm{Li}^{+}$in the anode side [120]. It is well known that the conventional SEI is mainly composed of stable inorganic components (such as $\mathrm{LiF}, \mathrm{Li}_{2} \mathrm{O}$ and $\mathrm{Li}_{2} \mathrm{CO}_{3}$ ) and some metastable organic components [such as polymers, $\mathrm{ROCO}_{2} \mathrm{Li},\left(\mathrm{CH}_{2} \mathrm{OCO}_{2} \mathrm{Li}\right)_{2}$ and $\mathrm{ROLi}$ [ [121]. Li ions intercalate into graphite in the range of $0.065-0.2 \mathrm{~V}$ over charging. As the potential is below $0 \mathrm{~V}, \mathrm{Li}$ ions would deposit on graphite and grow to Li dendrites on the anode surface, which may impale separators and hence lead to short circuit and heat generation [122].
Generally, the SEI film is relatively stable, which can permeate $\mathrm{Li}^{+}$to react with graphite. However, during operation, under some abuse conditions such as excessive currents, overcharging, internal/external short circuiting or high temperature, LIBs would be ignited to generate heat. Some researches show that SEIs could decompose at a relatively low temperature of $69^{\circ} \mathrm{C}$ [123], and the metastable organic components could exothermically decompose at $90-120^{\circ} \mathrm{C}$ to some gases like carbon dioxide and ethylene [124]:

$\left(\mathrm{CH}_{2} \mathrm{OCO}_{2} \mathrm{Li}\right)_{2} \rightarrow \mathrm{Li}_{2} \mathrm{CO}_{3}+\mathrm{C}_{2} \mathrm{H}_{4}+\mathrm{CO}_{2}+0.5 \mathrm{O}_{2}$

$2 \mathrm{Li}+\left(\mathrm{CH}_{2} \mathrm{OCO}_{2} \mathrm{Li}\right)_{2} \rightarrow 2 \mathrm{Li}_{2} \mathrm{CO}_{3}+\mathrm{C}_{2} \mathrm{H}_{4}$

As shown in Fig. 6, if the SEI layer is broken down, lithiated graphite anodes would exothermally react with electrolytes, which would further increase system temperature. If the intercalated lithium is exposed to electrolytes, it could react with carbonate-based organic solvents at about $100{ }^{\circ} \mathrm{C}[64$, 125]:
Fig. 6 Illustration of aging effects on graphite anodes. Reproduced with permission from Ref. [119]. Copyright 2013, Elsevier

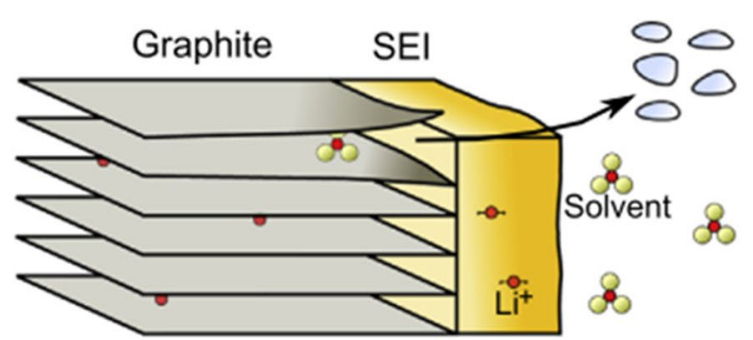

Graphite exfoliation, particle cracking, gas formation

SEI creation

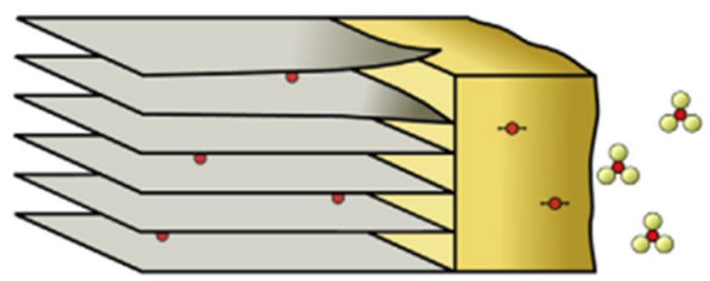

\section{SEI expansion}

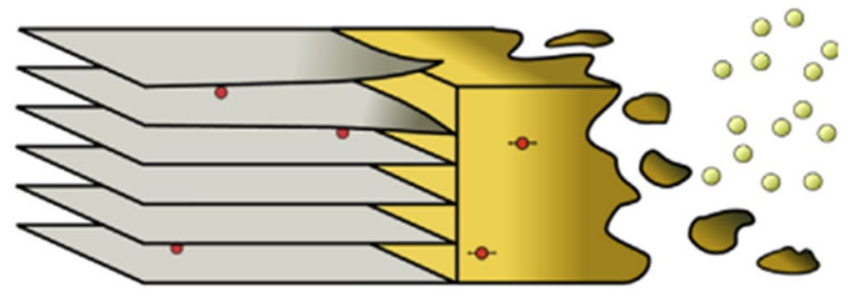

Negative / positive interactions

SEI dissolution

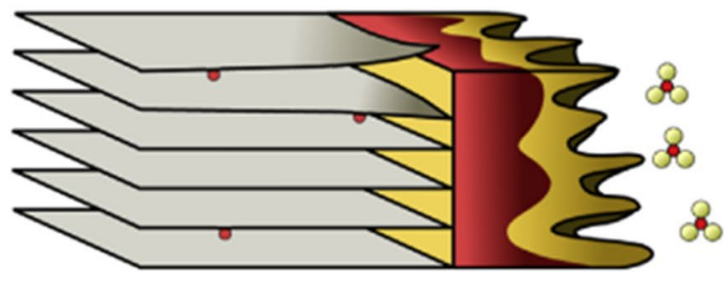

\section{Lithium plating}


$2 \mathrm{Li}+\mathrm{C}_{3} \mathrm{H}_{4} \mathrm{O}_{3}(\mathrm{EC}) \rightarrow \mathrm{Li}_{2} \mathrm{CO}_{3}+\mathrm{C}_{2} \mathrm{H}_{4}$

$2 \mathrm{Li}+\mathrm{C}_{4} \mathrm{H}_{6} \mathrm{O}_{3}(\mathrm{PC}) \rightarrow \mathrm{Li}_{2} \mathrm{CO}_{3}+\mathrm{C}_{3} \mathrm{H}_{6}$

$2 \mathrm{Li}+\mathrm{C}_{3} \mathrm{H}_{6} \mathrm{O}_{3}(\mathrm{DMC}) \rightarrow \mathrm{Li}_{2} \mathrm{CO}_{3}+\mathrm{C}_{2} \mathrm{H}_{4}$

The releasing flammable hydrocarbon gases, such as ethane and methane, would yield a pressure inside the cell. What's more, they will burn if the cathode releases oxygen and temperature provides suitable conditions, which is a huge risk for LIBs. Above all, side reactions at the graphite/ electrolyte interface as well as the poor thermal stability of lithiated graphite and SEIs have been regarded as the main sources for safety issues of anodes.

\subsubsection{Anode Modification for Safe Batteries}

According to the failure mechanism of the anode, the thermal stability of SEI plays an important role in battery safety
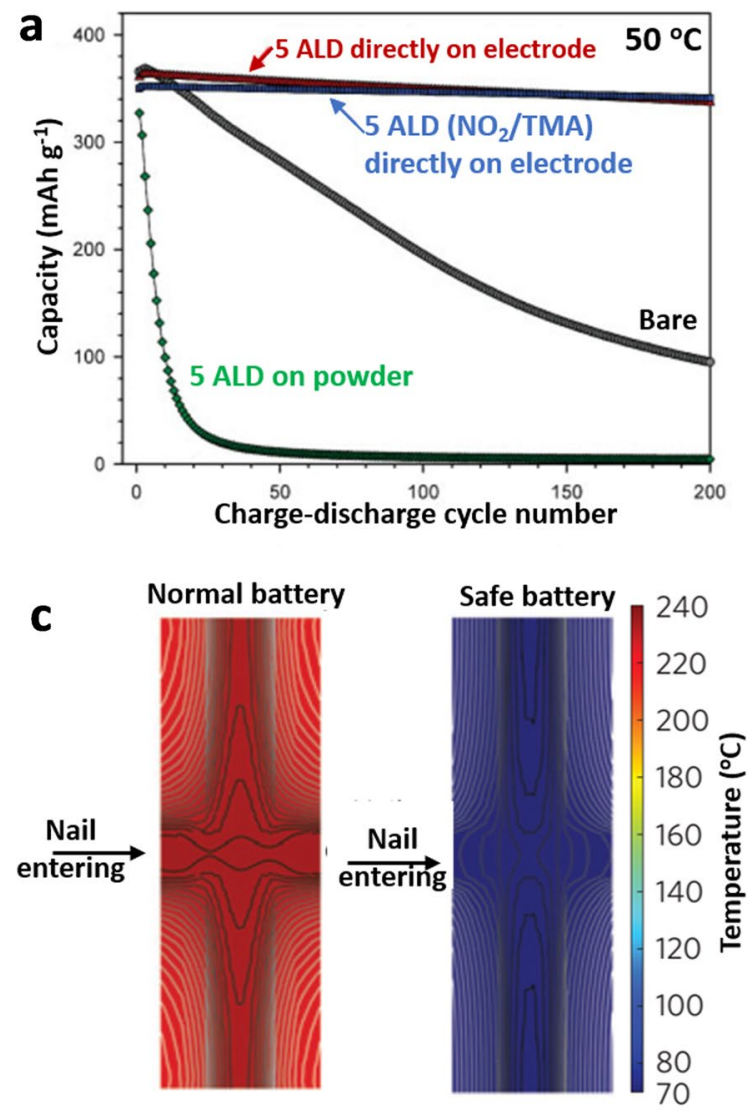

Fig. 7 a Cycling properties at $50{ }^{\circ} \mathrm{C}$ of $\mathrm{NG}$ electrodes with and without ALD coated. b DSC curves of fully lithiated graphite electrodes with (the solid line) and without ALD coated (the dotted line). Reproduced with permission from Ref. [126]. Copyright 2010, Wiley-VCH. c COMSOL simulation of two-dimensional temperature profiles on and how to improve it is a critical way to enhance LIBs safety. The alternative method is mainly focused on forming a stable artificial SEI layer with high thermal stability to protect lithiated graphite from being directly exposed to the electrolyte. As shown in Fig. 7a, compared with the rapid capacity decay of natural graphite, the graphite anode coated with $\mathrm{Al}_{2} \mathrm{O}_{3}$, prepared by Jung et al. [126] via ALD, showed excellent cycling stability with $98 \%$ capacity retention after 200 cycles, indicating that the artificial SEI of $\mathrm{Al}_{2} \mathrm{O}_{3}$ can effectively protect lithiated graphite from undesirable reactions. Additionally, as shown in Fig. 7b, DSC results indicate that the SEI film formed on NG anodes coated with $\mathrm{Al}_{2} \mathrm{O}_{3}$ is stabler than that without $\mathrm{Al}_{2} \mathrm{O}_{3}$. Cui et al. [127] reported that a thermoresponsive polymer switching (TRPS), consisting of graphene-coated spiky nickel nanoparticles mixed in a polymer composite, exhibited a high thermal expansion coefficient $(\sigma)$. It could be used as a current collector coating layer in the anode $(\mathrm{Cu})$. In Fig. 7c, d, the safe batteries with such TRPS materials show excellent battery performance at normal temperature and they can shut down rapidly under
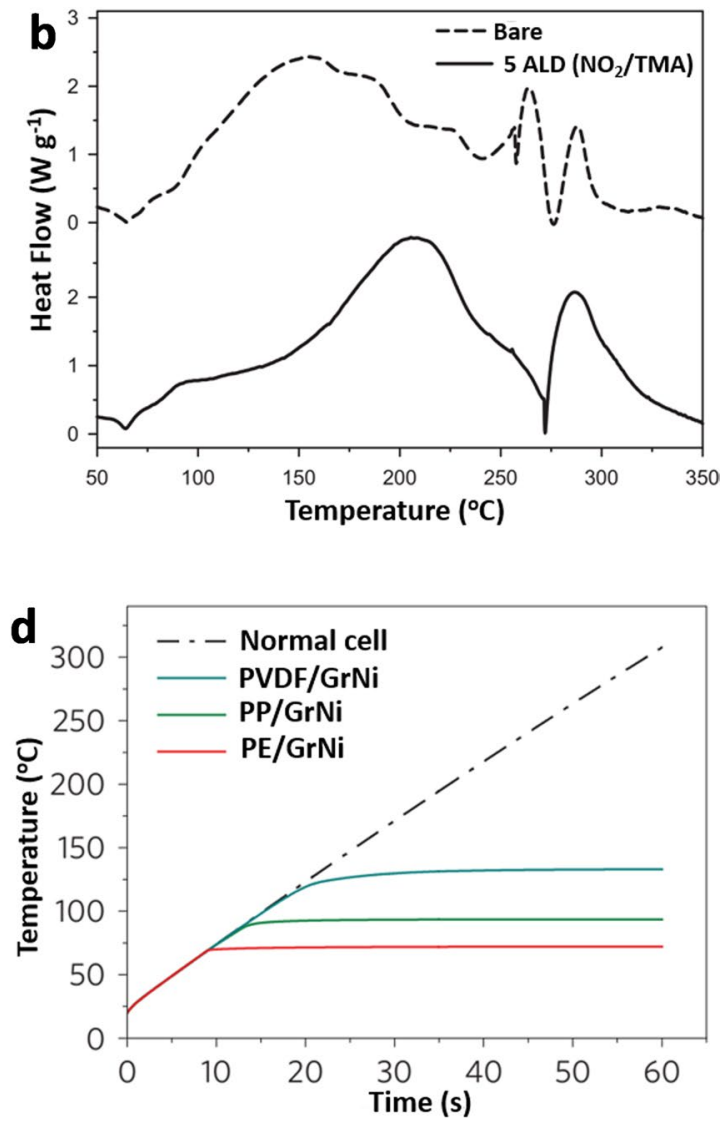

the cross section of normal and safe batteries after shorting for $30 \mathrm{~s}$. d COMSOL simulation of battery temperature dependence on shorting time. Reproduced with permission from Ref. [127]. Copyright 2016, Nature Publishing Group 
abnormal conditions like overheating and shorting due to the excellent mechanical flexibility, high room-temperature $\sigma$ and large operating voltage windows. Another approach to build thermally stable artificial SEIs is to add functional electrolyte additives, which can modify the surface and formation process of SEIs. The SEI supporting additives will be introduced in the part of safer electrolyte design. For the reduction additives [128], their reductive potentials are higher than electrolyte solvents, so the additives would be reduced to form an insoluble solid layer before the reduction of solvents. Therefore, they could reduce gases generation and improve the thermal stability of SEIs. However, the artificial SEI film would sacrifice the theoretical specific capacity of anode materials. Thus, it is necessary to develop some active artificial SEI layers in the future.

\subsection{Separator Materials}

In LIBs, the separator is a critical component with the function of preventing electronic contact and ensuring Li-ion transport between two electrodes during battery running. Except the demand for wettability and porous properties, the desired membrane should have high chemical/electrochemical stability, high thermal stability and excellent mechanical properties to ensure building a safe and reliable LIB.

Generally, the common separators for LIBs are polyolefin membranes such as polyethylene (PE) and polypropylene (PP), but they would be melted down at the temperatures of 130 and $170{ }^{\circ} \mathrm{C}$, respectively [129]. During the melting process, the micropores of separators will be destroyed, which will isolate the pathway of $\mathrm{Li}$ ions between the electrodes and drastically increase the internal resistance of LIBs [130]. If the separator is melted, the internal short circuit will occur, which may lead to a large amount of heat generation and trigger the thermal runaways $[129,131]$.

\subsubsection{Modification of Traditional Polyolefin Membranes}

By taking advantages of different melting points of PE and PP, a modified polyolefin membrane with self-shut
Fig. 8 a Closing pore processes and shutdown behaviors of PP/ PE/PP separators. Reproduced with permission from Ref. [148]. Copyright 2015, Elsevier. b The grafted mechanism of $\mathrm{TiO}_{2}$-modified PE separators with strong chemical bonds. Reproduced with permission from Ref. [140]. Copyright 2016, Elsevier. c The thermal behavior of PI/PE separators. Reproduced with permission from Ref. [148]. Copyright 2015, Elsevier. d Photograph, voltage and temperature profiles of cells assembled with PIC separators after a penetration test. e Photograph, voltage and temperature profiles of cells assembled with PE separators after a penetration test. Reproduced with permission from Ref. [149]. Copyright 2018, Elsevier

a

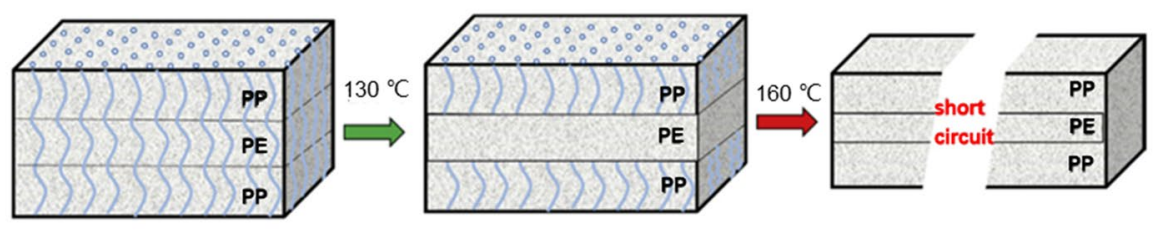

b

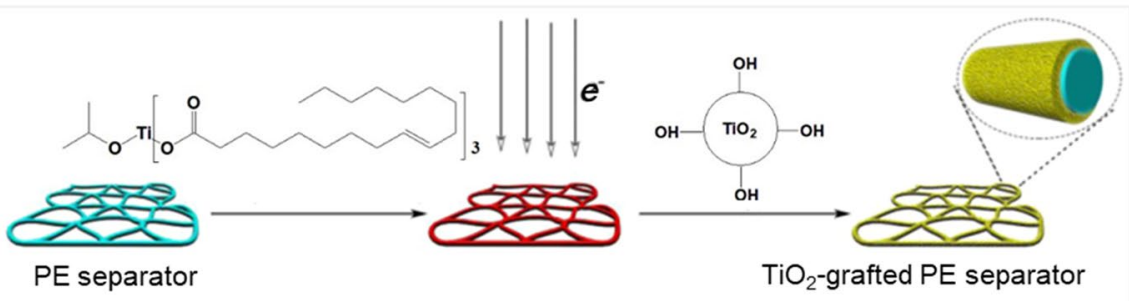

C

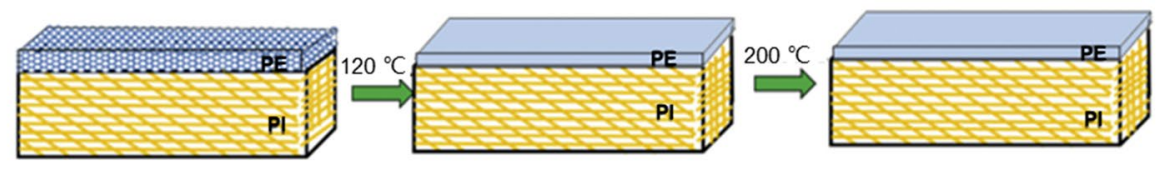

d

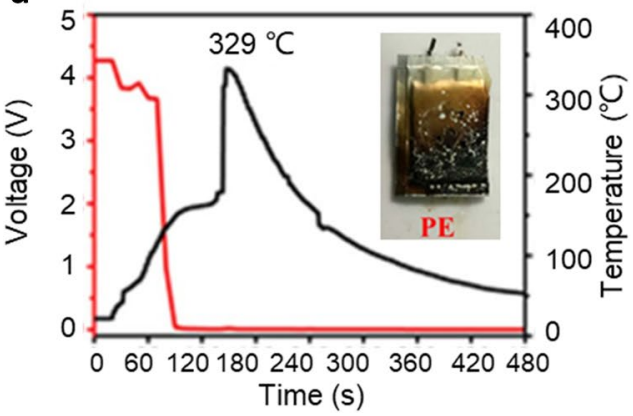

e

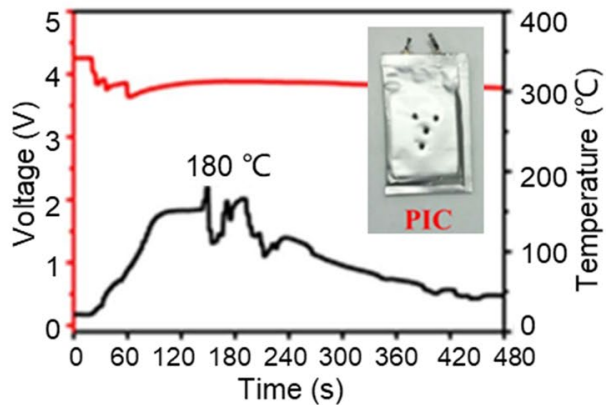


capability was developed [92]. As shown in Fig. 8a, a trilayer structured $\mathrm{PP} / \mathrm{PE} / \mathrm{PP}$ separator is constructed, in which PP layers with higher melting points serve as the frame to prevent separator collapse, while the middle PE layer plays the role of shutting down the agent. However, this kind of separators may still fail if the temperature continues to increase above the melting point of PP. Further improving the thermal stability of polyolefin membranes is desirable. One effective way is to coat a layer of other polymers with high temperature and voltage tolerance. Roh et al. [132] improved the thermal stability of PE separators by coating a layer of macroporous polyarylate (PAR) via the physical method. The melting temperature of the modified separator is enhanced up to $194^{\circ} \mathrm{C}$ [132]. However, the physical bond is so weak that the coated layer may peel off during cycling [133]. To overcome the above issue, dopamine was used to modify polyolefin membranes due to its strong self-polymerization and high hydrophilicity [133-135]. For example, $\mathrm{Hu}$ et al. [133] used dopamine as a mediator to achieve tightly coating aramid nanofiber (ANF) on PP separators and obtained stable cycle performance and improved thermal stability. Besides that, other polymerizable monomers were grafted to polyolefin separator with chemical bonds by UV, electron beams and $\gamma$-ray irradiation [136-138]. Lee et al. [139] prepared PE membranes grafted with siloxane by electron beam irradiation technique. Besides excellent cycle performance and improved thermal stability, the grafted PE separator shows enhanced electrochemical stability. What's more, it could remain stable up to $5.2 \mathrm{~V}$, which is helpful to design high-voltage LIBs and to improve overcharge endurance [139].

Besides polymers, ceramic materials with high thermal stability and excellent mechanical properties, such as aluminum oxide $\left(\mathrm{Al}_{2} \mathrm{O}_{3}\right)$, titanium dioxide $\left(\mathrm{TiO}_{2}\right)$ and silicon dioxide $\left(\mathrm{SiO}_{2}\right)$, have also been applied to coat polyolefin membranes [138, 140]. In order to achieve better coating effect, polymer binders are usually used as mediators to coat ceramic materials onto the membranes [141], which have a crucial effect on the final performance of the modified membrane. Lee et al. [142] found that $\mathrm{Al}_{2} \mathrm{O}_{3} /$ poly(vinylidene fluoride-co-hexafluoropropylene) (PVDF-HFP) composites would reduce the thermal stability of PP separators though the coating agent $\mathrm{Al}_{2} \mathrm{O}_{3}$ is thermally stable. When the temperature rises to about $140{ }^{\circ} \mathrm{C}$, the melting of the PVDF-HFP binder makes the $\mathrm{Al}_{2} \mathrm{O}_{3}$ particles agglomeration, which produces a strong driving force for the shrinkage of PP membranes. On the contrary, polyimide (PI) P84 [142] and phenolphthalein polyetherketone (PEK) [143] with higher thermal stability are proven as better choices. However, the traditional coating method is easy to obtain thick membranes due to excessive polymer binders, which would block the pores of separators and hence increase the cell internal resistance [140]. To decrease the interfacial resistance of separators and enhance cycle stability, binderfree coating methods have been proposed, such as grafting [140, 144, 145], ALD and magnetron sputtering deposition (MSD) [146, 147]. Zhu et al. [140, 144] developed novel $\mathrm{SiO}_{2}$-grafted $\mathrm{PE}$ separators and $\mathrm{TiO}_{2}$-grafted $\mathrm{PE}$ separators by electron beams. Figure $8 \mathrm{~b}$ shows the mechanisms of preparing $\mathrm{TiO}_{2}$-grafted $\mathrm{PE}$ separators; electron beam irradiation is used to create defects, which accelerate uniform coating of $\mathrm{TiO}_{2}$ [140]. The chemical bonds between coating materials and separators are the critical factor for improving stability of $\mathrm{TiO}_{2}$-grafted PE separators [140]. Chen et al. [146] and Peng et al. [147] deposited ultrathin $\mathrm{TiO}_{2}$ films on PP membranes by the ALD or MSD method. The modified PP separator could effectively avoid thermal shrinkage and poor wettability. However, the demand for special equipment and techniques makes chemical grafting difficult for large-scale application.

\subsubsection{Novel Separators with High Thermal Stability}

To overcome the congenital shortage of polyolefin membranes with poor thermal stability, new kinds of separators have been proposed.

The nonwoven separators based on high-heat-resistant polymer materials have been paid considerable attentions. For instance, poly(m-phenylene isophthalamide) (PMIA), polyimide (PI), poly(ethylene terephthalate) (PET) and poly(phthalazinone ether sulfone ketone) (PPESK) have extremely high thermal stability up to $250-500{ }^{\circ} \mathrm{C}$ [150], showing an obvious advantage over traditional polyolefin membranes. However, the intrinsic disadvantages of the large pore size and nonuniform pore distribution of nonwoven separators could result in serious self-discharge and lithium dendrites, which will hinder their extensive application in LIBs [151, 152]. Modifying nonwoven separators has been put forward, such as PVDF/PMIA/PVDF, PE/PI and PPESK/PVDF membranes [148, 153]. The excellent performance of PE/PI membrane is shown in Fig. 8c, as compared with PP/PE/PP separators [148]. Some inorganic particles, like $\mathrm{Al}_{2} \mathrm{O}_{3}, \mathrm{SiO}_{2}$ and $\mathrm{TiO}_{2}$, are also used to coat the nonwoven membrane for improving its electrochemical stability $[152,154,155]$.

Cellulose paper-based separators are also promising because of their low production costs, good mechanical properties and high electrochemical stability $[156,157]$. However, macro-/microfiber cellulose papers meet the intrinsic disadvantages of improper porous structure and poor mechanical/physicochemical properties [158]. Cladding is proposed as an effective way to overcome these disadvantages. Wang et al. [149] prepared paper-supported inorganic composite (PIC) membranes by spraying $\mathrm{Al}_{2} \mathrm{O}_{3}$ powders onto the surface of commercial paper substrates, 
which is helpful to improve the penetration test. As shown in Fig. 8d, during the test, the temperature of graphite/ $\mathrm{LiCoO}_{2}$ full cells with PIC separators slowly increases to $180^{\circ} \mathrm{C}$ and the voltage remains $3.78 \mathrm{~V}$ [149]. Additionally, the cell did not get fire after the nail test. By contrast, graphite/ $\mathrm{LiCoO}_{2}$ full cells with PE separators reacted violently, and the temperature sharply increased to $329{ }^{\circ} \mathrm{C}$, while the voltage dropped quickly down to $0 \mathrm{~V}$ (Fig. 8e) [149]. Furthermore, the PIC membrane exhibited high electrochemical stability with an oxidation decomposition voltage of $4.5 \mathrm{~V}$ (vs. $\mathrm{Li}^{+}$/ Li), higher than $4.2 \mathrm{~V}$ of the PE [149].

Employing inorganic separator materials with "absolutely" thermal stability and strong electrolyte wettability is another good way. Pure inorganic separators composed of $\mathrm{Al}_{2} \mathrm{O}_{3}$ and $\mathrm{SiO}_{2}$ show extremely high thermal stability up to 2054 and $1650^{\circ} \mathrm{C}$, respectively [159, 160]. Such separators also exhibit excellent electrochemical performance and strong compressive strength. But the poor flexibility and tensile strength may restrict their large-scale application [159]. To improve the tensile strength of inorganic separators, polymer binders are introduced although they will sacrifice some thermal performance. Raja et al. [161] prepared $\mathrm{MgAl}_{2} \mathrm{O}_{4}$-based ceramic membranes (PCMs) with PVDFHFP as the binder. Although the thermal stability has been reduced by polymers, the PCM membrane with a low binder ratio could resist the temperature up to $350{ }^{\circ} \mathrm{C}$ [161]. Similarly, Zhang et al. [162] prepared $\mathrm{Al}_{2} \mathrm{O}_{3}$-based ceramic membranes with styrene-butadiene rubber (SBR) as the binder. Then, He et al. [163] developed a pure ceramic membrane composed of $\mathrm{Al}_{2} \mathrm{O}_{3}$ nanowires with impressive flexibility by a filtration procedure, which provides a new mentality on overcoming the fragility of pure inorganic membranes.

\subsubsection{Functionalized Separators}

Although the separator with high thermal stability and strong mechanical properties could greatly inhibit the occurrence of an internal short circuit, some special functions have been introduced into the separator for enhancing the safety of LIBs. Adding fire retardants into the electrolytes has proven as an effective way to suppress the combustion of LIBs [164]. But in most cases, the addictive fire retardant will result in the poor electrochemical performance of LIBs [165]. Incorporating fire-extinguishing agents into separators as an automatic fire-extinguishing device has been proposed. Yim et al. [165] put forward a novel separator modified by integrating temperature-responsive microcapsules with fire-extinguishing agents, which could realize the self-extinguishing capability of LIBs. They chose $(1,1,1,2,2,3,4,5,5,5$-decafluoro-3-methoxy4-(trifluoromethyl)-pentane) (DMTP) as the extinguishing agent and PMMA as the temperature-responsive polymeric layer [165]. Figure 9a illustrates the extinguishing mechanism of this microcapsule modified separator. The subsequent standard nail penetration test shows that the temperature-responsive microcapsules could suppress the temperature change [165]. Liu et al. [166] developed novel separator integrating temperature-responsive microfibers

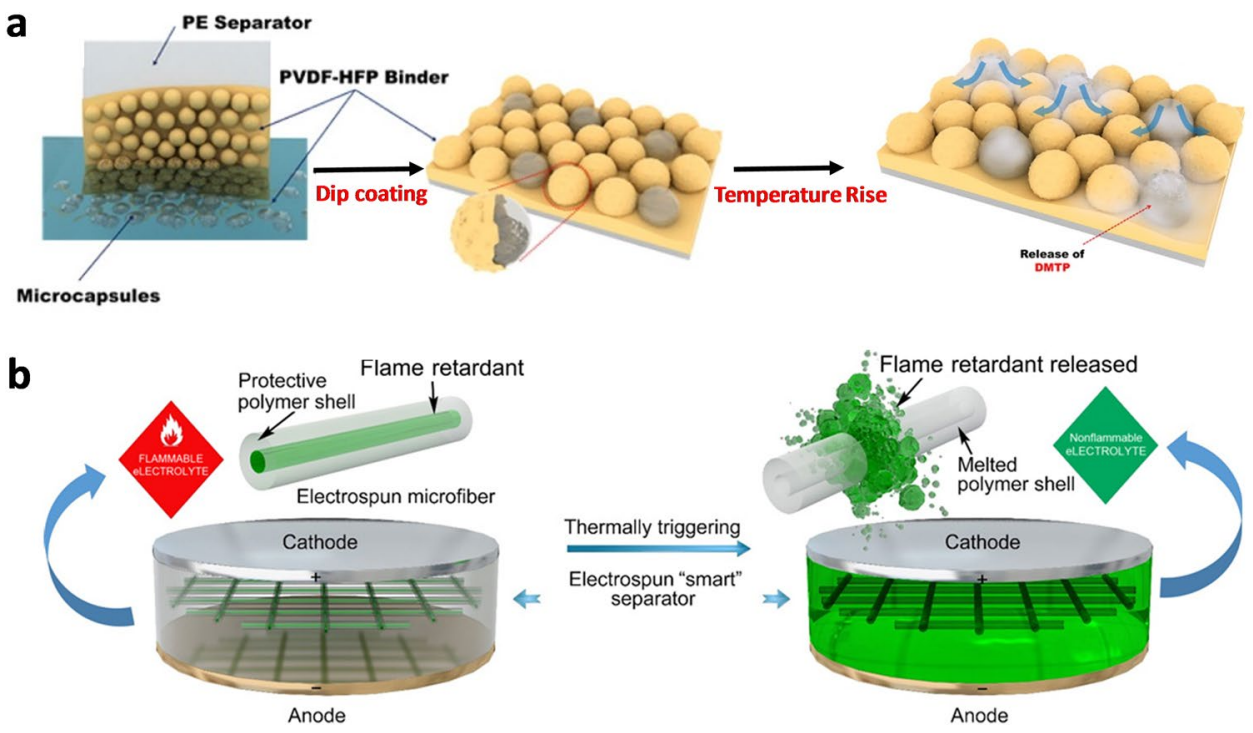

Fig. 9 a Schematic for the coating of microcapsules on a PE separator by the PVDF-HFP binder. Once the temperature surpasses the melting point of the PMMA shell, the internal extinguishing agent DMTP will release into the electrolyte, suppressing the burning of the electrolytes. Reproduced with permission from Ref. [165]. Copyright
2015, American Chemical Society. b Structure of core-shell structure microfibers. Once thermal triggering, the TPP agent will release into the electrolyte, suppressing the ignition of electrolytes. Reproduced with permission from Ref. [166]. Copyright 2017, Wiley-VCH 
with core-shell structure (Fig. 9b). They employed triphenyl phosphate (TPP) as the extinguishing agent (core) and PVDF-HFP as the temperature-responsive shell. If the temperature increases to the melting point of the temperatureresponsive shell, the encapsulated extinguishing agent is released into the electrolyte, effectively suppressing temperature rise $[165,166]$.

Some electroactive redox polymers, such as polypyrrole, polythiophene and polytriphenylamine, can be p-doped into an electronically conductive phase during oxidation and reversibly n-doped into the neutral isolating state over reduction $[167,168]$. This characteristic provides a new strategy to prevent LIBs from overcharging by developing potential-sensitive separators, which can produce an internal conducting bypass for shunting the charge current at the overcharged state [168]. The common way to prepare potential-sensitive separators is to incorporate the electroactive redox polymers into the pores of separator membranes $[168,169]$. Zhang et al. introduced poly(4-methoxytriphenylamine) (PMOTPA) to modify the commercial PE separator. The subsequent overcharge test shows that the voltage of the LFP/LTO full cell with this potential-sensitive separator could keep safe at about 2.6 V [168]. Li et al. [169] prepared a poly(3-decyl thiophene)-modified separator, which could maintain the voltage of $\mathrm{LiFePO}_{4} / \mathrm{C}$ cells at a safe value below $4 \mathrm{~V}$.

The reliability and safety problems caused by dissolved Mn cation in the electrolyte solution have received great attention for ternary oxide cathodes. Some experts proposed that modifying separators with specific chemical functionality is an effective way to shut down the migration path of Mn cations [170]. Ziv et al. proposed that polymeric materials functionalized with macrocycles or the alkali metal salts of organic acids could effectively trap the Mn cation [170-173]. The separators modified by poly(vinylbenzo18-crown-6) (PVB-18C6) [170] and poly(divinylbenzene(vinylbenzyl-aza-15-crown-5)-vinylbenzylchloride)) (PVB-A15C5) [172] ethers, as well as the dilithium salt of poly(ethylene-alternate-maleic acid) (PE-alt- $\mathrm{MaLi}_{2}$ ) [171], show an brilliant ability to chelate Mn species. Compared with the formers, PE-alt-MaLi ${ }_{2}$ exhibits better functionality [171]. It is reported that the amount of Mn on the graphite anode could be reduced by over $80 \%$ in the cells with the functional separator [171].

\subsection{Electrolyte Materials}

The electrolytes serve as a medium for ion charge transfer. Although nonaqueous organic electrolytes including carbonate solvents and lithium hexafluorophosphate $\left(\mathrm{LiPF}_{6}\right)$ have been used for decades since the invention of LIBs [174], they are essentially not safe. The instability of electrolytes origins from both solvents and lithium salt.

Presently, as shown in Table 5 [175], cyclic carbonates (e.g., EC, PC) are commonly used as electrolyte solvents, which possess high dielectric constants to ensure high-concentration lithium salts dissociation capability. However, their high melting points and high viscosity will hinder ion transportation during the storage process. In order to satisfy practical application, linear carbonates (e.g., DMC, DEC and EMC) with low viscosity are mixed with cyclic carbonates to become composite electrolytes with proper chemical/electrochemical stability and good interfacial properties [176]. To be mentioned, cyclic ethylene carbonate (EC) could electrochemically decompose at about $0.8 \mathrm{~V}$ versus $\mathrm{Li} / \mathrm{Li}^{+}$to form protective SEI films at the surface of
Table 5 Physical and electrochemical properties of state-of-the-art organic solvents for LIBs and a concluding evaluation regarding their safety. Reproduced with permission from Ref. [175]. Copyright 2015, Wiley-VCH

\begin{tabular}{|c|c|c|c|c|c|}
\hline Solvent & $\mathrm{EC}$ & $\mathrm{PC}$ & $\mathrm{DMC}$ & DEC & EMC \\
\hline Structure & & & & & \\
\hline Dielectric constant & + & + & - & - & - \\
\hline Viscosity & + & + & - & - & - \\
\hline Volatility & - & - & + & + & + \\
\hline Boiling temperature & + & + & - & - & - \\
\hline Flash point & + & + & - & - & - \\
\hline Melting temperature & + & - & o & - & - \\
\hline Construction to SEIs & + & - & - & - & - \\
\hline Anodic stability & + & + & o & o & o \\
\hline Safety & + & o & - & - & - \\
\hline
\end{tabular}

+, High; o, medium; -, low 
low-potential anodes [177]. Although the carbonates have been considered as the solvents with almost the best comprehensive properties, their low flash points make them easy to decompose to gases, which are inflammable and explosive [178]. Thus, constructing safer carbonate-based composite solvents and exploring innovative solvents would be important to design safe LIBs.

Another important component of electrolytes is the lithium salt that provides Li ions. At present, as shown in Table 6, the common lithium salts used in $\mathrm{LIBs}$ contain $\mathrm{LiPF}_{6}$, lithium tetrafluoroborate $\left(\mathrm{LiBF}_{4}\right)$, lithium hexafluoroarsenate $\left(\mathrm{LiAsF}_{6}\right)$ and lithium perchlorate $\left(\mathrm{LiClO}_{4}\right)$. Among these salts, $\mathrm{LiPF}_{6}$ is commercially used due to its good ionic conductivity and ability to passivate aluminum current collectors, but it is sensitive to a trace amount of water and would easily decompose to toxic and corrosive gases at high temperature [124]. $\mathrm{LiAsF}_{6}$ seems to be an ideal candidate due to good electrochemical properties and thermal stability, but its toxicity limits its practical application [179]. The fluoride-free alternative salt, $\mathrm{LiClO}_{4}$, exhibits comparable properties to $\mathrm{LiPF}_{6}$, and it is not sensitive to moisture and has no toxic decomposition products; however, there is a severe risk of explosion due to the high oxidizability of $\mathrm{ClO}_{4}{ }^{-}$and interaction with organic compounds. Thus, researchers pay more attention to developing novel lithium salts such as lithium bis(trifluoromethanesulfonyl) imide (LiTFSI) [180], lithium bis(fluorosulfonyl) imide (LiFSI) [181, 182], lithium bis(oxalate)borate (LiBOB) [183], lithium difluoro(oxalate) borate (LiODFB) [184] and lithium bis(fluorosulfonyl) amide [185].

\subsubsection{Failure Mechanism of Electrolytes}

Nonaqueous electrolytes account for a high percentage of the whole battery weight in a LIB. Almost all of the chemical reactions in the battery are related to the electrolyte. The carbonate solvents are usually flammable, and lithium salts are unstable. When LIBs are under abuse conditions, they could be easily ignited to generate a lot of heat and cause thermal

Table 6 Physical and electrochemical properties of various frequently utilized lithium salts for LIBs and a concluding evaluation regarding their safety aspects. Reproduced with permission from Ref. [175]. Copyright 2015, Wiley-VCH

\begin{tabular}{lllll}
\hline Lithium salt & $\mathrm{LiPF}_{6}$ & $\mathrm{LiBF}_{4}$ & $\mathrm{LiAsF}_{6}$ & $\mathrm{LiClO}_{4}$ \\
\hline Ionic conductivity & + & $\mathrm{o}$ & + & + \\
Electrochemical stability & + & $\mathrm{o}$ & + & + \\
Thermal stability & - & $\mathrm{o}$ & + & - \\
Stability toward moisture & - & o & o & 0 \\
Al current collector passivation & + & + & + & 0 \\
Nontoxicity & - & - & - & - \\
Safety & - & o & - & - \\
\hline
\end{tabular}

+ , High; o, medium; -, low runaways [120]. For the traditional graphite/ $\mathrm{LiCoO}_{2}$ battery, if the temperature reaches $69^{\circ} \mathrm{C}$, the SEI film on the anode surface would be destroyed and produce initial reaction heat, and then the exposed lithiated graphite will react with the organic solvent (EC) [186]:

$2 \mathrm{Li}+\mathrm{C}_{3} \mathrm{H}_{4} \mathrm{O}_{3} \rightarrow \mathrm{Li}_{2} \mathrm{Co}_{3}+\mathrm{C}_{2} \mathrm{H}_{4}$

For $\mathrm{Li}_{0.5} \mathrm{CoO}_{2}$ cathode, $\mathrm{Li}_{0.5} \mathrm{CoO}_{2}$ will react with $\mathrm{EC}$ at $70{ }^{\circ} \mathrm{C}$ to generate water [187]:

$$
\begin{aligned}
& \mathrm{Li}_{0.5} \mathrm{CoO}_{2}+0.1 \mathrm{C}_{3} \mathrm{H}_{4} \mathrm{O}_{3} \\
& \quad \rightarrow 0.5 \mathrm{LiCoO}_{2}+0.5 \mathrm{CoO}+0.3 \mathrm{CO}_{2}+0.2 \mathrm{H}_{2} \mathrm{O}
\end{aligned}
$$

Kerr et al. [188] reported that the initial decomposition temperature of the electrolyte $\left(\mathrm{LiPF}_{6} / \mathrm{EC}: \mathrm{DMC}\right)$ is about $80^{\circ} \mathrm{C}$. Once decomposition happens, complicated reactions in electrolyte would be triggered as follows [114, 189, 190]:

The decomposition of $\mathrm{LiPF}_{6}$ :

$\mathrm{LiPF}_{6} \leftrightarrow \mathrm{LiF}+\mathrm{PF}_{5}$

$\mathrm{PF}_{5}+\mathrm{H}_{2} \mathrm{O} \rightarrow \mathrm{PF}_{3} \mathrm{O}+2 \mathrm{HF}$

The series of reactions between strong Lewis acid $\mathrm{PF}_{5}$ and the organic solvent:

$\mathrm{C}_{2} \mathrm{H}_{5} \mathrm{OCOOC}_{2} \mathrm{H}_{5}+\mathrm{PF}_{5} \rightarrow \mathrm{C}_{2} \mathrm{H}_{5} \mathrm{OCOOPF}_{4}+\mathrm{HF}+\mathrm{CH}_{2}=\mathrm{CH}_{2}$

$\mathrm{C}_{2} \mathrm{H}_{5} \mathrm{OCOOC}_{2} \mathrm{H}_{5}+\mathrm{PF}_{5} \rightarrow \mathrm{C}_{2} \mathrm{H}_{5} \mathrm{OCOOPF}_{4}+\mathrm{C}_{2} \mathrm{H}_{5} \mathrm{~F}$

$\mathrm{C}_{2} \mathrm{H}_{5} \mathrm{OCOOPF}_{4} \rightarrow \mathrm{PF}_{3} \mathrm{O}+\mathrm{CO}_{2}+\mathrm{C}_{2} \mathrm{H}_{5} \mathrm{~F}$

$\mathrm{C}_{2} \mathrm{H}_{5} \mathrm{OCOOPF}_{4} \rightarrow \mathrm{PF}_{3} \mathrm{O}+\mathrm{CO}_{2}+\mathrm{C}_{2} \mathrm{H}_{4}+\mathrm{HF}$

$\mathrm{C}_{2} \mathrm{H}_{5} \mathrm{OCOOPF}_{4}+\mathrm{HF} \rightarrow \mathrm{PF}_{4} \mathrm{OH}+\mathrm{CO}_{2}+\mathrm{C}_{2} \mathrm{H}_{5} \mathrm{~F}$

$\mathrm{C}_{2} \mathrm{H}_{5} \mathrm{OH}+\mathrm{CH}_{2}=\mathrm{CH}_{2} \rightarrow \mathrm{C}_{2} \mathrm{H}_{5} \mathrm{OC}_{2} \mathrm{H}_{5}$

The oxidation reactions of various organic solvents:

$$
\begin{aligned}
& 2.5 \mathrm{O}_{2}+\mathrm{C}_{3} \mathrm{H}_{4} \mathrm{O}_{3}(\mathrm{EC}) \rightarrow 3 \mathrm{CO}_{2}+2 \mathrm{H}_{2} \mathrm{O} \\
& 6 \mathrm{O}_{2}+\mathrm{C}_{5} \mathrm{H}_{10} \mathrm{O}_{3}(\mathrm{DEC}) \rightarrow 5 \mathrm{CO}_{2}+5 \mathrm{H}_{2} \mathrm{O} \\
& 3 \mathrm{O}_{2}+\mathrm{C}_{3} \mathrm{H}_{6} \mathrm{O}_{3}(\mathrm{DMC}) \rightarrow 3 \mathrm{CO}_{2}+3 \mathrm{H}_{2} \mathrm{O} \\
& 4 \mathrm{O}_{2}+\mathrm{C}_{4} \mathrm{H}_{6} \mathrm{O}_{3}(\mathrm{PC}) \rightarrow 4 \mathrm{CO}_{2}+3 \mathrm{H}_{2} \mathrm{O} \\
& \mathrm{O}_{2}+\mathrm{C}_{3} \mathrm{H}_{4} \mathrm{O}_{3}(\mathrm{EC}) \rightarrow 3 \mathrm{CO}+2 \mathrm{H}_{2} \mathrm{O} \\
& 3.5 \mathrm{O}_{2}+\mathrm{C}_{5} \mathrm{H}_{10} \mathrm{O}_{3}(\mathrm{DEC}) \rightarrow 5 \mathrm{CO}+5 \mathrm{H}_{2} \mathrm{O}
\end{aligned}
$$


$1.5 \mathrm{O}_{2}+\mathrm{C}_{5} \mathrm{H}_{10} \mathrm{O}_{3}(\mathrm{DMC}) \rightarrow 3 \mathrm{CO}+3 \mathrm{H}_{2} \mathrm{O}$

$2 \mathrm{O}_{2}+\mathrm{C}_{4} \mathrm{H}_{6} \mathrm{O}_{3}(\mathrm{PC}) \rightarrow 4 \mathrm{CO}+3 \mathrm{H}_{2} \mathrm{O}$

Equation (7) presents the decomposition of $\mathrm{LiPF}_{6}$ in $\mathrm{LiPF}_{6}$-based electrolytes; Eqs. (8) and (9) show further reactions between strong Lewis acid phosphorus pentafluoride $\left(\mathrm{PF}_{5}\right)$ and organic solvents or water; $\mathrm{PF}_{5}$ may attack the electron lone pair of oxygen in the solvent molecule and then make it decompose. In the meantime, as shown in Eq. (9), the oxygen generated by cathodes would react with carbonate solvents to release $\mathrm{CO}_{2}$ or $\mathrm{CO}$. Kawamura et al. [189] found that the heat of $1 \mathrm{M} \mathrm{LiPF}_{6}$ was $375 \mathrm{~J} \mathrm{~g}^{-1}$ in 1:1 PC: DMC (or EC: DMC) and $515 \mathrm{~J} \mathrm{~g}^{-1}$ in 1:1 PC: DEC (or EC: DEC), and the exothermic peaks were located at 230 and $280{ }^{\circ} \mathrm{C}$, respectively. The above reactions could produce flammable gases and generate large amounts of heat, which would cause the flatulence and leakage of LIBs. Once the electrolytes leak out and contact with air, the batteries would be fired and probably exploded.

With increasing requirements on safety for LIBs used in EVs, developing extraordinary electrolytes with good thermal stability and excellent electrochemical properties is desirable and urgent. On the basis of the failure mechanism of traditional electrolytes and advanced in situ characterization techniques, many researchers are focusing on designing novel electrolytes.

\subsubsection{Novel Electrolytes for Safe LIBs}

The improvement of electrolyte thermal stability is significantly important to the safety of LIBs. The above failure

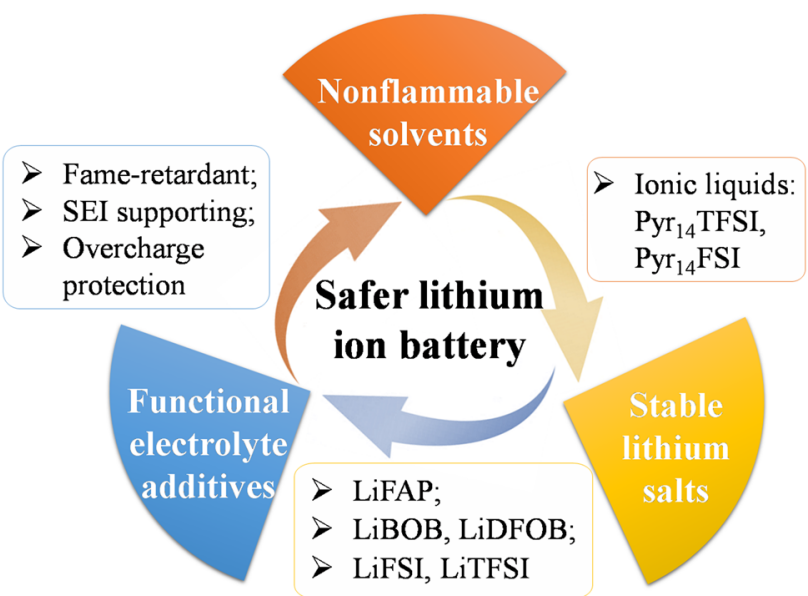

Fig. 10 Approaches to design safer lithium-ion battery electrolytes mechanisms reveal that the thermal stability of electrolytes is closely related to the components including organic carbonate solvents and lithium salts. Presently, many efforts have been devoted to designing stabler lithium salts, adding various functional additives for nonflammable electrolyte solvents and exploring nonflammable solvents, as shown in Fig. 10. In the following contents, detailed introduction and discussion will be presented.

\section{Alternative Lithium Salts}

$\mathrm{LiPF}_{6}$ is commercially used as a lithium salt due to its good ionic conductivity and ability to passivate aluminum current collectors, but it is easily hydrolyzed and decomposed to toxic and corrosive gases at high temperature [175]. Seeking alternative lithium salts with complex anions or the modification of $\mathrm{LiPF}_{6}$ would be effective for improving thermal stability.

Modification of LiPF $F_{6}$ by partially substituting fluoride atoms to construct stabler LiPF ${ }_{6}$ derivatives In order to solve the thermal instability of $\mathrm{LiPF}_{6}$, some works suggested using hydrophobic and electron-withdrawing groups to substitute one or more fluorine atoms. For example, Schmidt et al. considered lithium fluoroalkyl phosphates $\left[\mathrm{LiPF}_{3}\left(\mathrm{C}_{2} \mathrm{~F}_{5}\right)_{3}, \mathrm{LiFAP}\right]$ for LIBs, where three hydrophobic perfluorinated alkyl groups $\left(-\mathrm{CF}_{2} \mathrm{CF}_{3}\right)$ replace three $\mathrm{F}$ atoms. Compared with $\mathrm{LiPF}_{6}$, it showed superior stability to hydrolysis even in the presence of $1000 \mathrm{ppm}$ water for $70 \mathrm{~h}$, and its conductivity and specific capacity are better than $\mathrm{LiPF}_{6}$ [191]. The existence of perfluorinated alkyl groups would increase the flashing point [192]. However, its high costs may hinder commercialization. Additionally, Xu et al. [193] investigated lithium tetrafluoro oxalato phosphate $\left[\mathrm{LiPF}_{4}\left(\mathrm{C}_{2} \mathrm{O}_{4}\right)\right.$, LTFOP] as an alternative lithium salt, which also exhibits better thermal stability than $\mathrm{LiPF}_{6}$, while its conductivity, electrochemical windows and cycling stability are similar to $\mathrm{LiPF}_{6}$ after being stored at $65^{\circ} \mathrm{C}$. However, its increased surface impedance could affect the power capability of LIBs [194].

Novel lithium salts To improve the thermal stability and electrochemical properties of LIBs, some organic ligand-based anions [e.g., bis(oxalate)borate (BOB) and difluoro(oxalate)borate (DFOB)] and large complex anions [e.g., bis(fluorosulfonyl)imide (FSI) and bis(trifluoromethanesulfonyl)imide (TFSI)] are also used to construct innovative salts.

As shown in Table 7, LiBOB has been reported as a promising candidate for LIBs due to its advantages like good thermal stability and effect on accelerating SEI formation [195]. However, its lower solubility and conductivity render the electrolyte with poor low-temperature properties and LIBs with low rate capability. Thus, it can 
Table 7 Novel lithium salts as well as their physical and electrochemical properties. Reproduced with permission from Ref. [191, 197, 198]. Copyright 2001, Elsevier, Copyright 2015, Royal Society of Chemistry, and Copyright 2011, the Electrochemical Society

\begin{tabular}{|c|c|c|c|c|c|c|}
\hline Lithium salt & $\mathrm{LiPF}_{6}$ & LiFAP & $\mathrm{LiBOB}$ & LiDFOB & LiFSI & LiTFSI \\
\hline$T\left({ }^{\circ} \mathrm{C}\right)$ & 125 & 200 & 275 & 200 & 200 & 360 \\
\hline$C\left(\mathrm{mS} \mathrm{cm}^{-1}\right)$ & 10.8 & 8.2 & 14.9 & 8.58 & 9.73 & 9 \\
\hline Advantages & \multicolumn{6}{|c|}{$\begin{array}{l}L_{P} F_{6} \text { high conductivity, low cost, excellent cycling stability at room temperature } \\
L i F A P \text { stable in water, excellent thermal stability, good cycling stability } \\
L i B O B \text { wide voltage windows, beneficial to the formation of SEI interfaces, good } \\
\text { thermal stability, passivated aluminum current collectors } \\
\text { LiDFOB high solubility, beneficial to the formation of SEI and CEI interfaces, } \\
\text { wide voltage windows, good cycle performance at high temperature } \\
\text { LiFSI high conductivity, good compatibility with water, excellent cycle stability at } \\
\text { high temperature } \\
\text { LiTFSI high conductivity, high solubility, good thermal stability, good cycle } \\
\text { stability at low voltage }\end{array}$} \\
\hline Disadvantages & \multicolumn{6}{|c|}{$\begin{array}{l}\mathrm{LiPF}_{6} \text { sensitive to water, easy decomposition, } \mathrm{b} \\
\text { perature } \\
\text { LiFAP high cost } \\
\mathrm{LiBOB} \text { low solubility, low conductivity } \\
\mathrm{LiDFOB} \text { high cost } \\
\text { LiFSI corroding aluminum current collectors } \\
\text { LiTFSI corroding aluminum current collectors }\end{array}$} \\
\hline
\end{tabular}

$T$ decomposition temperature, $C$ electrical conductivity be used as an additive rather than an individual lithium salt. Compared with LiBOB, LiDFOB, with one oxalate ring, presents comparable properties but better solubility. It is found that the LIB with the electrolyte containing 5\% LiDFOB shows higher-capacity retention than that without LiDFOB [196]. In Table 7, other kinds of lithium salts containing sulfonyl groups such as LiTFSI and LiFSI also show great thermal stability, high conductivity and good solubility, but the most disadvantage is aluminum corrosion [197]. Therefore, we need to further develop lithium salts by designing extraordinary anions with high thermal stability and good electrochemical properties.

\section{Various Functional Additives}

The most flammable component in LIBs is organic solvents. Besides improving the thermal stability of lithium salts, the most straightforward way is to introduce functional additives to the solvents or thoroughly abandon the flammable solvents. Different kinds of additives have been reported. According to the functions, they can be divided into flame-retardant additives to reduce the burning risk [199], overcharge additives to suppress the continuous increase in overcharge voltage [200] and SEI supporting additives to accelerate formation of stable SEI films [201]. What's more, these additives show not only simple single function but also multiple synergistic effects.

\section{Flame-retardant additives}

Flame-retardant additives usually have high stability. Only about ten percent of addition can effectively decrease flammability of the electrolytes. Based on the mechanisms to suppress combustion, they can be divided into chemical retardants and physical retardants. The former will terminate free radical linear reaction by capturing hydrogen radicals $(\mathrm{H} \cdot$ or $\cdot \mathrm{OH})$, while the later will dilute combustible components with flame-retardant vapor. According to flameretardant mechanisms and element types, the flame-retardant additives can be classified into the following four types:

Fluoride-retardant additives Owing to the fluoride atom with the highest electronegativity and low polarization, fluorinated solvents show higher oxidation stability, lower melting points and higher flash points. Thus, fluoride-retardant additives are commonly used to improve the thermal stability of LIB electrolytes by the physical mechanism. Additionally, they also possess low viscosity under low temperature [202]. As shown in Fig. 11a and b, Xia et al. prepared F-electrolytes using 1,1,1,3,3,3-hexafluoroisopropyl methyl ether (HFPM) as fluorinated solvents, which show good wettability and nonflammability. Further, the $\mathrm{Li} / / \mathrm{LiNi}_{0.5} \mathrm{Mn}_{1.5} \mathrm{O}_{4}$ battery with this F-electrolyte presented enhanced safety and longevity (Fig. 11c) [203]. Song et al. [204] used $5 \mathrm{wt} \%$ methyl (2,2,2-trifluoroethyl) carbonate (FEMC), one kind of fluorinated linear carbonate, as a new electrolyte additive for the LIB with $\mathrm{LiNi}_{0.5} \mathrm{Co}_{0.2} \mathrm{Mn}_{0.3} \mathrm{O}_{2}$ cathodes, and obtained enhanced discharge capacity and cyclability. The analysis by ex situ IR and XPS demonstrates that FEMC plays an important role in forming stable SEI layers and effective passivation of the cathode surfaces.

Although fluorinated additives can remarkably improve the thermal stability of electrolytes and help to construct stable SEI films, the high cost, poor compatibility with $\mathrm{LiPF}_{6}$ 
a

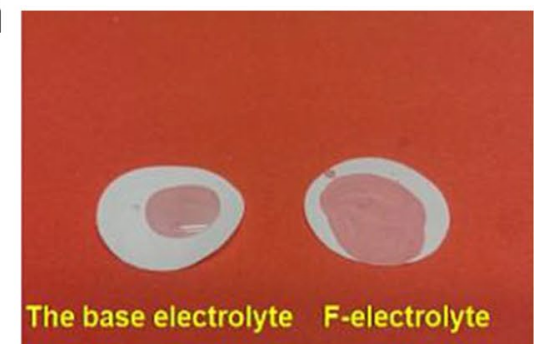

b

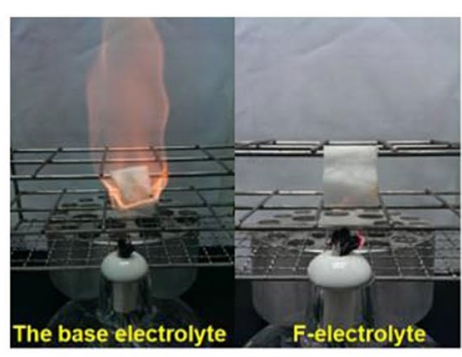

C

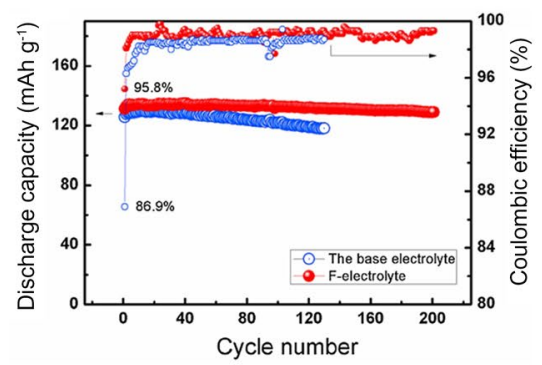

d

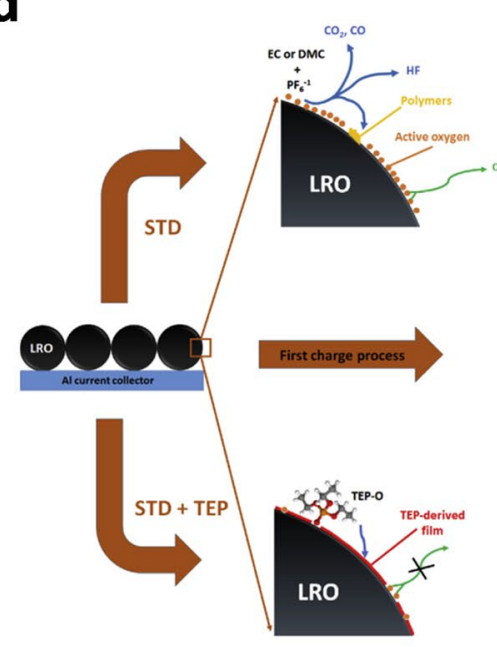

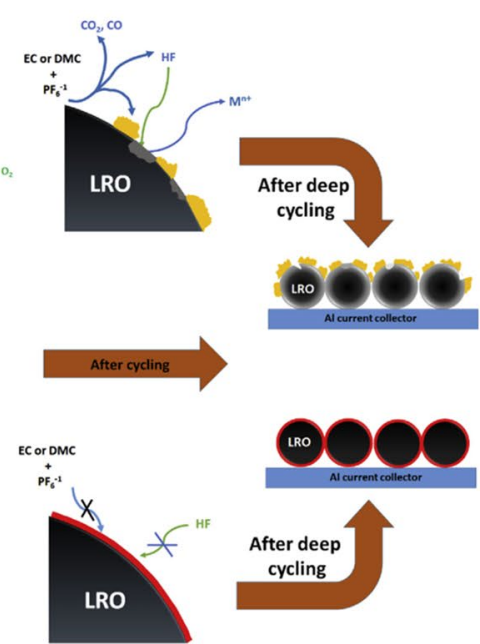

e

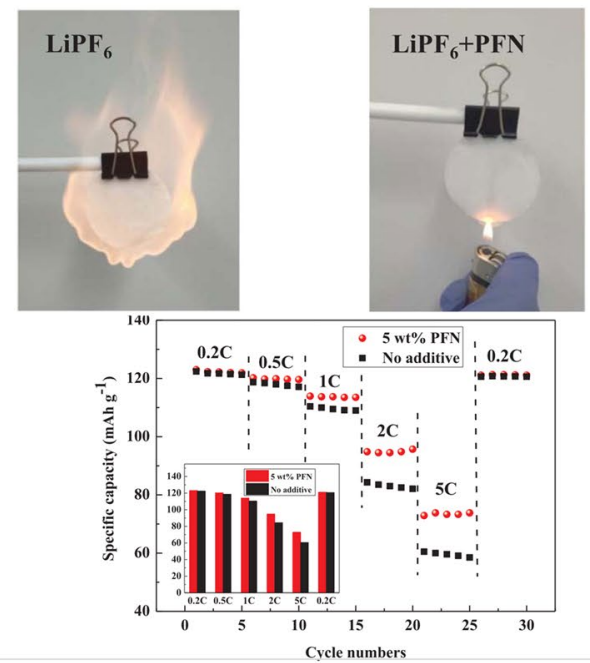

Fig. 11 a Photograph of the wetting behavior of the electrolyte with separators. b An illustration of the flammability testing of the electrolyte with and without HFPM. c Cycling stability and Coulombic efficiency of $\mathrm{Li} / / \mathrm{LiNi}_{0.5} \mathrm{Mn}_{1.5} \mathrm{O}_{4}$ coin cells in the electrolyte with and without HFPM. Reproduced with permission from Ref. [203]. Copyright 2015, Wiley-VCH. d Schematic illustration on the contri- bution of TEP to the structural integrity of LRO. Reproduced with permission from Ref. [207]. Copyright 2017, Elsevier. e Flammability testing of electrolytes and rate performance of $\mathrm{Li} / / \mathrm{LiNi}_{0.5} \mathrm{Mn}_{1.5} \mathrm{O}_{4}$ batteries with and without $5 \mathrm{wt} \%$ PFN additives. Reproduced with permission from Ref. [212]. Copyright 2018, Elsevier

combustion under a limited dosage. Moreover, narrow potential windows, high viscosity and reductive reactions occurred on the anode surface also hinder their practical application. Combining such additives with small amounts of other functional additives should be an efficient strategy.

Nitrogenous-retardant additives Nitrogenous-retardant additives generally have a high flash point, low volatility and wide potential windows. The commonly used ones for LIBs are nitrile derivatives, such as butyronitrile, succinonitrile, terephthalonitrile and adiponitrile, which affect the thermal stability of electrolytes by the physical mechanism. For example, Song et al. [211] introduced dinitriles $\left(\mathrm{CN}-\left[\mathrm{CH}_{2}\right]_{n}-\mathrm{CN}\right.$ with $n=2,5$ and 10$)$ and mononitriles $\left(\mathrm{CH}_{3}-\left[\mathrm{CH}_{2}\right]_{m}-\mathrm{CN}\right.$ with $m=2,5$ and 10$)$ as additives into a carbonate-based electrolyte. With the nitrile-present electrolytes, the graphite/ $\mathrm{LiCoO}_{2}$ pouch cells showed small dimensional expansion even when they were stored at $80^{\circ} \mathrm{C}$ for 3 days. The strong interaction between the electronegativity of nitrile functional groups and electropositivity of cobalt in $\mathrm{LiCoO}_{2}$ cathodes is responsible for the improved 
performance. However, the compatibility with graphite anodes is poor.

Composite-retardant additives Compared with singleelement-retardant additives, the composite additives present better flame-retardant efficiency, solubility and compatibility with electrolytes. Simultaneously, they guarantee good electrochemical performance with a small dosage due to the synergistic effects of multiple elements. The mostly reported composite additive is ethoxy-(pentafluoro)-cyclotriphosphazene (PFN). As shown in Fig. 11e, PFN presents excellent cycle stability, high rate and high-voltage performances with better CEI films. Besides, the electrolyte with only $5 \mathrm{wt} \%$ PFN is completely nonflammable (Fig. 11e) [212]. This further proves that the composite flame retardants would be a good choice to simultaneously improve thermal and electrochemical properties. However, the high-purity reagents cannot be easily prepared industrially, which is not favorable for practical application.

\section{SEI supporting and overcharge protection additives}

SEI decomposition and overcharge are two critical factors to ignite thermal runways. Thus, the SEI supporting and overcharge protection additives are necessary. Yamaki et al. revealed that the additives of methyl difluoroacetate (MFA) could accelerate the generation of $\mathrm{CHF}_{2} \mathrm{COOLi}$, which is a major component of SEIs. The results showed that the reaction product of $\mathrm{CHF}_{2} \mathrm{COOLi}$ and lithiated carbon could increase the thermal stability of the battery [213]. Other electrolyte additives including vinylene carbonate (VC) [214, 215] and vinyl ethylene carbonate (VEC) [216] also have been used to improve the thermal stability of SEI films.

Overcharge is one major cause of LIB failure. It is critical to prevent LIBs from overcharge during operation. Redox shuttle additives have been used as intrinsic overcharge protection to enhance the safety characteristics of LIBs. Amine et al. [217] comprehensively reviewed the state of the art of redox shuttles for safer LIBs. Additionally, electrochemical polymerization additives can also be used for overcharge protection. Ai et al. [218] investigated that biphenyl additive could be electrochemically polymerized at overcharged cathode surfaces, resulting in the formation of a conductive surface polymer film, which served as a conductive bridge to create an internal short circuit to avoid the cell voltage runaway.

\section{Innovative and nonflammable electrolyte systems}

The carbonate solvents are usually flammable. If LIBs are under abuse conditions, they could be easily ignited to generate a lot of heat. In order to improve the safety of LIBs, many efforts have been focused on seeking innovative solvents to construct a nonflammable electrolyte system.

Room-temperature ionic liquids (RTILs) appear to be good substitutes to conventional organic solvents due to their high ionic conductivity, nonvolatile feature, proper electrochemical windows, thermal stability and low flammability [219]. The anion and cation structures could greatly affect the electrochemical properties of ILs. Recently, TFSI was widely used as anions due to its outstanding electrochemical properties and thermal stability. Mixtures of $\mathrm{N}$-butyl- $\mathrm{N}$-methylpyrrolidinium bis(trifluoro-methanesulfonyl)imide ( $\mathrm{Pyr}_{14}$ TFSI), $N$-butyl- $N$-methylpyrrolidinium bis(fluorosulfonyl)imide ( $\left.\mathrm{Pyr}_{14} \mathrm{FSI}\right), \mathrm{N}$-methoxy-ethyl$N$-methyl-pyrrolidinium bis(trifluoromethanesulfonyl) imide $\left(\mathrm{Pyr}_{12 \mathrm{O} 1} \mathrm{TFSI}\right)$ or $N$ - $N$-diethyl- $N$-methyl- $N$-(2methoxyethyl)ammonium bis(trifluoro-methanesulfonyl)imide (DEMETFSI) ionic liquids with lithium bis(trifluoromethanesulfonyl)imide (LiTFSI) salts are comparatively evaluated for application as electrolytes in LIBs [220, 221]. Among these RTILs, the $\mathrm{Pyr}_{14}$ FSI-LiTFSI-based electrolyte shows remarkable electrochemical stability, suitable ionic conductivity and relatively low viscosity [222]. Using this electrolyte in full LIBs of $\mathrm{Sn}-\mathrm{C} / \mathrm{LiFePO}_{4}$, the capacity retention was close to $100 \%$ over 2000 cycles, and the rate capability could extend up to $500 \mathrm{~mA} \mathrm{~g}^{-1}$. Additionally, the neat $\left[\mathrm{BuEtPyrrol}^{+}\right]\left[\mathrm{NTf}^{2-}\right]$ ionic liquid exhibited extremely high thermal stability up to $367.8^{\circ} \mathrm{C}$ with only a mass loss of $10 \mathrm{wt} \%$ [223].

However, for RTILs, high-purity requirements, high cost and low conductivity at room temperature caused by high viscosity limit their practical applications in LIBs. Anyway, using RTILs as electrolytes is one of the most beneficial ways to improve safety for LIBs.

\subsection{Electrode Design}

The electrode is composed of the active materials, the binder and the conductor, which needs to have high density and low porosity to achieve high-volume energy density. The thick electrode is favorable to reduce cell production costs and raise energy density. A cost model of LIBs for EVs shows that the thickness increase in the $\mathrm{LiMn}_{2} \mathrm{O}_{4}$ cathode from 60 to $100 \mu \mathrm{m}$ reduces the manufacturing cost of the cell by $18 \%$ [224]. Meanwhile, homogeneous reaction distribution should be achieved for thick electrodes; otherwise, overcharge might occur in the cathode and Li dendrites might form on the anode, which may break the cell balance that is specifically designed for a commercial LIB. Here cell balance refers to the initial capacity ratio between the anode and the cathode. There are several factors that influence the reaction homogeneity and distribution of phases in a porous electrode, such as Li-ion diffusion, electronic connection and solid-state transport in the electrode materials. These 

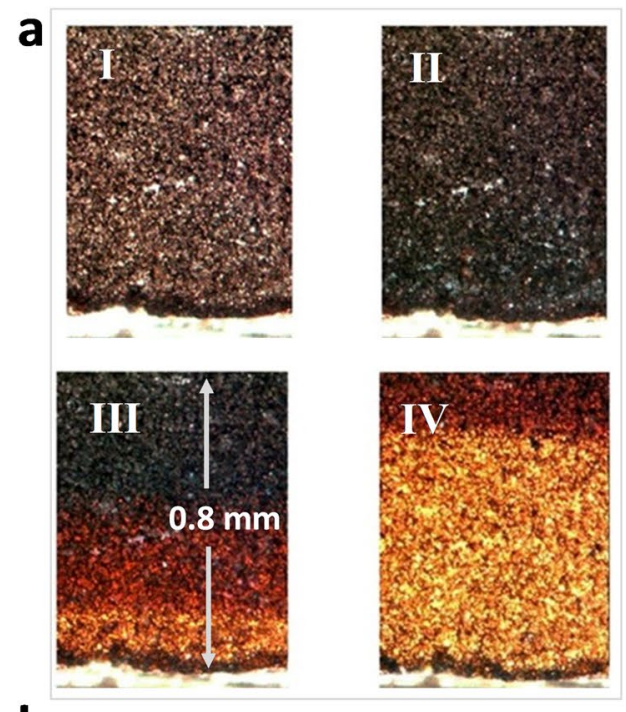

b

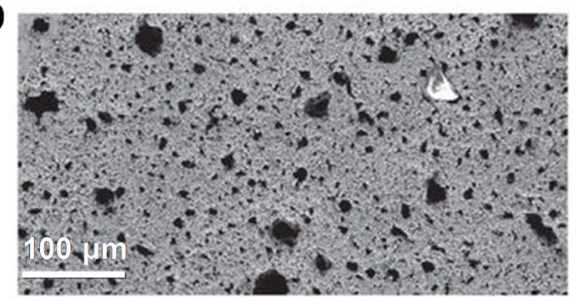

C

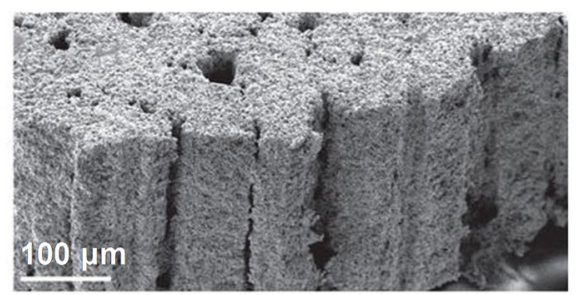

d

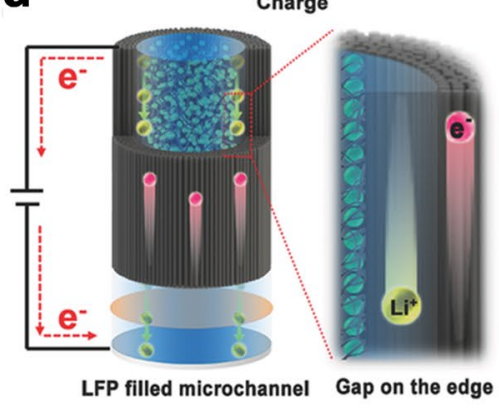

e

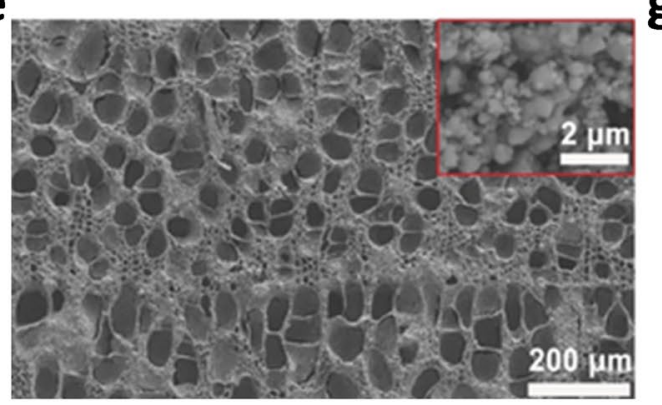

f

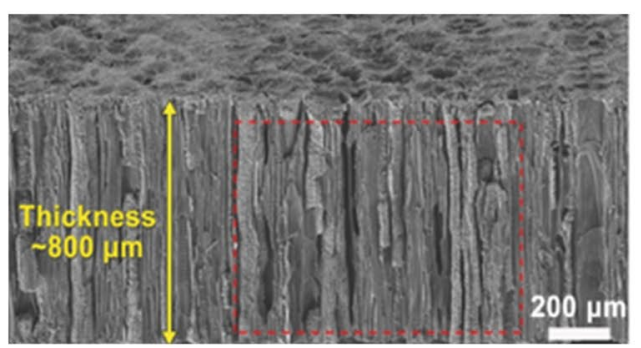

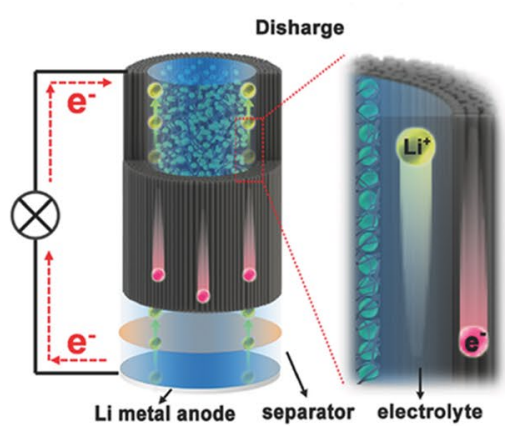

$\mathbf{g}$

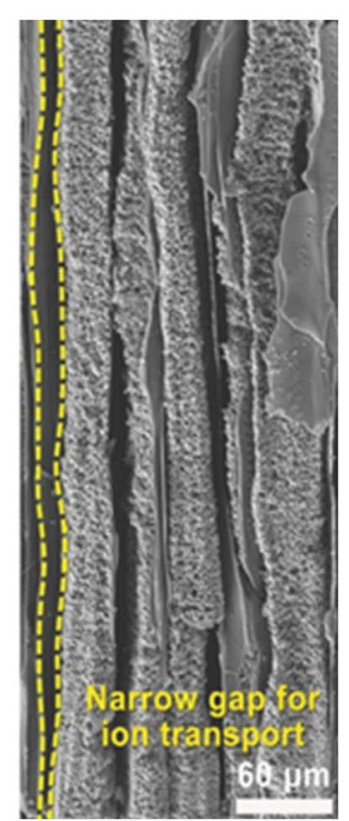

Fig. 12 A sequence of four optical micrographs showing the time evolution of color in the electrode: a-I the fresh electrode, a-II charge for $6 \mathrm{~h}$, a-III charge for $9 \mathrm{~h}$ and a-IV charge for $13 \mathrm{~h}$. Reproduced with permission from Ref. [226]. Copyright 2010, Elsevier. SEM images of the bulk $\mathrm{LiCoO}_{2}$ electrode synthesis by magnetic templating $\mathbf{b}$ the top view and $\mathbf{c}$ the side view. Reproduced with permis-

factors can be analyzed with the help of in situ/operando techniques. Blidberg et al. [225] took advantage of an extension of an in-operando XRD technique to detect the phase distribution in the porous $\mathrm{Li}_{x} \mathrm{FeSO}_{4} \mathrm{~F}(x=1,0.5,0)$ battery electrode. In-depth analysis of the electrode nonequilibrium behavior was obtained. Harris et al. used an optical half-cell, and the optical data were taken with a microscope viewing the quartz window from above. The lithiation process of the graphite electrode is shown in Fig. 12a [226]. The fully lithiated graphite looked golden yellow, while the delithiated graphite looked black. During the lithiation process, the upper layer of the electrode became golden yellow, indicating that fully lithiated graphite was obtained, while the bottom layer remained black. The electrode showed huge reaction inhomogeneity due to the slow Li-ion migration sion from Ref. [227]. Copyright 2016, Nature Publishing Group. d Schematic diagram of the working mechanism of the carbon framework-based LFP Li-ion battery. SEM images of the carbon framework-based LFP electrode: $\mathbf{e}$ the top view, $\mathbf{f}$ the side view and $\mathbf{g}$ the enlarged view of the side of the electrode. Reproduced with permission from Ref. [229]. Copyright 2017, Wiley-VCH

ability in thick electrode films. Anode electrodes with such reaction inhomogeneity would exhibit limited rate capability and form lithium dendrites easily, which may cause severe safety issues.

Proper design of electrodes is another issue to be addressed. One of the parameters used to characterize the design of electrodes is tortuosity, which is defined as $\tau=\varepsilon$ $\left(\sigma_{0} / \sigma\right)$, where $\varepsilon$ is the pore volume fraction, $\sigma_{0}$ the conductivity of the electrolyte and $\sigma$ the effective ion conductivity of the electrolyte [227]. In order to give a good estimate of the tortuosity, differential effective medium (DEM) is used, which provides particle parameters such as size, shape and orientation [228]. Electrodes with low tortuosity and high ion/electron diffusivity are favored in obtaining higher energy density. Sander et al. created linear pores 
with orientations perpendicular to the electrode sheet for fast $\mathrm{Li}$-ion transportation by magnetic templating (Fig. 12b, c). The resulting pores with $25-30 \mu \mathrm{m}$ average array spacing provided a more direct path for the diffusion of lithium ions to the bottom layer active materials [227]. With the same porosity, the electrodes with isotropic porosity and aligned porosity show different rate capabilities. At a rate of $2 \mathrm{C}$, the capacity of the latter is 2 times higher than that of the former, showing that a direct path is effective for the Li-ion transportation in a thick electrode [227]. Chen et al. [229] took natural wood as a template to construct a thick electrode with low tortuosity and high ion diffusion/electron conductivity (Fig. 12d). The natural basswood was an ideal template for its aligned pores and effective electron conductivity after carbonization. After filling with LFP nanoparticle slurry, there were aligned pores left, giving a high Li-ion conductivity (Fig. 12e). The obtained thick electrode of $\sim 800 \mu \mathrm{m}$ showed excellent performance (Fig. 12f). As shown in the schematic diagram (Fig. 12g), during cycling, the ions quickly diffuse along with the unfilled aligned pores, while the electrons transfer in the wood-carbonized matrix, realizing fast exchange in both electrons and ions in the active materials.

\subsection{Temperature Coefficient Device}

Thermal runaways are often caused by the accumulation of heat generation when LIBs are variously abused, such as overcharge, high-temperature impact and short circuit. To hold back the sustaining heat generation, a component called the positive temperature coefficient (PTC) device is equipped, which acts as a current limiter to prevent the cell overheating [32, 230, 231]. The PTC device is constituted by a thin conductive polymer layer, whose volume resistivity is positively sensitive to the temperature. Once the temperature exceeds the critical point, the PTC device will be activated and its resistance will increase dramatically to restrict the current flow [32]. Unfortunately, since the electric vehicles and large-scale energy storage systems demand higher capacity and larger energy density [32], the outer PTC device cannot meet the requirement of large batteries because of the hysteresis of heat conduction from inside to outside. The consequence of this delay is more dangerous when the thermal runaway takes place rapidly, and thus, more chain reactions will launch before the outer PTC device works [232]. Therefore, reducing the distance between the PTC device and the electrode could be an effective method to improve the efficiency of the PTC device. PTC-modified current collectors to construct a sandwich structure become

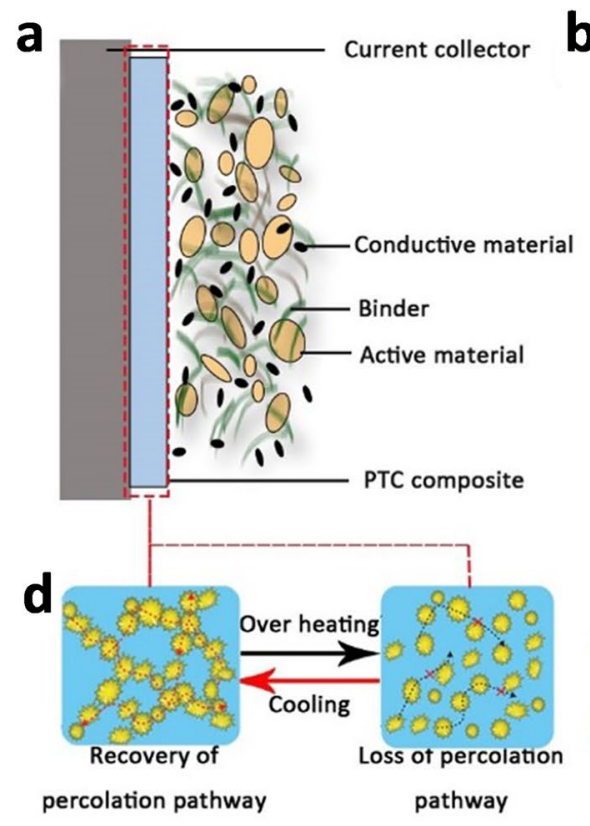

Fig. 13 a Schematic illustration of the sandwich structure electrode, including active layers, PTC layers and current collectors. Reproduced with permission from Ref. [234]. Copyright 2015, Elsevier. b Schematic illustration of directly mixture electrodes. Reproduced with permission from Ref. [232]. Copyright 2012, Elsevier. c Schematic illustration of an electrode composed of coating active materials with PTC materials. Reproduced with permission from Ref. [239]. Copyright 2011, Royal Society of Chemistry. d Schematic illustra- tion of improved PTC layers for the sandwich structure electrode. The TRPS will activate to increase the resistance and shut down the battery when the temperature exceeds the safety value. Reproduced with permission from Ref. [127]. Copyright 2016, Nature Publishing Group. e Schematic illustration of coating active materials with PTC materials as cathode-active particles. Reproduced with permission from Ref. [239]. Copyright 2011, Royal Society of Chemistry 
a promising approach (Fig. 13a). Feng et al. [233] proposed a PTC-modified current collector by coating the PTC layer consisting of epoxy-carbon composites between the active $\mathrm{LiCoO}_{2}$ layer and the $\mathrm{Al}$ current collector. Zhong et al. [232] introduced an ethylene vinyl acetate (EVA)-based PTC layer between the current collector and the $\mathrm{LiFePO}_{4}$ electrode membrane. Zhang et al. [234] introduced poly(3butylthiophene)-based PTC between $\operatorname{Li}\left(\mathrm{Ni}_{0.5} \mathrm{Co}_{0.2} \mathrm{Mn}_{0.3}\right)$ $\mathrm{O}_{2}$ layer and the $\mathrm{Al}$ foil substrate. To overcome the lowtemperature conductivity, Chen et al. [127] synthesized a thermoresponsive polymer switching (TRPS) composed of conductive graphene-coated spiky nanostructured nickel particles as the conductive filler and the polymer matrix with large thermal expansion coefficients to improve the performance of sandwich structure. Once overheating, the polymer matrix will expand and then separate the conductive particles. When the battery has been cooled down, the polymer would regain the original conductive pathways (see Fig. 13d) $[127,235]$. Although the PTC-modified current collector is sensitive to the temperature rise caused by external electric abuse, it is helpless to hold back internal short circuit between the electrodes. PTC-modified active materials can solve this problem. Figure $13 \mathrm{~b}$ illustrates the directly mixed electrode. Kise et al. [236, 237] put forward a carbon black/ polyethylene composite as a PTC material to blend with active materials. Zhong et al. [238] prepared the cathode by mixing the EVA-based PTC material with other reagents such as binders, conductive carbon and $\mathrm{LiFePO}_{4}$-active materials. However, a mechanical mixture of the PTC materials with active materials cannot efficiently shut down the thermal runaway reactions occurring on the surface of highly active electrode materials at elevated temperatures. Coating active materials with PTC materials as cathodeactive particles is considered as a more effective way for thermally unstable cathode materials (as Fig. 13c shows). Xia et al. [239] synthesized poly(3-decylthiophene)-coated $\mathrm{LiCoO}_{2}$ particles by a spray-drying method as a temperaturesensitive cathode. Figure 13e illustrates the structure and the working mechanism of the poly(3-decylthiophene)-coated $\mathrm{LiCoO}_{2}\left(\mathrm{LiCoO}_{2} @ \mathrm{P} 3 \mathrm{DT}\right)$ particles [239].

\section{Monitoring Cells for EV Applications}

The battery contains a high amount of electric energy and combustible electrolytes; it is still a threat for users in some cases such as improper use, manufacturing defects and longtime reliability even if it is designed to safety. The application of operando techniques for monitoring the internal condition of LIBs is necessary [240].

\subsection{Monitoring Temperature and Voltage}

The fundamentals of ensuring the LIBs working in the "comfortable zone" are to monitor voltage and temperature of the battery. As mentioned above, when the temperature reaches approximately $90{ }^{\circ} \mathrm{C}$, the self-heating of the cell begins due to the start of the SEI layer decomposition. Monitoring the internal temperature for early warning is supposed as a feasible strategy for battery management systems to improve the safety and performance of LIBs.

In order to get the accurately central temperature of LIBs, some researchers insert sensors into the batteries. Invasive sensors should meet the requirements as below [241]: (1) $\mathrm{Li}^{+}$migration should not be affected; (2) the sensor should resist to corrosion; (3) the sensor should be friendly to the cell assembly process.

Commercial thermocouples are not suitable due to their large diameter (over $1 \mathrm{~mm}$ ), which would damage the structure of batteries [242, 243]. Mutyala et al. [241] fabricated and transferred flexible thin-film thermocouples onto the battery current collectors. This special sensor could be embedded inside the battery without any alteration or destruction to the cell. Besides that, the sensor geometry can be tailored to fit the structure of an existing pouch cell as shown in Fig. 14a [241]. In order to further enhance the performance of flexible thin-film sensors, Lee et al. [244, 245] developed a two-in-one flexible microsensor by depositing erosion-resistant parylene and other sensor materials layerby-layer using physical vapor deposition (PVD) technique, which could in situ monitor the temperature and voltage of the battery.

Fiber Bragg grating (FBG) sensors are integrated to measure the temperature because Bragg grating reflects a narrow band of wavelengths based on the grating period [246]. The common method to prepare an FBG is a phase mask method, and the size of the FBG sensor is subjected to optical fibers. The diameter of FBG sensors should be less than $125 \mu \mathrm{m}$, which is friendly to cell assembly [246, 247]. The schematic diagram of FBG sensors is shown in Fig. 14b [246]. To improve the internal discrimination of temperature, Nascimento et al. [248] proposed hybrid methodology based on an FBG in series with a Fabry-Perot (FP) cavity. Some researchers wrote multiple FBGs in an optical fiber to monitor the multipoint temperature. Nascimento et al. wrote 3 FBGs in fibers and fixed them into the cell on its extremities to monitor the temperature of top, middle and bottom of the battery (Fig. 14c). Thus, it would be possible to monitor the temperature of every cell in the module by an optical fiber with FBGs in the future. Besides temperature, FBG sensors are also sensitive to strain, pressure, bending, even the state of charge (SOC), the state of health $(\mathrm{SOH})$ and so on [246, 249]. The advantages of small size, flexibility, antiinterference and multifunction make FBG sensors highly 


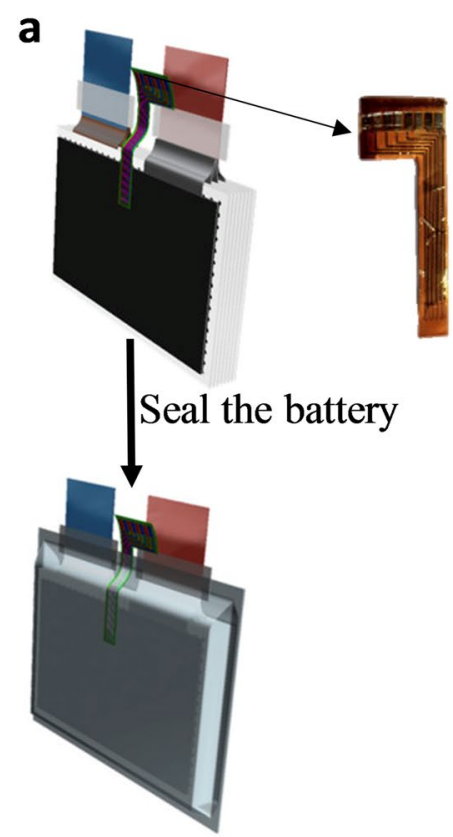

Fig. 14 a Pouch cell with embedded flexible thin-film sensors. Reproduced with permission from Ref. [241]. Copyright 2014, Elsevier. b Schematic diagram of FBG sensors. Reproduced with permission from Ref. [246]. Copyright 2017, American Chemical Society.

attractive [250]. However, the expensive optical interrogator of FBG sensors to measure wavelength shifts restricts their practical application.

Electrochemical impedance spectroscopy (EIS) has attracted much attention because it is a versatile experimental method for nondestructive estimation of some electrochemical parameters [251, 252]. Munichandraiah et al. [251] found the SEI layer impedance $\left(Z_{\mathrm{SEI}}\right)$ is only sensitive to the temperature when the LIBs are under normal use. The $Z_{\mathrm{SEI}}$ is frequency-dependent (a wide range of frequency from $10 \mathrm{~Hz}$ to $1 \mathrm{kHz}$ ), and its quadrature component is capacitive (negative phase shifts) [251]. Srinivasan et al. [253] proved that simply measuring the phase shift $(\varphi)$ to estimate the temperature of the cell is feasible. Compared with deriving SEI layer resistance $\left(R_{\mathrm{SEI}}\right)$ and electrolyte resistance $\left(R_{\mathrm{S}}\right)$ [57, 254], $\varphi$ is easier to estimate the temperature without requiring multiple-frequency impedance, and it is well matched with measured data of the electrical equivalent circuit model [255]. $\varphi$ has been supposed to be an effective substitution of $R_{\mathrm{SEI}}$ and $R_{\mathrm{S}}$ to estimate temperature [255]. Zhu et al. [252] demonstrated that choosing an appropriate frequency range to exclude the influence of the SOC and the $\mathrm{SOH}$ is important. They find that the typical frequency range is $10-100 \mathrm{~Hz}$ [252]. The temperature measurement based on EIS is a promising online estimation method for the battery management system (BMS) to monitor the temperature of the battery, but most of the tests require the battery with c Schematic diagram of multipoint temperature monitoring by optical sensors. Reproduced with permission from Ref. [248]. Copyright 2019, Elsevier

fully out operation states, which restricts its practical applications. To overcome this limitation, dynamic conditions should be considered. Zhu et al. [243] studied the regularity of $\varphi$ after current excitations with short relaxation time and put forward a multilinear regression to correct the relationship between $\varphi$ and temperature. But it is still not suitable for all operating conditions. The temperature monitoring for dynamic operation should be extensively studied. Besides accurately monitoring the temperature of cells, the phase shift has proved to be an effective parameter to predict cell venting, which could be a decisive condition for best control of the batteries [253].

Sometimes monitoring voltage is more effective than monitoring temperature. For example, Feng et al. [20] investigated the thermal runaway features of large format batteries by accelerating the rate calorimetry. They found that the interval between the voltage drop and the temperature rise was $15 \mathrm{~s}$ when the battery suffered external heating [20]. Besides that, they found that the internal resistance $\left(R_{\text {in }}\right)$ would rise slowly from 20 to $60 \mathrm{~m} \Omega$ before thermal runaways. Once the thermal runaway occurs, the $R_{\text {in }}$ will rise dramatically to $370 \mathrm{~m} \Omega$. Their works provide another method to predict and monitor the thermal runaway process [20]. 


\subsection{Monitoring the Dendrites}

The lithium dendrite is a potential risk of an internal short circuit in LIBs. Dendritic lithium is much easy to be formed under high charging current, overcharge, low charging temperature, improper cell balance and the uneven casting of the electrode [34]. It is necessary to detect the lithium dendrites before a complete internal short circuit.

\subsubsection{Online Monitoring}

Measuring anode potential (vs. $\left.\mathrm{Li} / \mathrm{Li}{ }^{+}\right)$with a reference electrode $(R E)[256,257]$. The critical criterion is that lithium dendrites will be formed if the anode potential drops below $0 \mathrm{~V}[256,257]$. The typical RE is metallic lithium foil. However, the potential of metallic lithium is highly related to the SEI interface. Some researchers propose lithium alloys including $\mathrm{Li}_{y} \mathrm{Sn}$ and $\mathrm{Li}_{y} \mathrm{Al}$. [258] or lithium intercalation compounds like LFP and LTO as Ref. [259]. Lithium intercalation compounds with stable operating potential and less reaction with electrolytes have been recognized as the promising REs. To reduce the impact on the ionic pathway, the reference electrode should be miniaturized. Some researchers proposed depositing reference materials onto inert substrates such as thin $\mathrm{Ni}, \mathrm{Cu}$ or $\mathrm{Au}$ wires [260]. In recent years, Wu et al. [261] developed a new kind of separator integrated with a reference electrode (Fig. 15a) and designed a sandwiched separator with thin and porous conducting metal as the middle layer. By monitoring the voltage between the middle metal and the anode, the dendrite could be predicted before the internal short circuit happens. a

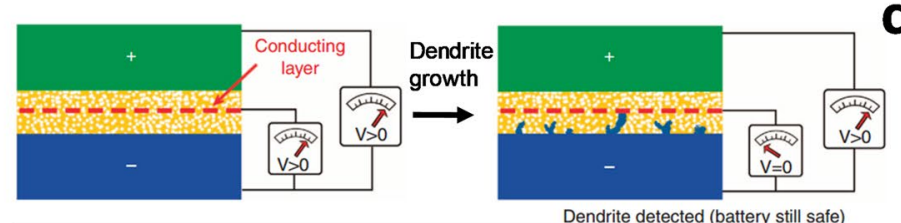

b
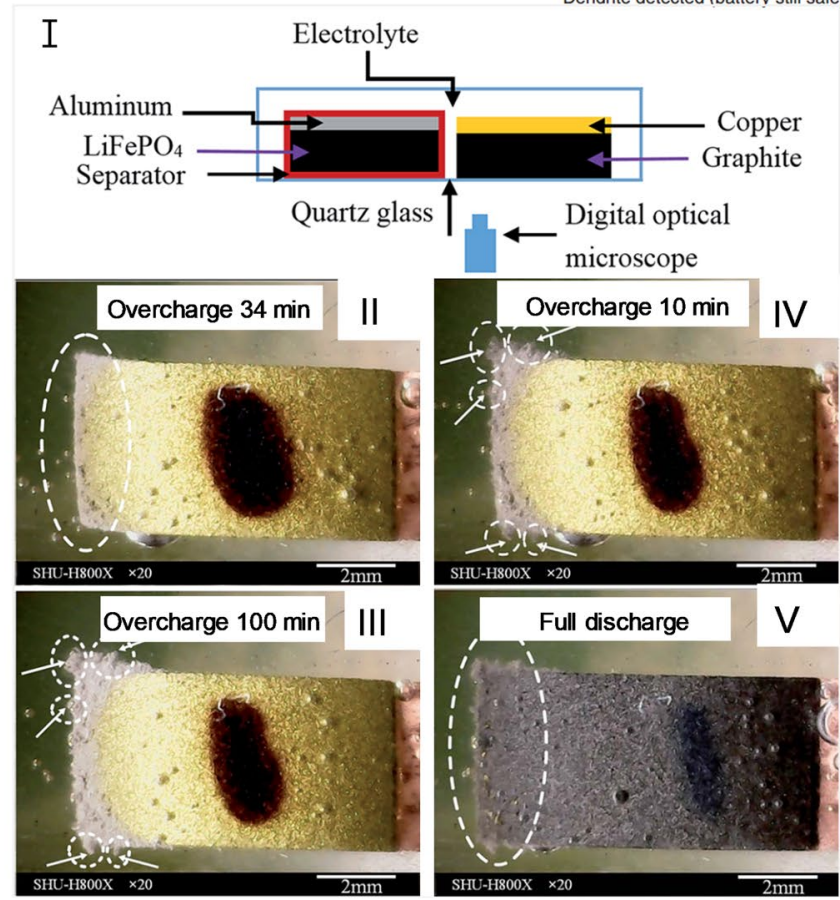

C
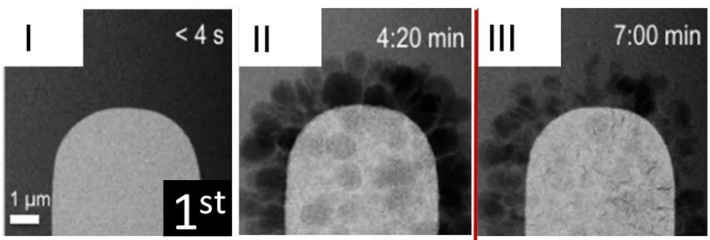

IV

d
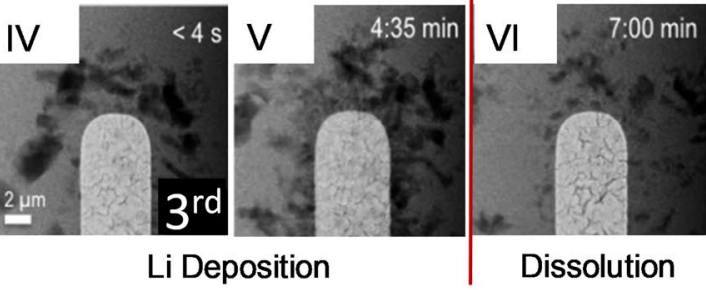

Li Deposition
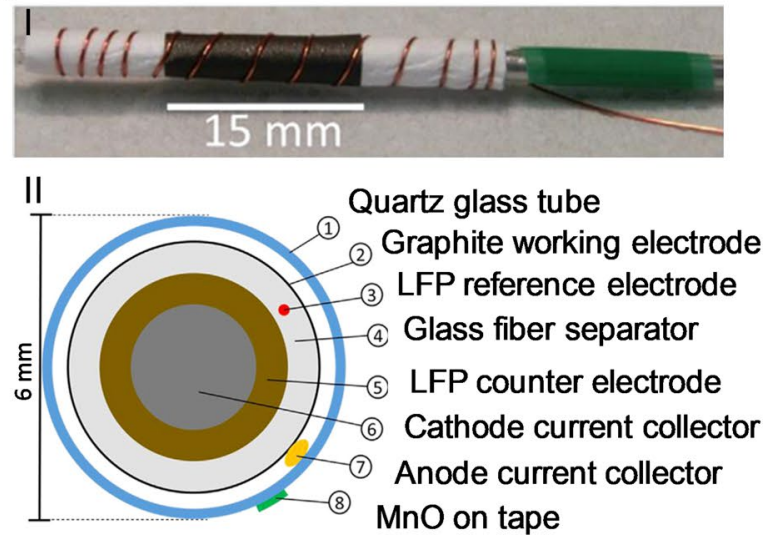

Fig. 15 a A new kind of sandwiched separator integrated with a reference electrode which could predict lithium dendrite by monitoring the voltage between the middle conducting metal and the anode. Reproduced with permission from Ref. [261]. Copyright 2014, Nature. b-I Schematic of the in situ optical cell designed as side-byside arrangements. b-II and b-III In situ observation about the lithium deposition during the overcharge process. b-IV and b-V In situ observation of dissolution of lithium dendrites during the discharge process. Reproduced with permission from Ref. [271]. Copyright 2015, Royal Society of Chemistry. c-I and c-II In situ TEM images of lithium deposition at the interface of a Pt working electrode during the first charge cycle. c-III Dissolution of lithium dendrites during the first discharge cycle. c-IV and $\mathbf{c - V}$ The lithium deposition during the third charge cycle. c-VI Dissolution of lithium dendrites during the third discharge cycle. Reproduced with permission from Ref. [272]. Copyright 2015, American Chemical Society. d-I and d-II Schematic of the operando EPR cell with a reference electrode. Reproduced with permission from Ref. [274]. Copyright 2017, Elsevier 
High-precision measurement of Coulombic efficiency It is reported that the metallic lithium plating on the anode will reduce the Coulombic efficiency (CE) of the battery [260]. Recognizing subtle change in CE to detect the lithium plating is feasible. Dahn et al. [262] got the critical charging rate to avoid lithium deposition at different ambient temperatures by measuring $\mathrm{CE}$ with precision of $0.01 \%$. However, the side reaction such as the oxidizing reaction of electrolytes during the cycle will affect $\mathrm{CE}$ too, which will disturb the measuring accuracy of lithium deposition.

High-precision measurement of the thickness of batteries It is reported that the volume of graphite anodes is sensitive to the lithiated elementary state, while the volume change of cathode materials during cycles is much smaller [260]. Compared with intercalating lithium into the graphite, depositing lithium on the surface of the anode shows an extra increase in overall volume. Lithium plating will bring about a gain in volume of $0.37 \mathrm{~cm}^{3} \mathrm{Ah}^{-1}$, while charging $1 \mathrm{Ah}$ by intercalating lithium will cause a volume change of $0.12 \mathrm{~cm}^{3}$ [263]. Based on this theory, Bitzer et al. [263] developed a spring gauge measurement setup with precision of $1 \mu \mathrm{m}$ to detect the lithium plating by measuring the thickness change of the cell during charge. Rieger et al. [264] applied a more accurate laser scanning technique to detect local thickness changes during operation. Grimsmann et al. [265] proposed an inductance sensor based on the eddy current principle with the advantage of high resolution and noncontact to monitor the thickness change of the cell. However, this method is only suitable for pouch cells to detect the volume change after lithium plating. Besides that, side reactions such as electrolyte redox reaction will produce gases, which may disturb the accuracy of this method.

Detecting the difference of the voltage plateau after charging The potential of metallic lithium depositing on the graphite surface is lower than $\mathrm{Li}_{x} \mathrm{C}_{6}$, which results in the preferential oxidation of lithium plating during the following discharge process [260, 266]. It is reported that the preferential oxidation of lithium plating will generate a high-voltage plateau during the following discharge process. Smart et al. proved that the quantity of lithium plating could be evaluated by the length of the plateau [267]. Petzl et al. [268] detected the quantity of deposited lithium by differential voltage $(\mathrm{d} V / \mathrm{d} Q)$ analysis by taking the SOC into consideration. In addition, the potential difference between deposited lithium and $\mathrm{Li}_{x} \mathrm{C}_{6}$ will push the metallic lithium to be reinserted into the graphite [260]. The potential difference will drop during the subsequent relaxation and result in a voltage plateau, which offers a new method to monitor the lithium plating [257, 266, 269]. Schindler et al. [270] introduced an improved voltage differential $(\mathrm{d} V / \mathrm{d} t)$ to study the voltage relaxation processes. Luders et al. detected the lithium plating by voltage relaxation combined with neutron diffraction. Their results showed that the improved $\mathrm{d} V / \mathrm{d} t$ could effectively monitor the lithium plating in different tests [269]. Monitoring the voltage plateau is a promising online method to detect lithium plating because it does not need special and expensive equipment.

\subsubsection{In Situ/Ex Situ Detection}

Lithium plating can also be discriminated by optical microscopy, transmission electron microscopy (TEM), scanning electron microscopy (SEM), atomic force microscopy (AFM), neutron diffraction, electron paramagnetic resonance (EPR) and nuclear magnetic resonance spectroscopy (NMR), etc. These techniques are suitable for investigating the mechanisms of lithium plating rather than only online detection. Among them, neutron diffraction measurement, NMR and EPR can be conducted without destroying the cell.

Morphology characterization Optical microscopy is the common technology used to observe the lithium dendrite growth on the anode side by side or face to face with a quartz glass window in an in situ optical cell [266, 271]. Figure 15b-I illustrates the side-by-side optical cell designed by Guo et al. [271]. Figure 15(b-II) and (b-III) shows the formation process of lithium plating during charge [271]. Figure 15(b-IV) and (b-V) displays the dissolution of lithium dendrites on graphite during discharge [271]. SEM, TEM and AFM are effective to characterize the formation of lithium plating in the microscale in situ or ex situ [272, 273]. Figure $15 \mathrm{c}$ shows the typical images about lithium dendrite growth, and stripping on the Pt working electrode is taken by in situ TEM [272].

Neutron diffraction Neutron diffraction measurement is a powerful tool to study the lithium dendrites because it can analyze the distribution of lithium in the electrode without interference from another component of the cell. Zinth et al. [47] researched the influence of the charge rate on anode lithium plating by in situ neutron diffraction. To match with the voltage relaxation behavior, Luders et al. [269] extended the experimental approach by combining voltage relaxation and in situ neutron diffraction. They got the relationship between C-rates and lithium plating [269].

NMR and EPR NMR and EPR are deemed to be practical tools to detect lithium metal within graphite anodes based on the particular range of resonance frequency related to metallic lithium [257, 274]. It is reported that the lithium plating could be quantified by the intensity of ${ }^{7} \mathrm{Li}$ signals. Gotoh et al. [275] applied in situ ${ }^{7} \mathrm{Li}$ NMR to research the behavior of deposited lithium when the battery is overcharged. They found that the lithium plating could reinsert into the graphite anode, which provides the theoretical basis for detecting lithium plating by analyzing the voltage plateau after charging mentioned above [275]. Compared with NMR, EPR shows higher sensitivity for lithium plating detection because EPR microwaves have about ten times more skin 
depth in comparison with NMR radio waves [25]. Wandt et al. [25] applied operando EPR to compare two cells with different electrolyte additives and found that the fluoroethylene carbonate (FEC) additive could reduce the formation of lithium plating. Then, they improved the battery combining with the LFP reference electrode (Fig. 15d-I and d-II) [274]. They deconvoluted the Coulombic inefficiency and quantified the contributions of both dead lithium and active lithium loss due to SEI formation, which is useful to optimize the fast charging procedure, model validation and so on [274].

\subsection{Detecting Gas Leakage}

The battery seal is an important factor related to safety. A damaged battery seal may result in the leakage of volatile and flammable solvents, which poses serious safety concerns for users. There are several abuse circumstances that lead to the fracture of the cell, such as the undetectable damage during battery production, battery system assembly or maintenance [24]. Furthermore, overcharge, overheat, internal short circuit, etc., will cause violent chemical reactions and hence release gases [15, 276]. Once the safety valve or shell cannot stand the pressure, the battery will fracture and vent dangerous toxic gaseous mixtures $\left(\mathrm{CH}_{4}, \mathrm{C}_{2} \mathrm{H}_{4}, \mathrm{C}_{2} \mathrm{H}_{6}\right.$, $\mathrm{C}_{3} \mathrm{H}_{6}, \mathrm{H}_{2}, \mathrm{CO}, \mathrm{CO}_{2}, \mathrm{HF}, \mathrm{PF}_{5}$, etc.) [32, 277]. Golubkov et al. studied the breakup process of 18650 consumer cell with three types of cathodes (LFP, NMC, LCO/NMC) in an argon atmosphere. In their experiment, the safety vent will open at $160{ }^{\circ} \mathrm{C}$ [31]. The results showed that the amount of gas strongly depended on the cell type. Both metal-oxide cells released a large amount of gas at a high rate [31]. The gas evolution was detected as shown in Fig. 16(a-I)-(a-III). Fernandes et al. [278] identified the gases emitted by overcharging 26,650 cells with LFP cathodes. Their analysis showed that $\mathrm{CO}_{2}$ accounted for $47 \%$ of the gas production, while $\mathrm{H}_{2}$ for $23 \%, \mathrm{C}_{2} \mathrm{H}_{4}$ for $10 \%, \mathrm{CO} 4.9 \%$ and $\mathrm{C}_{2} \mathrm{H}_{5} \mathrm{~F} 4.6 \%$ [278]. It is reported that the main components of gas evolution are $\mathrm{H}_{2}$ and $\mathrm{CO}_{2}$ and that almost all of the metal-oxide cells will produce a considerable quantity of $\mathrm{CO}[30,31,277]$. This may open a new avenue for monitoring working condition and preventing the thermal runaway for LIB systems.

Wenger et al. [24] used a gas sensor to detect volatile organic compounds (VOCs) when electrolyte leakage occurs at an early stage. Figure $16 \mathrm{a}-\mathrm{c}$ shows the photograph of the sensor based on MEMS MOS gas sensors, and Fig. 16d, e shows the picture of the test setup with a 5 -Ah cell placed in a container in which a MEMS MOSbased sensor is installed [24]. Compared with the traditional detection methods such as temperature and voltage detection of a cell failure, the gas sensor shows much more a

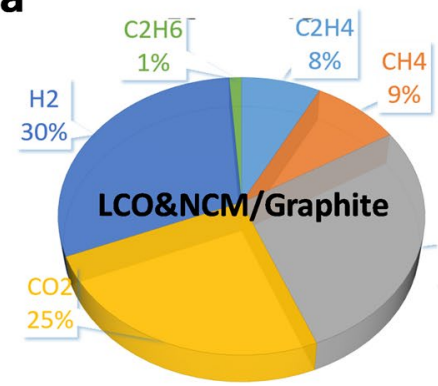

d

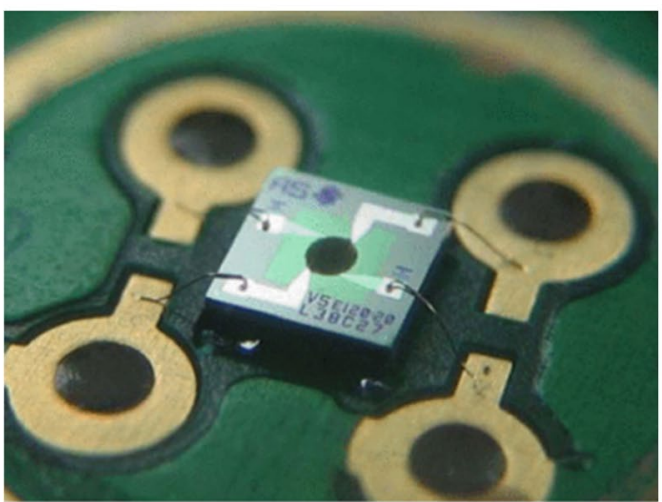

Fig. 16 a The compositions of produced gases for LCO/NMC cells. $\mathbf{b}$ The compositions of produced gases for NMC cells. c The compositions of produced gases for LFP cells. Reproduced with permission from Ref. [31]. Copyright 2014, Springer. d Digital image of the gas
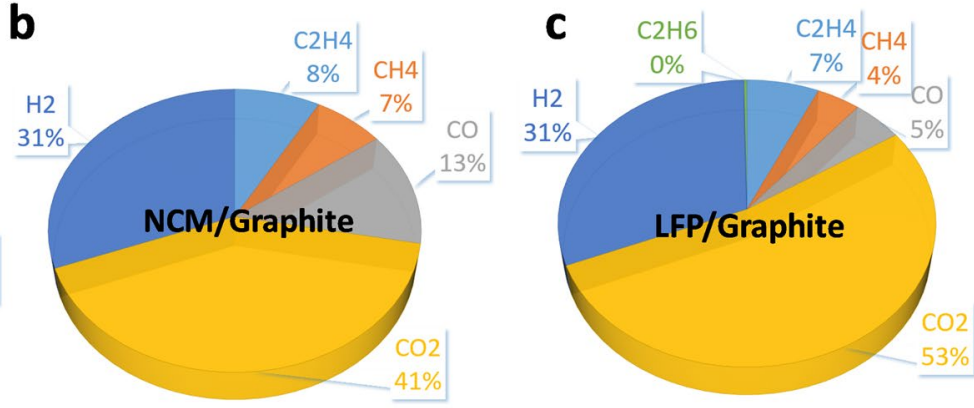

e

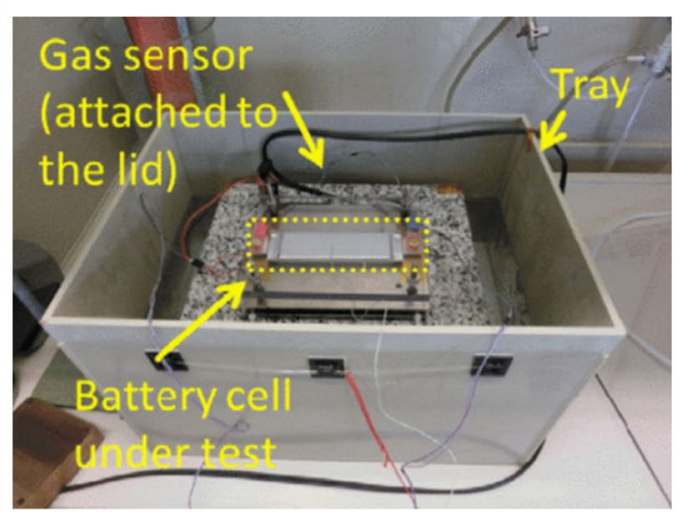

sensor. e Equipment setup for leakage tests. Reproduced with permission from Ref. [24]. Copyright 2014, IECON 2014-40th Annual Conference of the IEEE Industrial Electronics Society 
sensitive detection capability [24]. For instance, during the overcharging experiment, the gas sensor detected the failure earlier than the temperature sensor when the cell temperature was below $60{ }^{\circ} \mathrm{C}$ [24]. Thus, performance and practicality should be considered together in real applications [24]. Raghavan et al. [30] developed a safety device to monitor the battery states based on sensing the quantity of $\mathrm{CO}_{2}$ and hydrocarbon gas. Their device showed good sensitivity to the internal short circuit [30]. In summary, monitoring gas is a useful method to timely alert the safety status. However, too sensitive detection may cause a false alarm.

\section{Summary and Prospects}

The invention and application of LIBs brings a lot of convenience to our life. But the safety issue always exists and needs to be urgently investigated, especially for the LIBs with high energy density. In-depth understanding the failure mechanism and building safe batteries effectively are of critical importance in the future research, which we have discussed in this review. Here, the complicated triggering conditions of EV safety issues are divided into mechanical, thermal and electrical abuse, which specifically include car crash, battery leakage, overheat, overcharge, electrical system failure and so on. In order to simulate these abusive conditions, many compulsory test standards have been formulated to test LIBs before application in EVs.

Generally, LIBs are voltage and temperature-sensitive products. In all abuse conditions, overcharge and overheat are the most serious events that may lead to thermal runaways. Upon a deep understanding of the failure mechanisms of cell components, constructing full gradient concentration Ni-rich oxide cathodes to balance energy density and thermal stability, building robust SEIs for the anode, improving thermal stability for separators have proven applicable to build safe batteries. Additionally, alternative lithium salts, effective functional additives and nonflammable solvent systems like novel aqueous electrolytes and polymer electrolytes have been proposed. Furthermore, high-concentration lithium salts and novel encapsulation technologies have been used to avoid direct contact between additives and electrolytes and hence to improve battery performance. Since the battery is a frail system, improving one parameter may sacrifice other battery merits. With better components, the durable boundaries of batteries could be expanded. Although componentlevel safety is so important, the application of operando techniques for monitoring the internal condition of LIBs is also necessary, it could ensure the cell working in the suitable voltage/temperature range and identify potential risks ahead of time, but it still has not drawn enough attention. More importantly, temperature, voltage, dendrites and gas release are important factors that we should pay much attention to. New online monitoring approaches, especially for lithium dendrites, should be further developed.

Although great progress has been made on the design of safer cells and packs for LIBs, many intrinsic challenges still remain due to the existence of flammable organic solvents and some other uncertainties. To completely address this safety problem, undoubtedly, solid-state batteries (SSBs) are good choices. Nonflammable electrolytes and lithium anodes are combined to achieve high energy density and safety together. However, there are many challenges in the development of SSBs. For example, qualified solid-state electrolytes with high ionic conductivity and good manipulating ability are still under investigation; poor compatibility between lithium metal and solid electrolytes would induce great interfacial resistance and result in poor electrochemical performance, and the manufacturing technology for SSBs is not mature. Fortunately, lots of progress has been achieved with more and more researchers involved in the field of SSBs in recent years. With continuous and intensive worldwide efforts, we believe that SSBs will no doubt become the choice of next-generation safe rechargeable batteries in the near future.

Acknowledgements The authors gratefully acknowledge National Natural Science Foundation of China (Nos. U1764256, 51632001). This work was also supported by the Fundamental Research Funds for the Central Universities.

Open Access This article is licensed under a Creative Commons Attribution 4.0 International License, which permits use, sharing, adaptation, distribution and reproduction in any medium or format, as long as you give appropriate credit to the original author(s) and the source, provide a link to the Creative Commons licence, and indicate if changes were made. The images or other third party material in this article are included in the article's Creative Commons licence, unless indicated otherwise in a credit line to the material. If material is not included in the article's Creative Commons licence and your intended use is not permitted by statutory regulation or exceeds the permitted use, you will need to obtain permission directly from the copyright holder. To view a copy of this licence, visit http://creativecommons.org/licenses/by/4.0/.

\section{References}

1. Whittingham, M.S.: Lithium batteries and cathode materials. Chem. Rev. 104, 4271-4302 (2004). https://doi.org/10.1021/ cr020731c

2. Zhou, L.M., Zhang, K., Hu, Z., et al.: Recent developments on and prospects for electrode materials with hierarchical structures for lithium-ion batteries. Adv. Energy Mater. 8, 1701415 (2018). https://doi.org/10.1002/aenm.201701415

3. Wei, Q.L., Xiong, F.Y., Tan, S.S., et al.: Energy storage: porous one-dimensional nanomaterials: design, fabrication and 
applications in electrochemical energy storage. Adv. Mater. 29, 1602300 (2017). https://doi.org/10.1002/adma.201770134

4. Hao, H., Cheng, X., Liu, Z.W., et al.: China's traction battery technology roadmap: targets, impacts and concerns. Energy Policy 108, 355-358 (2017). https://doi.org/10.1016/j.enpol .2017.06.011

5. Ding, Y.L., Cano, Z.P., Yu, A.P., et al.: Automotive Li-ion batteries: current status and future perspectives. Electrochem. Energ. Rev. 2, 1-28 (2019). https://doi.org/10.1007/s41918-018-0022-z

6. Wu, H.L., Zhang, Y.B., Deng, Y.Q., et al.: A lightweight carbon nanofiber-based 3D structured matrix with high nitrogen-doping level for lithium metal anodes. Sci. China Mater. 62, 87-94 (2019). https://doi.org/10.1007/s40843-018-9298-x

7. Li, S., Jiang, M.W., Xie, Y., et al.: Developing high-performance lithium metal anode in liquid electrolytes: challenges and progress. Adv. Mater. 30, 1706375 (2018). https://doi.org/10.1002/ adma.201706375

8. Li, W.D., Liu, X.M., Celio, H., et al.: Mn versus Al in layered oxide cathodes in lithium-ion batteries: a comprehensive evaluation on long-term cyclability. Adv. Energy Mater. 8, 1703154 (2018). https://doi.org/10.1002/aenm.201703154

9. Li, Y., Li, X.H., Wang, Z.X., et al.: An Ostwald ripening route towards Ni-rich layered cathode material with cobalt-rich surface for lithium ion battery. Sci. China Mater. 61, 719-727 (2018). https://doi.org/10.1007/s40843-017-9162-3

10. Liu, Z.H., Yu, Q., Zhao, Y.L., et al.: Silicon oxides: a promising family of anode materials for lithium-ion batteries. Chem. Soc. Rev. 48, 285-309 (2019). https://doi.org/10.1039/c8cs00441b

11. Ding, X.L., Liu, X.X., Huang, Y.Y., et al.: Enhanced electrochemical performance promoted by monolayer graphene and void space in silicon composite anode materials. Nano Energy 27, 647-657 (2016). https://doi.org/10.1016/j.nanoen.2016.07.031

12. Noh, H.J., Youn, S., Yoon, C.S., et al.: Comparison of the structural and electrochemical properties of layered $\mathrm{Li}\left[\mathrm{Ni}_{x} \mathrm{Co}_{y} \mathrm{Mnz}\right] \mathrm{O}_{2}$ $(x=1 / 3,0.5,0.6,0.7,0.8$ and 0.85$)$ cathode material for lithiumion batteries. J. Power Sources 233, 121-130 (2013). https://doi. org/10.1016/j.jpowsour.2013.01.063

13. Cao, G.Z.: Solvent-salt synergy offers a safe pathway towards next generation high voltage $\mathrm{Li}$-ion batteries. Sci. China Mater. 61, 1360-1362 (2018). https://doi.org/10.1007/s4084 3-018-9296-y

14. Peng, P., Jiang, F.M.: Thermal safety of lithium-ion batteries with various cathode materials: a numerical study. Int. J. Heat Mass Transf. 103, 1008-1016 (2016). https://doi.org/10.1016/j.ijhea tmasstransfer.2016.07.088

15. Ren, D.S., Feng, X.N., Lu, L.G., et al.: An electrochemical-thermal coupled overcharge-to-thermal-runaway model for lithium ion battery. J. Power Sources 364, 328-340 (2017). https://doi. org/10.1016/j.jpowsour.2017.08.035

16. Shi, J.L., Fang, L.F., Li, H., et al.: Improved thermal and electrochemical performances of PMMA modified PE separator skeleton prepared via dopamine-initiated ATRP for lithium ion batteries. J. Membr. Sci. 437, 160-168 (2013). https://doi. org/10.1016/j.memsci.2013.03.006

17. Ravdel, B., Abraham, K.M., Gitzendanner, R., et al.: Thermal stability of lithium-ion battery electrolytes. J. Power Sources 119(120/121), 805-810 (2003). https://doi.org/10.1016/s0378 -7753(03)00257-x

18. Li, J.C., Ma, C., Chi, M.F., et al.: Solid electrolyte: the key for high-voltage lithium batteries. Adv. Energy Mater. 5, 1401408 (2015). https://doi.org/10.1002/aenm.201401408

19. Jhu, C.Y., Wang, Y.W., Shu, C.M., et al.: Thermal explosion hazards on 18650 lithium ion batteries with a VSP2 adiabatic calorimeter. J. Hazard. Mater. 192, 99-107 (2011). https://doi. org/10.1016/j.jhazmat.2011.04.097
20. Feng, X.N., Fang, M., He, X.M., et al.: Thermal runaway features of large format prismatic lithium ion battery using extended volume accelerating rate calorimetry. J. Power Sources 255, 294 301 (2014). https://doi.org/10.1016/j.jpowsour.2014.01.005

21. Park, S., Jung, D.: Battery cell arrangement and heat transfer fluid effects on the parasitic power consumption and the cell temperature distribution in a hybrid electric vehicle. J. Power Sources 227, 191-198 (2013). https://doi.org/10.1016/j.jpows our.2012.11.039

22. Zhu, L.T., Sun, Z.C., Dai, H.F., et al.: A novel modeling methodology of open circuit voltage hysteresis for $\mathrm{LiFePO}_{4}$ batteries based on an adaptive discrete Preisach model. Appl. Energy 155, 91-109 (2015). https://doi.org/10.1016/j.apenergy.2015.05.103

23. Wang, X.Y., Wei, X.Z., Dai, H.F.: Estimation of state of health of lithium-ion batteries based on charge transfer resistance considering different temperature and state of charge. J. Energy Storage 21, 618-631 (2019). https://doi.org/10.1016/j.est.2018.11.020

24. Wenger, M., Waller, R., Lorentz, V.R.H., et al.: Investigation of gas sensing in large lithium-ion battery systems for early fault detection and safety improvement. In: IECON 2014-40th Annual Conference of the IEEE Industrial Electronics Society October 29-November 1, 2014. IEEE, Dallas, TX, USA. New York, USA. https://doi.org/10.1109/iecon.2014.7049366

25. Wandt, J., Marino, C., Gasteiger, H.A., et al.: Operando electron paramagnetic resonance spectroscopy-formation of mossy lithium on lithium anodes during charge-discharge cycling. Energy Environ. Sci. 8, 1358-1367 (2015). https://doi.org/10.1039/c4ee0 $2730 \mathrm{~b}$

26. Hsieh, A.G., Bhadra, S., Hertzberg, B.J., et al.: Electrochemical-acoustic time of flight: in operando correlation of physical dynamics with battery charge and health. Energy Environ. Sci. 8, 1569-1577 (2015). https://doi.org/10.1039/c5ee00111k

27. Sharma, N., Peterson, V.K., Elcombe, M.M., et al.: Structural changes in a commercial lithium-ion battery during electrochemical cycling: an in situ neutron diffraction study. J. Power Sources 195, 8258-8266 (2010). https://doi.org/10.1016/j.jpows our.2010.06.114

28. Scrosati, B.: History of lithium batteries. J. Solid State Electrochem. 15, 1623-1630 (2011). https://doi.org/10.1007/s 1000 8-011-1386-8

29. Li, X.Y., Wang, Z.P.: A novel fault diagnosis method for lithiumion battery packs of electric vehicles. Measurement 116, 402411 (2018). https://doi.org/10.1016/j.measurement.2017.11.034

30. Wang, Y., Gao, Q., Wang, G.H., et al.: A review on research status and key technologies of battery thermal management and its enhanced safety. Int. J. Energy Res. 42, 4008-4033 (2018). https://doi.org/10.1002/er.4158

31. Golubkov, A.W., Fuchs, D.: Thermal runaway: causes and consequences on cell level. In: Thaler, A., Watzenig, D. (eds.) Automotive Battery Technology, pp. 37-51. Springer, Cham (2014). https://doi.org/10.1007/978-3-319-02523-0_3

32. Wen, J.W., Yu, Y., Chen, C.H.: A review on lithium-ion batteries safety issues: existing problems and possible solutions. Mater. Express 2, 197-212 (2012). https://doi.org/10.1166/ mex.2012.1075

33. Zhang, R., Zheng, Y., Duan, J., et al.: Batteries for electric vehicles: opportunities and challenges. Science 358, 10-13 (2017). (special issue)

34. Minggao, O., Ren, D.S., Lu, L.G., et al.: Overcharge-induced capacity fading analysis for large format lithium-ion batteries with $\mathrm{Li}_{y} \mathrm{Ni}_{1 / 3} \mathrm{Co}_{1 / 3} \mathrm{Mn}_{1 / 3} \mathrm{O}_{2}+\mathrm{Li}_{y} \mathrm{Mn}_{2} \mathrm{O}_{4}$ composite cathode. $\mathrm{J}$. Power Sources 279, 626-635 (2015). https://doi.org/10.1016/j. jpowsour.2015.01.051

35. Zeng, Y.Q., Wu, K., Wang, D.Y., et al.: Overcharge investigation of lithium-ion polymer batteries. J. Power Sources 160, 13021307 (2006). https://doi.org/10.1016/j.jpowsour.2006.02.009 
36. Iriyama, Y., Yokoyama, M., Yada, C., et al.: Preparation of $\mathrm{LiFePO}_{4}$ thin films by pulsed laser deposition and their electrochemical properties. Electrochem. Solid-State Lett. 7, A340 (2004). https://doi.org/10.1149/1.1795052

37. Ohsaki, T., Kishi, T., Kuboki, T., et al.: Overcharge reaction of lithium-ion batteries. J. Power Sources 146, 97-100 (2005). https ://doi.org/10.1016/j.jpowsour.2005.03.105

38. Wu, L.J., Nam, K.W., Wang, X.J., et al.: Structural origin of overcharge-induced thermal instability of Ni-containing layeredcathodes for high-energy-density lithium batteries. Chem. Mater. 23, 3953-3960 (2011). https://doi.org/10.1021/cm201452q

39. Wang, H.Y., Tang, A.D., Huang, K.L.: Oxygen evolution in overcharged $\mathrm{Li}_{x} \mathrm{Ni}_{1 / 3} \mathrm{Co}_{1 / 3} \mathrm{Mn}_{1 / 3} \mathrm{O}_{2}$ electrode and its thermal analysis kinetics. Chin. J. Chem. 29, 1583-1588 (2011). https://doi. org/10.1002/cjoc.201180284

40. Yuan, Q.F., Zhao, F.G., Wang, W.D., et al.: Overcharge failure investigation of lithium-ion batteries. Electrochim. Acta 178, 682-688 (2015). https://doi.org/10.1016/j.electacta.2015.07.147

41. Zheng, H.H., Sun, Q.N., Liu, G., et al.: Correlation between dissolution behavior and electrochemical cycling performance for $\mathrm{LiNi}_{1 / 3} \mathrm{Co}_{1 / 3} \mathrm{Mn}_{1 / 3} \mathrm{O}_{2}$-based cells. J. Power Sources 207, 134-140 (2012). https://doi.org/10.1016/j.jpowsour.2012.01.122

42. Wu, X.W., Wang, Z.X., Li, X.H., et al.: Effect of lithium difluoro(oxalato)borate and heptamethyldisilazane with different concentrations on cycling performance of $\mathrm{LiMn}_{2} \mathrm{O}_{4}$. J. Power Sources 204, 133-138 (2012). https://doi.org/10.1016/j.jpows our.2011.12.012

43. Abraham, D.P., Spila, T., Furczon, M.M., et al.: Evidence of transition-metal accumulation on aged graphite anodes by SIMS. Electrochem. Solid-State Lett. 11, A226 (2008). https://doi. org/10.1149/1.2987680

44. Sharma, N., Peterson, V.K.: Overcharging a lithium-ion battery: effect on the $\mathrm{Li}_{x} \mathrm{C} 6$ negative electrode determined by in situ neutron diffraction. J. Power Sources 244, 695-701 (2013). https:// doi.org/10.1016/j.jpowsour.2012.12.019

45. Li, Z., Huang, J., Yann Liaw, B., et al.: A review of lithium deposition in lithium-ion and lithium metal secondary batteries. J. Power Sources 254, 168-182 (2014). https://doi.org/10.1016/j. jpowsour.2013.12.099

46. Abraham, D.P., Roth, E.P., Kostecki, R., et al.: Diagnostic examination of thermally abused high-power lithium-ion cells. J. Power Sources 161, 648-657 (2006). https://doi.org/10.1016/j.jpows our.2006.04.088

47. Zinth, V., von Lüders, C., Hofmann, M., et al.: Lithium plating in lithium-ion batteries at sub-ambient temperatures investigated by in situ neutron diffraction. J. Power Sources 271, 152-159 (2014). https://doi.org/10.1016/j.jpowsour.2014.07.168

48. Li, H.F., Gao, J.K., Zhang, S.L.: Effect of overdischarge on swelling and recharge performance of lithium ion cells. Chin. J. Chem. 26, 1585-1588 (2008). https://doi.org/10.1002/cjoc.200890286

49. Zhang, L.L., Ma, Y.L., Cheng, X.Q., et al.: Capacity fading mechanism during long-term cycling of over-discharged $\mathrm{LiCoO}_{2} /$ mesocarbon microbeads battery. J. Power Sources 293, 10061015 (2015). https://doi.org/10.1016/j.jpowsour.2015.06.040

50. Zhao, M.C., Kariuki, S., Dewald, H.D., et al.: Electrochemical stability of copper in lithium-ion battery electrolytes. J. Electrochem. Soc. 147, 2874 (2000). https://doi.org/10.1149/1.1393619

51. Guo, R., Lu, L.G., Ouyang, M.G., et al.: Mechanism of the entire overdischarge process and overdischarge-induced internal short circuit in lithium-ion batteries. Sci. Rep. 6, 30248 (2016). https ://doi.org/10.1038/srep30248

52. Shu, J., Shui, M., Xu, D., et al.: A comparative study of overdischarge behaviors of cathode materials for lithium-ion batteries. J. Solid State Electrochem. 16, 819-824 (2012). https://doi. org/10.1007/s10008-011-1484-7
53. Shu, J., Shui, M., Huang, F.T., et al.: A new look at lithium cobalt oxide in a broad voltage range for lithium-ion batteries. J. Phys. Chem. C 114, 3323-3328 (2010). https://doi.org/10.1021/jp911 994b

54. Peramunage, D.: Preparation and electrochemical characterization of overlithiated spinel $\mathrm{LiMn}_{2} \mathrm{O}_{4}$. J. Electrochem. Soc. 145, 1131 (1998). https://doi.org/10.1149/1.1838428

55. Zhu, J.G., Sun, Z.C., Wei, X.Z., et al.: Experimental investigations of an AC pulse heating method for vehicular high power lithium-ion batteries at subzero temperatures. J. Power Sources 367, 145-157 (2017). https://doi.org/10.1016/j.jpows our.2017.09.063

56. Jiang, J.C., Ruan, H.J., Sun, B.X., et al.: A reduced low-temperature electro-thermal coupled model for lithium-ion batteries. Appl. Energy 177, 804-816 (2016). https://doi.org/10.1016/j. apenergy.2016.05.153

57. Zhang, S.S., Xu, K., Jow, T.R.: Electrochemical impedance study on the low temperature of Li-ion batteries. Electrochim. Acta 49, 1057-1061 (2004). https://doi.org/10.1016/j.elect acta.2003.10.016

58. Herreyre, S., Huchet, O., Barusseau, S., et al.: New Li-ion electrolytes for low temperature applications. J. Power Sources 97(98), 576-580 (2001). https://doi.org/10.1016/s0378 -7753(01)00670-x

59. Zhu, J.G., Sun, Z.C., Wei, X.Z., et al.: An alternating current heating method for lithium-ion batteries from subzero temperatures. Int. J. Energy Res. 40, 1869-1883 (2016). https://doi. org/10.1002/er.3576

60. Smart, M.C., Ratnakumar, B.V., Whitcanack, L.D., et al.: Improved low-temperature performance of lithium-ion cells with quaternary carbonate-based electrolytes. J. Power Sources 119(120/121), 349-358 (2003). https://doi.org/10.1016/s0378 -7753(03)00154-x

61. Senyshyn, A., Mühlbauer, M.J., Dolotko, O., et al.: Low-temperature performance of $\mathrm{Li}$-ion batteries: the behavior of lithiated graphite. J. Power Sources 282, 235-240 (2015). https:// doi.org/10.1016/j.jpowsour.2015.02.008

62. Orsini, F., du Pasquier, A., Beaudoin, B., et al.: In situ scanning electron microscopy (SEM) observation of interfaces within plastic lithium batteries. J. Power Sources 76, 19-29 (1998). https://doi.org/10.1016/s0378-7753(98)00128-1

63. Kim, G.H., Pesaran, A., Spotnitz, R.: A three-dimensional thermal abuse model for lithium-ion cells. J. Power Sources 170, 476-489 (2007). https://doi.org/10.1016/j.jpows our.2007.04.018

64. Maleki, H.: Thermal stability studies of Li-ion cells and components. J. Electrochem. Soc. 146, 3224 (1999). https://doi. org/10.1149/1.1392458

65. Zhao, R., Zhang, S.J., Liu, J., et al.: A review of thermal performance improving methods of lithium ion battery: electrode modification and thermal management system. J. Power Sources 299, 557-577 (2015). https://doi.org/10.1016/j.jpowsour.2015.09.001

66. Liu, H.Q., Wei, Z.B., He, W.D., et al.: Thermal issues about Li-ion batteries and recent progress in battery thermal management systems: a review. Energy Convers. Manag. 150, 304-330 (2017). https://doi.org/10.1016/j.enconman.2017.08.016

67. Feng, X.N., Ouyang, M.G., Liu, X., et al.: Thermal runaway mechanism of lithium ion battery for electric vehicles: a review. Energy Storage Mater. 10, 246-267 (2018). https://doi. org/10.1016/j.ensm.2017.05.013

68. Doughty, D.H., Crafts, C.C.: FreedomCAR: electrical energy storage system abuse test manual for electric and hybrid electric vehicle applications. Off. Sci. Tech. Inf. (2006). https://doi. org/10.2172/889934 
69. Myung, S.T., Maglia, F., Park, K.J., et al.: Nickel-rich layered cathode materials for automotive lithium-ion batteries: achievements and perspectives. ACS Energy Lett. 2, 196-223 (2017). https://doi.org/10.1021/acsenergylett.6b00594

70. Jiang, J., Dahn, J.R.: ARC studies of the thermal stability of three different cathode materials: $\mathrm{LiCoO}_{2} ; \mathrm{Li}\left[\mathrm{Ni}_{0.1} \mathrm{Co}_{0.8} \mathrm{Mn}_{0.1}\right] \mathrm{O}_{2}$; and $\mathrm{LiFePO}_{4}$, in LiPF6 and LiBoB EC/DEC electrolytes. Electrochem. Commun. 6, 39-43 (2004). https://doi.org/10.1016/j.eleco m.2003.10.011

71. Andersson, A.: Lithium extraction/insertion in $\mathrm{LiFePO}_{4}$ : an X-ray diffraction and Mössbauer spectroscopy study. Solid State Ionics 130, 41-52 (2000). https://doi.org/10.1016/s0167 $-2738(00) 00311-8$

72. Röder, P., Baba, N., Friedrich, K.A., et al.: Impact of delithiated $\mathrm{Li}_{0} \mathrm{FePO}_{4}$ on the decomposition of $\mathrm{LiPF}_{6}$-based electrolyte studied by accelerating rate calorimetry. J. Power Sources 236, 151-157 (2013). https://doi.org/10.1016/j.jpowsour.2013.02.044

73. Dahn, J., Fuller, E., Obrovac, M., et al.: Thermal stability of $\mathrm{Li}_{x} \mathrm{CoO}_{2}, \mathrm{Li}_{x} \mathrm{NiO}_{2}$ and $\lambda-\mathrm{MnO}_{2}$ and consequences for the safety of Li-ion cells. Solid State Ionics 69, 265-270 (1994). https:// doi.org/10.1016/0167-2738(94)90415-4

74. Cao, H., Xia, B.J., Xu, N.X., et al.: Structural and electrochemical characteristics of $\mathrm{Co}$ and $\mathrm{Al}$ co-doped lithium nickelate cathode materials for lithium-ion batteries. J. Alloy. Compd. 376, 282-286 (2004). https://doi.org/10.1016/j.jallcom.2004.01.008

75. Yabuuchi, N., Ohzuku, T.: Novel lithium insertion material of $\mathrm{LiCo}_{1 / 3} \mathrm{Ni}_{1 / 3} \mathrm{Mn}_{1 / 3} \mathrm{O}_{2}$ for advanced lithium-ion batteries. J. Power Sources 119(120/121), 171-174 (2003). https://doi.org/10.1016/ S0378-7753(03)00173-3

76. Bak, S.M., Hu, E.Y., Zhou, Y.N., et al.: Structural changes and thermal stability of charged $\mathrm{LiNi}_{x} \mathrm{Mn}_{y} \mathrm{Co}_{z} \mathrm{O}_{2}$ cathode materials studied by combined in situ time-resolved XRD and mass spectroscopy. ACS Appl. Mater. Interfaces. 6, 22594-22601 (2014). https://doi.org/10.1021/am506712c

77. Liang, C.P., Kong, F.T., Longo, R.C., et al.: Unraveling the origin of instability in Ni-rich $\mathrm{LiNi}_{1-2 x} \mathrm{Co}_{x} \mathrm{Mn}_{x} \mathrm{O}_{2}(\mathrm{NCM})$ cathode materials. J. Phys. Chem. C 120, 6383-6393 (2016). https:// doi.org/10.1021/acs.jpcc.6b00369

78. Wang, Y.D., Jiang, J.W., Dahn, J.R.: The reactivity of delithiated $\mathrm{Li}\left(\mathrm{Ni}_{1 / 3} \mathrm{Co}_{1 / 3} \mathrm{Mn}_{1 / 3}\right) \mathrm{O}_{2}, \mathrm{Li}\left(\mathrm{Ni}_{0.8} \mathrm{Co}_{0.15} \mathrm{Al}_{0.05}\right) \mathrm{O}_{2}$ or $\mathrm{LiCoO}_{2}$ with non-aqueous electrolyte. Electrochem. Commun. 9, 25342540 (2007). https://doi.org/10.1016/j.elecom.2007.07.033

79. Hwang, S., Kim, S.M., Bak, S.M., et al.: Investigating local degradation and thermal stability of charged nickel-based cathode materials through real-time electron microscopy. ACS Appl. Mater. Interfaces. 6, 15140-15147 (2014). https://doi. org/10.1021/am503278f

80. Bang, H.J., Joachin, H., Yang, H., et al.: Contribution of the structural changes of $\mathrm{LiNi}_{0.8} \mathrm{Co}_{0.15} \mathrm{Al}_{0.05} \mathrm{O}_{2}$ cathodes on the exothermic reactions in Li-ion cells. J. Electrochem. Soc. 153, A731 (2006). https://doi.org/10.1149/1.2171828

81. Belharouak, I., Lu, W.Q., Liu, J., et al.: Thermal behavior of delithiated $\mathrm{Li}\left(\mathrm{Ni}_{0.8} \mathrm{Co}_{0.15} \mathrm{Al}_{0.05}\right) \mathrm{O}_{2}$ and $\mathrm{Li}_{1.1}\left(\mathrm{Ni}_{1 / 3} \mathrm{Co}_{1 / 3} \mathrm{Mn}_{1 / 3}\right)_{0.9} \mathrm{O}_{2}$ powders. J. Power Sources 174, 905-909 (2007). https://doi. org/10.1016/j.jpowsour.2007.06.092

82. Hua, W.B., Schwarz, B., Knapp, M., et al.: (De)lithiation mechanism of hierarchically layered $\mathrm{LiNi}_{1 / 3} \mathrm{Co}_{1 / 3} \mathrm{Mn}_{1 / 3} \mathrm{O}_{2}$ cathodes during high-voltage cycling. J. Electrochem. Soc. 166, A5025A5032 (2019). https://doi.org/10.1149/2.0051903jes

83. Chen, Z.H., Ren, Y., Lee, E., et al.: Study of thermal decomposition of $\mathrm{Li}_{1-x}\left(\mathrm{Ni}_{1 / 3} \mathrm{Mn}_{1 / 3} \mathrm{Co}_{1 / 3}\right)_{0.9} \mathrm{O}_{2}$ using in situ high-energy X-ray diffraction. Adv. Energy Mater. 3, 729-736 (2013). https ://doi.org/10.1002/aenm.201201059

84. Miller, D.J., Proff, C., Wen, J.G., et al.: Observation of microstructural evolution in Li battery cathode oxide particles by in situ electron microscopy. Adv. Energy Mater. 3, 1098-1103 (2013). https://doi.org/10.1002/aenm.201300015

85. Kondrakov, A.O., Schmidt, A., Xu, J., et al.: Anisotropic lattice strain and mechanical degradation of high- and low-nickel NCM cathode materials for Li-ion batteries. J. Phys. Chem. C 121, 3286-3294 (2017). https://doi.org/10.1021/acs.jpcc.6b128 85

86. Ding, Y., Mu, D.B., Wu, B.R., et al.: Recent progresses on nickelrich layered oxide positive electrode materials used in lithiumion batteries for electric vehicles. Appl. Energy 195, 586-599 (2017). https://doi.org/10.1016/j.apenergy.2017.03.074

87. Luo, W.B., Zhou, F., Zhao, X.M., et al.: Synthesis, characterization, and thermal stability of $\mathrm{LiNi}_{1 / 3} \mathrm{Mn}_{1 / 3} \mathrm{Co}_{1 / 3-z} \mathrm{Mg}_{2} \mathrm{O}_{2}$, $\mathrm{LiNi}_{1 / 3-z} \mathrm{Mn}_{1 / 3} \mathrm{Co}_{1 / 3} \mathrm{Mg}_{z} \mathrm{O}_{2}$, and $\mathrm{LiNi}_{1 / 3} \mathrm{Mn}_{1 / 3-z} \mathrm{Co}_{1 / 3} \mathrm{Mg}_{z} \mathrm{O}_{2}$. Chem. Mater. 22, 1164-1172 (2010). https://doi.org/10.1021/ cm902593n

88. Sun, Y.K., Kim, D.H., Yoon, C.S., et al.: A novel cathode material with a concentration-gradient for high-energy and safe lithium-ion batteries. Adv. Funct. Mater. 20, 485-491 (2010). https ://doi.org/10.1002/adfm.200901730

89. Zeng, X.Q., Zhan, C., Lu, J., et al.: Stabilization of a highcapacity and high-power nickel-based cathode for Li-ion batteries. Chem 4, 690-704 (2018). https://doi.org/10.1016/j.chemp r.2017.12.027

90. Kam, K.C., Doeff, M.M.: Aliovalent titanium substitution in layered mixed $\mathrm{Li}-\mathrm{Ni}-\mathrm{Mn}-\mathrm{Co}$ oxides for lithium battery applications. J. Mater. Chem. 21, 9991 (2011). https://doi.org/10.1039/ c0jm04193a

91. Liu, W.M., Hu, G.R., Peng, Z.D., et al.: Synthesis of spherical $\mathrm{LiNi}_{0.8} \mathrm{Co}_{0.15} \mathrm{Al}_{0.05} \mathrm{O}_{2}$ cathode materials for lithium-ion batteries by a co-oxidation-controlled crystallization method. Chin. Chem. Lett. 22, 1099-1102 (2011). https://doi.org/10.1016/j. cclet.2011.01.041

92. Li, X., Xie, Z.W., Liu, W.J., et al.: Effects of fluorine doping on structure, surface chemistry, and electrochemical performance of $\mathrm{LiNi}_{0.8} \mathrm{Co}_{0.15} \mathrm{Al}_{0.05} \mathrm{O}_{2}$. Electrochim. Acta 174, 1122-1130 (2015). https://doi.org/10.1016/j.electacta.2015.06.099

93. Wang, Y., Gu, H.T., Song, J.H., et al.: Suppressing Mn reduction of Li-rich Mn-based cathodes by F-doping for advanced lithium-ion batteries. J. Phys. Chem. C 122, 27836-27842 (2018). https://doi.org/10.1021/acs.jpcc.8b08669

94. Rastgoo-Deylami, M., Javanbakht, M., Omidvar, H.: Enhanced performance of layered $\mathrm{Li}_{1.2} \mathrm{Mn}_{0.54} \mathrm{Ni}_{0.13} \mathrm{Co}_{0.13} \mathrm{O}_{2}$ cathode material in $\mathrm{Li}$-ion batteries using nanoscale surface coating with fluorine-doped anatase $\mathrm{TiO}_{2}$. Solid State Ionics 331, 74-88 (2019). https://doi.org/10.1016/j.ssi.2018.12.025

95. Dai, G.L., Du, H.J., Wang, S.S., et al.: Improved electrochemical performance of $\mathrm{LiNi}_{0.8} \mathrm{Co}_{0.15} \mathrm{Al}_{0.05} \mathrm{O}_{2}$ with ultrathin and thickness-controlled $\mathrm{TiO}_{2}$ shell via atomic layer deposition technology. RSC Adv. 6, 100841-100848 (2016). https://doi. org/10.1039/c6ra21903a

96. Myung, S.T., Izumi, K., Komaba, S., et al.: Role of alumina coating on $\mathrm{Li}-\mathrm{Ni}-\mathrm{Co}-\mathrm{Mn}-\mathrm{O}$ particles as positive electrode material for lithium-ion batteries. Chem. Mater. 17, 3695-3704 (2005). https://doi.org/10.1021/cm050566s

97. Yoon, W.S., Nam, K.W., Jang, D., et al.: Structural study of the coating effect on the thermal stability of charged MgO-coated $\mathrm{LiNi}_{0.8} \mathrm{Co}_{0.2} \mathrm{O}_{2}$ cathodes investigated by in situ XRD. J. Power Sources 217, 128-134 (2012). https://doi.org/10.1016/j.jpows our.2012.05.028

98. Lee, S.M., Oh, S.H., Ahn, J.P., et al.: Electrochemical properties of $\mathrm{ZrO}_{2}$-coated $\mathrm{LiNi}_{0.8} \mathrm{Co}_{0.2} \mathrm{O}_{2}$ cathode materials. J. Power Sources 159, 1334-1339 (2006). https://doi.org/10.1016/j. jpowsour.2005.12.035

99. Meng, X.B., Yang, X.Q., Sun, X.L.: Emerging applications of atomic layer deposition for lithium-ion battery studies. 
Adv. Mater. 24, 3589-3615 (2012). https://doi.org/10.1002/ adma.201200397

100. Yan, P.F., Zheng, J.M., Zhang, X.F., et al.: Atomic to nanoscale investigation of functionalities of an $\mathrm{Al}_{2} \mathrm{O}_{3}$ coating layer on a cathode for enhanced battery performance. Chem. Mater. 28, 857-863 (2016). https://doi.org/10.1021/acs.chemmater.5b043 01

101. Liu, W., Oh, P., Liu, X.E., et al.: Nickel-rich layered lithium transition-metal oxide for high-energy lithium-ion batteries. Angew. Chem. Int. Ed. 54, 4440-4457 (2015). https://doi. org/10.1002/anie.201409262

102. Manthiram, A., Knight, J.C., Myung, S.T., et al.: Nickel-rich and lithium-rich layered oxide cathodes: progress and perspectives. Adv. Energy Mater. 6, 1501010 (2016). https://doi. org/10.1002/aenm.201501010

103. Sun, Y.K., Myung, S.T., Shin, H.S., et al.: Novel core-shellstructured $\mathrm{Li}\left[\left(\mathrm{Ni}_{0.8} \mathrm{Co}_{0.2}\right)_{0.8}\left(\mathrm{Ni}_{0.5} \mathrm{Mn}_{0.5}\right)_{0.2}\right] \mathrm{O}_{2}$ via coprecipitation as positive electrode material for lithium secondary batteries. J. Phys. Chem. B 110, 6810-6815 (2006). https://doi. org/10.1021/jp0571473

104. Sun, Y.K., Bae, Y.C., Myung, S.T.: Synthesis and electrochemical properties of layered $\mathrm{LiNi}_{1 / 2} \mathrm{Mn}_{1 / 2} \mathrm{O}_{2}$ prepared by coprecipitation. J. Appl. Electrochem. 35, 151-156 (2005). https:// doi.org/10.1007/s10800-004-6197-5

105. Sun, Y.K., Myung, S.T., Park, B.C., et al.: Synthesis of spherical nano- to microscale core-shell particles $\mathrm{Li}\left[\left(\mathrm{Ni}_{0.8} \mathrm{Co}_{0.1} \mathrm{Mn}_{0.1}\right.\right.$ )$\left._{1-x}\left(\mathrm{Ni}_{0.5} \mathrm{Mn}_{0.5}\right)_{x}\right] \mathrm{O}_{2}$ and their applications to lithium batteries. Chem. Mater. 18, 5159-5163 (2006). https://doi.org/10.1021/ cm061746k

106. Sun, Y.K., Chen, Z.H., Noh, H.J., et al.: Nanostructured highenergy cathode materials for advanced lithium batteries. Nat. Mater. 11, 942-947 (2012). https://doi.org/10.1038/nmat3435

107. Park, K.J., Choi, M.J., Maglia, F., et al.: High-capacity concentration gradient $\mathrm{Li}\left[\mathrm{Ni}_{0.865} \mathrm{Co}_{0.120} \mathrm{Al}_{0.015}\right] \mathrm{O}_{2}$ cathode for lithium-ion batteries. Adv. Energy Mater. 8, 1703612 (2018). https://doi. org/10.1002/aenm.201703612

108. Lu, J., Wu, T.P., Amine, K.: State-of-the-art characterization techniques for advanced lithium-ion batteries. Nat. Energy 2, 17011 (2017). https://doi.org/10.1038/nenergy.2017.11

109. Kim, H., Kim, M.G., Jeong, H.Y., et al.: A new coating method for alleviating surface degradation of $\mathrm{LiNi}_{0.6} \mathrm{Co}_{0.2} \mathrm{Mn}_{0.2} \mathrm{O}_{2}$ Cathode material: nanoscale surface treatment of primary particles. Nano Lett. 15, 2111-2119 (2015). https://doi.org/10.1021/acs. nanolett.5b00045

110. Xu, X., Huo, H., Jian, J.Y., et al.: Lithium-ion batteries: radially oriented single-crystal primary nanosheets enable ultrahigh rate and cycling properties of $\mathrm{LiNi}_{0.8} \mathrm{Co}_{0.1} \mathrm{Mn}_{0.1} \mathrm{O}_{2}$ cathode material for lithium-ion batteries. Adv. Energy Mater. 9, 1970051 (2019). https://doi.org/10.1002/aenm.201970051

111. Noh, H.J., Chen, Z.H., Yoon, C.S., et al.: Cathode material with nanorod structure: an application for advanced high-energy and safe lithium batteries. Chem. Mater. 25, 2109-2115 (2013). https ://doi.org/10.1021/cm4006772

112. Lu, J., Chen, Z.W., Pan, F., et al.: High-performance anode materials for rechargeable lithium-ion batteries. Electrochem. Energ. Rev. 1, 35-53 (2018). https://doi.org/10.1007/s4191 8-018-0001-4

113. Takami, N., Hoshina, K., Inagaki, H.: Lithium diffusion in $\mathrm{Li}_{4 / 3} \mathrm{Ti}_{5 / 3} \mathrm{O}_{4}$ particles during insertion and extraction. J. Electrochem. Soc. 158, A725 (2011). https://doi.org/10.1149/1.35740 37

114. Wu, K., Yang, J., Zhang, Y., et al.: Investigation on $\mathrm{Li}_{4} \mathrm{Ti}_{5} \mathrm{O}_{12}$ batteries developed for hybrid electric vehicle. J. Appl. Electrochem. 42, 989-995 (2012). https://doi.org/10.1007/s10800-012-0442-0

115. Li, P.H., Wang, W., Gong, S., et al.: Hydrogenated $\mathrm{Na}_{2} \mathrm{Ti}_{3} \mathrm{O}_{7}$ epitaxially grown on flexible $\mathrm{N}$-doped carbon sponge for potassium-ion batteries. ACS Appl. Mater. Interfaces. 10, 37974-37980 (2018). https://doi.org/10.1021/acsami.8b11354

116. Dou, F., Shi, L.Y., Chen, G.R., et al.: Silicon/carbon composite anode materials for lithium-ion batteries. Electrochem. Energ. Rev. 2, 149-198 (2019). https://doi.org/10.1007/s41918-01800028-w

117. Vetter, J., Novák, P., Wagner, M.R., et al.: Ageing mechanisms in lithium-ion batteries. J. Power Sources 147, 269-281 (2005). https://doi.org/10.1016/j.jpowsour.2005.01.006

118. Chen, Z.H., Qin, Y., Ren, Y., et al.: Multi-scale study of thermal stability of lithiated graphite. Energy Environ. Sci. 4, 4023 (2011). https://doi.org/10.1039/c1ee01786a

119. Barré, A., Deguilhem, B., Grolleau, S., et al.: A review on lithium-ion battery ageing mechanisms and estimations for automotive applications. J. Power Sources 241, 680-689 (2013). https:// doi.org/10.1016/j.jpowsour.2013.05.040

120. Xu, K.: Nonaqueous liquid electrolytes for lithium-based rechargeable batteries. Chem. Rev. 104, 4303-4418 (2004). https ://doi.org/10.1021/cr030203g

121. Zhao, L.W., Watanabe, I., Doi, T., et al.: TG-MS analysis of solid electrolyte interphase (SEI) on graphite negative-electrode in lithium-ion batteries. J. Power Sources 161, 1275-1280 (2006). https://doi.org/10.1016/j.jpowsour.2006.05.045

122. Waldmann, T., Hogg, B.I., Wohlfahrt-Mehrens, M.: Li plating as unwanted side reaction in commercial Li-ion cells-a review. J. Power Sources 384, 107-124 (2018). https://doi.org/10.1016/j. jpowsour.2018.02.063

123. Wang, Q.S., Sun, J.H., Yao, X.L., et al.: Thermal behavior of lithiated graphite with electrolyte in lithium-ion batteries. J. Electrochem. Soc. 153, A329 (2006). https://doi.org/10.1149/1.21399 55

124. Aurbach, D., Zaban, A., Ein-Eli, Y., et al.: Recent studies on the correlation between surface chemistry, morphology, threedimensional structures and performance of $\mathrm{Li}$ and $\mathrm{Li}-\mathrm{C}$ intercalation anodes in several important electrolyte systems. J. Power Sources 68, 91-98 (1997). https://doi.org/10.1016/s0378 -7753(97)02575-5

125. Spotnitz, R., Franklin, J.: Abuse behavior of high-power, lithium-ion cells. J. Power Sources 113, 81-100 (2003). https://doi. org/10.1016/s0378-7753(02)00488-3

126. Jung, Y.S., Cavanagh, A.S., Riley, L.A., et al.: Ultrathin direct atomic layer deposition on composite electrodes for highly durable and safe Li-ion batteries. Adv. Mater. 22, 2172-2176 (2010). https://doi.org/10.1002/adma.200903951

127. Chen, Z., Hsu, P.C., Lopez, J., et al.: Fast and reversible thermoresponsive polymer switching materials for safer batteries. Nat. Energy 1, 15009 (2016). https://doi.org/10.1038/nener gy.2015.9

128. Zhang, S.S.: A review on electrolyte additives for lithium-ion batteries. J. Power Sources 162, 1379-1394 (2006). https://doi. org/10.1016/j.jpowsour.2006.07.074

129. Chung, Y.S., Yoo, S.H., Kim, C.K.: Enhancement of meltdown temperature of the polyethylene lithium-ion battery separator via surface coating with polymers having high thermal resistance. Ind. Eng. Chem. Res. 48, 4346-4351 (2009). https://doi. org/10.1021/ie900096z

130. Orendorff, C.J.: The role of separators in lithium-ion cell safety. Electrochem. Soc. Interface 21, 61-65 (2012). https://doi. org/10.1149/2.f07122if

131. Wang, Q.S., Sun, J.H.: Enhancing the safety of lithium ion batteries by 4-isopropyl phenyl diphenyl phosphate. Mater. Lett. 61, 3338-3340 (2007). https://doi.org/10.1016/j.matlet.2006.11.060

132. Roh, S.C., Song, K.W., Kim, C.K.: Effects of nonsolvent molecular structure and its content on the formation of the macroporous polyarylate layer coated onto the polyethylene separator. 
Ind. Eng. Chem. Res. 50, 12596-12605 (2011). https://doi. org/10.1021/ie201716m

133. Hu, S.Y., Lin, S.D., Tu, Y.Y., et al.: Novel aramid nanofibercoated polypropylene separators for lithium ion batteries. J. Mater. Chem. A 4, 3513-3526 (2016). https://doi.org/10.1039/ c5ta08694a

134. Lee, B.P., Messersmith, P.B., Israelachvili, J.N., et al.: Musselinspired adhesives and coatings. Annu. Rev. Mater. Res. 41, 99-132 (2011). https://doi.org/10.1146/annurev-matsci-06291 $0-100429$

135. Waite, J.H.: Mussel power. Nat. Mater. 7, 8-9 (2008). https://doi. org/10.1038/nmat2087

136. Lv, X., Li, H., Zhang, Z.Q., et al.: UV grafting modification of polyethylene separator for Li-ion battery. Phys. Procedia 25, 227-232 (2012). https://doi.org/10.1016/j.phpro.2012.03.076

137. Yamamoto, K., Tanaka, H., Sakaguchi, M., et al.: Well-defined poly(methyl methacrylate) grafted to polyethylene with reverse atom transfer radical polymerization initiated by peroxides. Polymer 44, 7661-7669 (2003). https://doi.org/10.1016/j.polym er.2003.10.006

138. Ko, J.M., Min, B.G., Kim, D.W., et al.: Thin-film type Li-ion battery, using a polyethylene separator grafted with glycidyl methacrylate. Electrochim. Acta 50, 367-370 (2004). https:// doi.org/10.1016/j.electacta.2004.01.127

139. Lee, J.Y., Lee, Y.M., Bhattacharya, B., et al.: Separator grafted with siloxane by electron beam irradiation for lithium secondary batteries. Electrochim. Acta 54, 4312-4315 (2009). https://doi. org/10.1016/j.electacta.2009.02.088

140. Zhu, X.M., Jiang, X.Y., Ai, X.P., et al.: $\mathrm{TiO}_{2}$ ceramic-grafted polyethylene separators for enhanced thermostability and electrochemical performance of lithium-ion batteries. J. Membr. Sci. 504, 97-103 (2016). https://doi.org/10.1016/j.memsc i.2015.12.059

141. Xiang, Y.Y., Li, J.S., Lei, J.H., et al.: Advanced separators for lithium-ion and lithium-sulfur batteries: a review of recent progress. Chemsuschem 9, 3023-3039 (2016). https://doi. org/10.1002/cssc.201600943

142. Lee, Y., Lee, H., Lee, T., et al.: Synergistic thermal stabilization of ceramic/co-polyimide coated polypropylene separators for lithium-ion batteries. J. Power Sources 294, 537-544 (2015). https://doi.org/10.1016/j.jpowsour.2015.06.106

143. Wang, J., Hu, Z.Y., Yin, X.N., et al.: Alumina/phenolphthalein polyetherketone ceramic composite polypropylene separator film for lithium ion power batteries. Electrochim. Acta 159, 61-65 (2015). https://doi.org/10.1016/j.electacta.2015.01.208

144. Zhu, X.M., Jiang, X.Y., Ai, X.P., et al.: A highly thermostable ceramic-grafted microporous polyethylene separator for safer lithium-ion batteries. ACS Appl. Mater. Interfaces. 7, 24119 24126 (2015). https://doi.org/10.1021/acsami.5b07230

145. Nho, Y.C., Sohn, J.Y., Shin, J., et al.: Preparation of nanocomposite $\gamma-\mathrm{Al}_{2} \mathrm{O}_{3}$ /polyethylene separator crosslinked by electron beam irradiation for lithium secondary battery. Radiat. Phys. Chem. 132, 65-70 (2017). https://doi.org/10.1016/j.radphysche m.2016.12.002

146. Chen, H., Lin, Q., Xu, Q., et al.: Plasma activation and atomic layer deposition of $\mathrm{TiO}_{2}$ on polypropylene membranes for improved performances of lithium-ion batteries. J. Membr. Sci. 458, 217-224 (2014). https://doi.org/10.1016/j.memsc i.2014.02.004

147. Peng, K., Wang, B., Li, Y.M., et al.: Magnetron sputtering deposition of $\mathrm{TiO}_{2}$ particles on polypropylene separators for lithiumion batteries. RSC Adv. 5, 81468-81473 (2015). https://doi. org/10.1039/c5ra18171b

148. Shi, C., Zhang, P., Huang, S.H., et al.: Functional separator consisted of polyimide nonwoven fabrics and polyethylene coating layer for lithium-ion batteries. J. Power Sources 298, 158-165 (2015). https://doi.org/10.1016/j.jpowsour.2015.08.008

149. Wang, Z.H., Xiang, H.F., Wang, L.J., et al.: A paper-supported inorganic composite separator for high-safety lithium-ion batteries. J. Membr. Sci. 553, 10-16 (2018). https://doi.org/10.1016/j. memsci.2018.02.040

150. Gong, W.Z., Wei, S.Y., Ruan, S.L., et al.: Electrospun coaxial PPESK/PVDF fibrous membranes with thermal shutdown property used for lithium-ion batteries. Mater. Lett. 244, 126-129 (2019). https://doi.org/10.1016/j.matlet.2019.02.009

151. Zhang, H., Zhang, Y., Xu, T.G., et al.: Poly(m-phenylene isophthalamide) separator for improving the heat resistance and power density of lithium-ion batteries. J. Power Sources 329, 8-16 (2016). https://doi.org/10.1016/j.jpowsour.2016.08.036

152. Lee, J.R., Won, J.H., Kim, J.H., et al.: Evaporation-induced selfassembled silica colloidal particle-assisted nanoporous structural evolution of poly(ethylene terephthalate) nonwoven composite separators for high-safety/high-rate lithium-ion batteries. J. Power Sources 216, 42-47 (2012). https://doi.org/10.1016/j. jpowsour.2012.05.052

153. Zhai, Y.Y., Wang, N., Mao, X., et al.: Sandwich-structured PVdF/ PMIA/PVdF nanofibrous separators with robust mechanical strength and thermal stability for lithium ion batteries. J. Mater. Chem. A 2, 14511-14518 (2014). https://doi.org/10.1039/c4ta0 $2151 \mathrm{~g}$

154. Jeon, K.S., Nirmala, R., Navamathavan, R., et al.: The study of efficiency of $\mathrm{Al}_{2} \mathrm{O}_{3}$ drop coated electrospun meta-aramid nanofibers as separating membrane in lithium-ion secondary batteries. Mater. Lett. 132, 384-388 (2014). https://doi. org/10.1016/j.matlet.2014.06.117

155. Lee, J., Lee, C.L., Park, K., et al.: Synthesis of an $\mathrm{Al}_{2} \mathrm{O}_{3}$-coated polyimide nanofiber mat and its electrochemical characteristics as a separator for lithium ion batteries. J. Power Sources 248, 1211-1217 (2014). https://doi.org/10.1016/j.jpows our.2013.10.056

156. Jiang, F.J., Yin, L., Yu, Q.C., et al.: Bacterial cellulose nanofibrous membrane as thermal stable separator for lithium-ion batteries. J. Power Sources 279, 21-27 (2015). https://doi. org/10.1016/j.jpowsour.2014.12.090

157. Krol, L.F., Beneventi, D., Alloin, F., et al.: Microfibrillated cellulose- $\mathrm{SiO}_{2}$ composite nanopapers produced by spray deposition. $\mathrm{J}$. Mater. Sci. 50, 4095-4103 (2015). https://doi.org/10.1007/s1085 3-015-8965-5

158. Chun, S.J., Choi, E.S., Lee, E.H., et al.: Eco-friendly cellulose nanofiber paper-derived separator membranes featuring tunable nanoporous network channels for lithium-ion batteries. J. Mater. Chem. 22, 16618 (2012). https://doi.org/10.1039/c2jm32415f

159. Xiang, H.F., Chen, J.J., Li, Z., et al.: An inorganic membrane as a separator for lithium-ion battery. J. Power Sources 196, 86518655 (2011). https://doi.org/10.1016/j.jpowsour.2011.06.055

160. Chen, J.J., Wang, S.Q., Cai, D.D., et al.: Porous $\mathrm{SiO}_{2}$ as a separator to improve the electrochemical performance of spinel $\mathrm{LiMn}_{2} \mathrm{O}_{4}$ cathode. J. Membr. Sci. 449, 169-175 (2014). https:// doi.org/10.1016/j.memsci.2013.08.028

161. Raja, M., Angulakshmi, N., Thomas, S., et al.: Thin, flexible and thermally stable ceramic membranes as separator for lithiumion batteries. J. Membr. Sci. 471, 103-109 (2014). https://doi. org/10.1016/j.memsci.2014.07.058

162. Zhang, Y.C., Wang, Z.H., Xiang, H.F., et al.: A thin inorganic composite separator for lithium-ion batteries. J. Membr. Sci. 509, 19-26 (2016). https://doi.org/10.1016/j.memsci.2016.02.047

163. He, M.N., Zhang, X.J., Jiang, K.Y., et al.: Pure inorganic separator for lithium ion batteries. ACS Appl. Mater. Interfaces. 7, 738-742 (2015). https://doi.org/10.1021/am507145h 
164. Shim, E.G., Nam, T.H., Kim, J.G., et al.: Electrochemical performance of lithium-ion batteries with triphenylphosphate as a flame-retardant additive. J. Power Sources 172, 919-924 (2007). https://doi.org/10.1016/j.jpowsour.2007.04.088

165. Yim, T., Park, M.S., Woo, S.G., et al.: Self-extinguishing lithium ion batteries based on internally embedded fire-extinguishing microcapsules with temperature-responsiveness. Nano Lett. 15, 5059-5067 (2015). https://doi.org/10.1021/acs.nanolett.5b01167

166. Liu, K., Liu, W., Qiu, Y.C., et al.: Electrospun core-shell microfiber separator with thermal-triggered flame-retardant properties for lithium-ion batteries. Sci. Adv. 3, e1601978 (2017). https:// doi.org/10.1126/sciadv.1601978

167. Zhang, H.Y., Cao, Y.L., Yang, H.X., et al.: Facile preparation and electrochemical characterization of poly (4-methoxytriphenylamine)-modified separator as a self-activated potential switch for lithium ion batteries. Electrochim. Acta 108, 191-195 (2013). https://doi.org/10.1016/j.elect acta.2013.06.116

168. Kim, S.Y., Hong, J., Palmore, G.T.R.: Polypyrrole decorated cellulose for energy storage applications. Synth. Met. 162, 14781481 (2012). https://doi.org/10.1016/j.synthmet.2012.06.003

169. Li, S.L., Xia, L., Zhang, H.Y., et al.: A poly(3-decyl thiophene)modified separator with self-actuating overcharge protection mechanism for $\mathrm{LiFePO}_{4}$-based lithium ion battery. J. Power Sources 196, 7021-7024 (2011). https://doi.org/10.1016/j.jpows our.2010.09.111

170. Ziv, B., Levy, N., Borgel, V., et al.: Manganese sequestration and Li-ion batteries durability enhancement by polymeric 18-crown- 6 ethers. J. Electrochem. Soc. 161, A1213-A1217 (2014). https:// doi.org/10.1149/2.0091409jes

171. Banerjee, A., Ziv, B., Shilina, Y., et al.: Multifunctional manganese ions trapping and hydrofluoric acid scavenging separator for lithium ion batteries based on poly(ethylene-alternate-maleic acid) dilithium salt. Adv. Energy Mater. 7, 1601556 (2017). https ://doi.org/10.1002/aenm.201601556

172. Li, Z.C., Pauric, A.D., Goward, G.R., et al.: Manganese sequestration and improved high-temperature cycling of Li-ion batteries by polymeric aza-15-crown-5. J. Power Sources 272, 1134-1141 (2014). https://doi.org/10.1016/j.jpowsour.2014.04.073

173. Banerjee, A., Ziv, B., Luski, S., et al.: Increasing the durability of Li-ion batteries by means of manganese ion trapping materials with nitrogen functionalities. J. Power Sources 341, 457-465 (2017). https://doi.org/10.1016/j.jpowsour.2016.12.036

174. Nishi, Y.: Lithium ion secondary batteries; past 10 years and the future. J. Power Sources 100, 101-106 (2001). https://doi. org/10.1016/s0378-7753(01)00887-4

175. Kalhoff, J., Eshetu, G.G., Bresser, D., et al.: Safer electrolytes for lithium-ion batteries: state of the art and perspectives. Chemsuschem 8, 2154-2175 (2015). https://doi.org/10.1002/cssc.20150 0284

176. $\mathrm{Xu}, \mathrm{K}$.: Electrolytes and interphases in Li-ion batteries and beyond. Chem. Rev. 114, 11503-11618 (2014). https://doi. org/10.1021/cr500003w

177. Jiang, J.W., Dahn, J.R.: Effects of solvents and salts on the thermal stability of LiC6. Electrochim. Acta 49, 4599-4604 (2004). https://doi.org/10.1016/j.electacta.2004.05.014

178. Haregewoin, A.M., Wotango, A.S., Hwang, B.J.: Electrolyte additives for lithium ion battery electrodes: progress and perspectives. Energy Environ. Sci. 9, 1955-1988 (2016). https:// doi.org/10.1039/c6ee00123h

179. Moumouzias, G., Ritzoulis, G., Siapkas, D., et al.: Comparative study of $\mathrm{LiBF}_{4}, \mathrm{LiAsF} 6, \mathrm{LiPF} 6$, and $\mathrm{LiClO}_{4}$ as electrolytes in propylene carbonate-diethyl carbonate solutions for $\mathrm{Li} /$ $\mathrm{LiMn}_{2} \mathrm{O}_{4}$ cells. J. Power Sources 122, 57-66 (2003). https://doi. org/10.1016/S0378-7753(03)00348-3
180. Ferrari, S., Quartarone, E., Mustarelli, P., et al.: A binary ionic liquid system composed of $N$-methoxyethyl- $N$-methylpyrrolidinium bis(trifluoromethanesulfonyl)-imide and lithium bis(trifluoromethanesulfonyl)imide: a new promising electrolyte for lithium batteries. J. Power Sources 194, 45-50 (2009). https ://doi.org/10.1016/j.jpowsour.2008.12.013

181. Han, H.B., Zhou, S.S., Zhang, D.J., et al.: Lithium bis(fluorosulfonyl)imide (LiFSI) as conducting salt for nonaqueous liquid electrolytes for lithium-ion batteries: physicochemical and electrochemical properties. J. Power Sources 196, 36233632 (2011). https://doi.org/10.1016/j.jpowsour.2010.12.040

182. Zuo, X.X., Fan, C.J., Liu, J.S., et al.: Lithium tetrafluoroborate as an electrolyte additive to improve the high voltage performance of lithium-ion battery. J. Electrochem. Soc. 160, A1199-A1204 (2013). https://doi.org/10.1149/2.066308jes

183. Larush-Asraf, L., Biton, M., Teller, H., et al.: On the electrochemical and thermal behavior of lithium bis(oxalato)borate (LiBOB) solutions. J. Power Sources 174, 400-407 (2007). https ://doi.org/10.1016/j.jpowsour.2007.06.171

184. Wu, F., Zhu, Q.Z., Chen, R.J., et al.: Ionic liquid electrolytes with protective lithium difluoro(oxalate)borate for high voltage lithium-ion batteries. Nano Energy 13, 546-553 (2015). https:// doi.org/10.1016/j.nanoen.2015.03.042

185. Okuoka, S.I., Ogasawara, Y., Suga, Y., et al.: A new sealed lithium-peroxide battery with a co-doped $\mathrm{Li}_{2} \mathrm{O}$ cathode in a superconcentrated lithium bis(fluorosulfonyl)amide electrolyte. Sci. Rep. 4, 5684 (2015). https://doi.org/10.1038/srep05684

186. Wang, Q.S., Ping, P., Zhao, X.J., et al.: Thermal runaway caused fire and explosion of lithium ion battery. J. Power Sources 208, 210-224 (2012). https://doi.org/10.1016/j.jpowsour.2012.02.038

187. MacNeil, D.D., Dahn, J.R.: The reaction of charged cathodes with

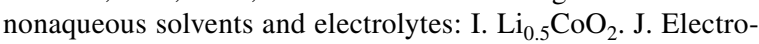
chem. Soc. 148, A1205 (2001). https://doi.org/10.1149/1.14072 45

188. Sloop, S.E., Kerr, J.B., Kinoshita, K.: The role of Li-ion battery electrolyte reactivity in performance decline and self-discharge. J. Power Sources 119(120/121), 330-337 (2003). https://doi. org/10.1016/s0378-7753(03)00149-6

189. Kawamura, T., Kimura, A., Egashira, M., et al.: Thermal stability of alkyl carbonate mixed-solvent electrolytes for lithium ion cells. J. Power Sources 104, 260-264 (2002). https://doi. org/10.1016/S0378-7753(01)00960-0

190. Sloop, S.E., Pugh, J.K., Wang, S., et al.: Chemical reactivity of $\mathrm{PF}_{5}$ and $\mathrm{LiPF}_{6}$ in ethylene carbonate/dimethyl carbonate solutions. Electrochem. Solid-State Lett. 4, A42 (2001). https://doi. org/10.1149/1.1353158

191. Schmidt, M., Heider, U., Kuehner, A., et al.: Lithium fluoroalkylphosphates: a new class of conducting salts for electrolytes for high energy lithium-ion batteries. J. Power Sources 97(98), 557-560 (2001). https://doi.org/10.1016/s0378-7753(01)00640 $-1$

192. Gnanaraj, J.S., Zinigrad, E., Asraf, L., et al.: On the use of $\mathrm{LiPF}_{3}\left(\mathrm{CF}_{2} \mathrm{CF}_{3}\right)_{3}$ (LiFAP) solutions for Li-ion batteries. electrochemical and thermal studies. Electrochem. Commun. 5, 946-951 (2003). https://doi.org/10.1016/j.elecom.2003.08.020

193. Xu, M.Q., Xiao, A., Li, W.S., et al.: Investigation of lithium tetrafluorooxalatophosphate as a lithium-ion battery electrolyte. Electrochem. Solid-State Lett. 12, A155 (2009). https://doi. org/10.1149/1.3134462

194. Qin, Y., Chen, Z.H., Liu, J., et al.: Lithium tetrafluoro oxalato phosphate as electrolyte additive for lithium-ion cells. Electrochem. Solid-State Lett. 13, A11 (2010). https://doi. org/10.1149/1.3261738

195. Huang, J.Y., Liu, X.J., Kang, X.L., et al.: Study on $\gamma$-butyrolactone for LiBOB-based electrolytes. J. Power 
Sources 189, 458-461 (2009). https://doi.org/10.1016/j.jpows our.2008.12.088

196. Xu, M.Q., Zhou, L., Hao, L.S., et al.: Investigation and application of lithium difluoro(oxalate)borate (LiDFOB) as additive to improve the thermal stability of electrolyte for lithium-ion batteries. J. Power Sources 196, 6794-6801 (2011). https://doi. org/10.1016/j.jpowsour.2010.10.050

197. Younesi, R., Veith, G.M., Johansson, P., et al.: Lithium salts for advanced lithium batteries: $\mathrm{Li}-$ metal, $\mathrm{Li}-\mathrm{O}_{2}$, and $\mathrm{Li}-\mathrm{S}$. Energy Environ. Sci. 8, 1905-1922 (2015). https://doi.org/10.1039/c5ee0 $1215 \mathrm{e}$

198. Yang, L., Zhang, H.J., Driscoll, P.F., et al.: Six-MemberedRing Malonatoborate-Based Lithium Salts as Electrolytes for Lithium Ion Batteries. ECS, Las Vegas, NV (2011). https://doi. org/10.1149/1.3589921

199. McMillan, R., Slegr, H., Shu, Z.X., et al.: Fluoroethylene carbonate electrolyte and its use in lithium ion batteries with graphite anodes. J. Power Sources 81(82), 20-26 (1999). https://doi. org/10.1016/s0378-7753(98)00201-8

200. Korepp, C., Kern, W., Lanzer, E.A., et al.: 4-Bromobenzyl isocyanate versus benzyl isocyanate: new film-forming electrolyte additives and overcharge protection additives for lithium ion batteries. J. Power Sources 174, 637-642 (2007). https://doi. org/10.1016/j.jpowsour.2007.06.142

201. Li, Z.D., Zhang, Y.C., Xiang, H.F., et al.: Trimethyl phosphite as an electrolyte additive for high-voltage lithium-ion batteries using lithium-rich layered oxide cathode. J. Power Sources 240, 471-475 (2013). https://doi.org/10.1016/j.jpowsour.2013.04.038

202. Chandrasekaran, R., Koh, M., Ozhawa, Y., et al.: Electrochemical cell studies on fluorinated natural graphite in propylene carbonate electrolyte with difluoromethyl acetate (MFA) additive for low temperature lithium battery application. J. Chem. Sci. 121, 339-346 (2009). https://doi.org/10.1007/s12039-009-0039-2

203. Xia, L., Xia, Y.G., Wang, C.S., et al.: 5 V-class electrolytes based on fluorinated solvents for $\mathrm{Li}$-ion batteries with excellent cyclability. ChemElectroChem 2, 1707-1712 (2015). https://doi. org/10.1002/celc.201500286

204. Lee, Y.M., Nam, K.M., Hwang, E.H., et al.: Interfacial origin of performance improvement and fade for $4.6 \mathrm{~V}$ $\mathrm{LiNi}_{0.5} \mathrm{Co}_{0.2} \mathrm{Mn}_{0.3} \mathrm{O}_{2}$ battery cathodes. J. Phys. Chem. C 118, 10631-10639 (2014). https://doi.org/10.1021/jp501670g

205. Xiang, H.F., Xu, H.Y., Wang, Z.Z., et al.: Dimethyl methylphosphonate (DMMP) as an efficient flame retardant additive for the lithium-ion battery electrolytes. J. Power Sources 173, 562-564 (2007). https://doi.org/10.1016/j.jpowsour.2007.05.001

206. Levchik, S.V., Weil, E.D.: A review of recent progress in phosphorus-based flame retardants. J. Fire Sci. 24, 345-364 (2006). https://doi.org/10.1177/0734904106068426

207. Tu, W.Q., Xia, P., Zheng, X.W., et al.: Insight into the interaction between layered lithium-rich oxide and additive-containing electrolyte. J. Power Sources 341, 348-356 (2017). https://doi. org/10.1016/j.jpowsour.2016.12.012

208. Nam, T.H., Shim, E.G., Kim, J.G., et al.: Diphenyloctyl phosphate and tris(2,2,2-trifluoroethyl) phosphite as flame-retardant additives for Li-ion cell electrolytes at elevated temperature. J. Power Sources 180, 561-567 (2008). https://doi.org/10.1016/j. jpowsour.2008.01.061

209. Wang, X.M., Yasukawa, E., Kasuya, S.: Nonflammable trimethyl phosphate solvent-containing electrolytes for lithium-ion batteries: I. fundamental properties. J. Electrochem. Soc. 148, A1058 (2001). https://doi.org/10.1149/1.1397773

210. Xu, K., Ding, M.S., Zhang, S.S., et al.: An attempt to formulate nonflammable lithium ion electrolytes with alkyl phosphates and phosphazenes. J. Electrochem. Soc. 149, A622 (2002). https:// doi.org/10.1149/1.1467946
211. Yoon, W.S., Haas, O., Muhammad, S., et al.: In situ soft XAS study on nickel-based layered cathode material at elevated temperatures: a novel approach to study thermal stability. Sci. Rep. 4, 6827 (2015). https://doi.org/10.1038/srep06827

212. Liu, J.W., Song, X., Zhou, L., et al.: Fluorinated phosphazene derivative-a promising electrolyte additive for high voltage lithium ion batteries: from electrochemical performance to corrosion mechanism. Nano Energy 46, 404-414 (2018). https://doi. org/10.1016/j.nanoen.2018.02.029

213. Ihara, M., Hang, B.T., Sato, K., et al.: Properties of carbon anodes and thermal stability in $\mathrm{LiPF}_{6} /$ methyl difluoroacetate electrolyte. J. Electrochem. Soc. 150, A1476 (2003). https://doi. org/10.1149/1.1614269

214. Lee, H.H., Wang, Y.Y., Wan, C.C., et al.: The function of vinylene carbonate as a thermal additive to electrolyte in lithium batteries. J. Appl. Electrochem. 35, 615-623 (2005). https://doi. org/10.1007/s10800-005-2700-x

215. Ota, H., Sakata, Y., Inoue, A., et al.: Analysis of vinylene carbonate derived SEI layers on graphite anode. J. Electrochem. Soc. 151, A1659 (2004). https://doi.org/10.1149/1.1785795

216. Vollmer, J.M., Curtiss, L.A., Vissers, D.R., et al.: Reduction mechanisms of ethylene, propylene, and vinylethylene carbonates. J. Electrochem. Soc. 151, A178 (2004). https://doi. org/10.1149/1.1633765

217. Chen, Z.H., Qin, Y., Amine, K.: Redox shuttles for safer lithiumion batteries. Electrochim. Acta 54, 5605-5613 (2009). https:// doi.org/10.1016/j.electacta.2009.05.017

218. Xiao, L.F., Ai, X.P., Cao, Y.L., et al.: Electrochemical behavior of biphenyl as polymerizable additive for overcharge protection of lithium ion batteries. Electrochim. Acta 49, 4189-4196 (2004). https://doi.org/10.1016/j.electacta.2004.04.013

219. Elia, G.A., Ulissi, U., Jeong, S., et al.: Exceptional long-life performance of lithium-ion batteries using ionic liquid-based electrolytes. Energy Environ. Sci. 9, 3210-3220 (2016). https://doi. org/10.1039/c6ee01295g

220. Bhatt, A.I., Best, A.S., Huang, J.H., et al.: Application of the $N$-propyl- $N$-methyl-pyrrolidinium bis(fluorosulfonyl)imide RTIL containing lithium bis(fluorosulfonyl)imide in ionic liquid based lithium batteries. J. Electrochem. Soc. 157, A66 (2010). https:// doi.org/10.1149/1.3257978

221. Mun, J., Yim, T., Jurng, S., et al.: The feasibility of a pyrrolidinium-based ionic liquid solvent for non-graphitic carbon electrodes. Electrochem. Commun. 13, 1256-1259 (2011). https:// doi.org/10.1016/j.elecom.2011.08.030

222. Lewandowski, A., Świderska-Mocek, A.: Ionic liquids as electrolytes for Li-ion batteries: an overview of electrochemical studies. J. Power Sources 194, 601-609 (2009). https://doi.org/10.1016/j. jpowsour.2009.06.089

223. Fernicola, A., Croce, F., Scrosati, B., et al.: LiTFSI-BEPyTFSI as an improved ionic liquid electrolyte for rechargeable lithium batteries. J. Power Sources 174, 342-348 (2007). https://doi. org/10.1016/j.jpowsour.2007.09.013

224. Patry, G., Romagny, A., Martinet, S., et al.: Cost modeling of lithium-ion battery cells for automotive applications. Energy Sci. Eng. 3, 71-82 (2015). https://doi.org/10.1002/ese3.47

225. Blidberg, A., Gustafsson, T., Tengstedt, C., et al.: Monitoring $\mathrm{Li}_{x} \mathrm{FeSO}_{4} \mathrm{~F}(x=1,0.5,0)$ phase distributions in operando to determine reaction homogeneity in porous battery electrodes. Chem. Mater. 29, 7159-7169 (2017). https://doi.org/10.1021/acs. chemmater.7b01019

226. Harris, S.J., Timmons, A., Baker, D.R., et al.: Direct in situ measurements of Li transport in Li-ion battery negative electrodes. Chem. Phys. Lett. 485, 265-274 (2010). https://doi. org/10.1016/j.cplett.2009.12.033 
227. Sander, J.S., Erb, R.M., Li, L., et al.: High-performance battery electrodes via magnetic templating. Nat. Energy 1, 16099 (2016). https://doi.org/10.1038/nenergy.2016.99

228. Ebner, M., Chung, D.W., García, R.E., et al.: Electrodes: tortuosity anisotropy in lithium-ion battery electrodes. Adv. Energy Mater. 4, 1301278 (2014). https://doi.org/10.1002/aenm.20147 0024

229. Chen, C.J., Zhang, Y., Li, Y.J., et al.: Highly conductive, lightweight, low-tortuosity carbon frameworks as ultrathick 3D current collectors. Adv. Energy Mater. 7, 1700595 (2017). https:// doi.org/10.1002/aenm.201700595

230. Wilke, S., Schweitzer, B., Khateeb, S., et al.: Preventing thermal runaway propagation in lithium ion battery packs using a phase change composite material: an experimental study. J. Power Sources 340, 51-59 (2017). https://doi.org/10.1016/j.jpows our.2016.11.018

231. Finegan, D.P., Scheel, M., Robinson, J.B., et al.: In-operando high-speed tomography of lithium-ion batteries during thermal runaway. Nat. Commun. 6, 6924 (2015). https://doi.org/10.1038/ ncomms 7924

232. Zhong, H., Kong, C., Zhan, H., et al.: Safe positive temperature coefficient composite cathode for lithium ion battery. J. Power Sources 216, 273-280 (2012). https://doi.org/10.1016/j.jpows our.2012.05.015

233. Feng, X.M., Ai, X.P., Yang, H.X.: A positive-temperaturecoefficient electrode with thermal cut-off mechanism for use in rechargeable lithium batteries. Electrochem. Commun. 6, 10211024 (2004). https://doi.org/10.1016/j.elecom.2004.07.021

234. Zhang, H.Y., Pang, J., Ai, X.P., et al.: Poly(3-butylthiophene)based positive-temperature-coefficient electrodes for safer lithium-ion batteries. Electrochim. Acta 187, 173-178 (2016). https ://doi.org/10.1016/j.electacta.2015.11.036

235. Yang, H., Leow, W.R., Chen, X.D.: Thermal-responsive polymers for enhancing safety of electrochemical storage devices. Adv. Mater. 30, 1704347 (2018). https://doi.org/10.1002/adma.20170 4347

236. Kise, M., Yoshioka, S., Hamano, K., et al.: Development of new safe electrode for lithium rechargeable battery. J. Power Sources 146, 775-778 (2005). https://doi.org/10.1016/j.jpows our.2005.03.158

237. Kise, M., Yoshioka, S., Hamano, K., et al.: Alternating current impedance behavior and overcharge tolerance of lithiumion batteries using positive temperature coefficient cathodes. J. Electrochem. Soc. 153, A1004 (2006). https://doi. org/10.1149/1.2189262

238. Abada, S., Marlair, G., Lecocq, A., et al.: Safety focused modeling of lithium-ion batteries: a review. J. Power Sources 306, 178-192 (2016). https://doi.org/10.1016/j.jpows our.2015.11.100

239. Xia, L., Li, S.L., Ai, X.P., et al.: Temperature-sensitive cathode materials for safer lithium-ion batteries. Energy Environ. Sci. 4, 2845 (2011). https://doi.org/10.1039/c0ee00590h

240. Mai, L.Q., Yan, M.Y., Zhao, Y.L.: Track batteries degrading in real time. Nature 546, 469-470 (2017). https://doi. org/10.1038/546469a

241. Mutyala, M.S.K., Zhao, J.Z., Li, J.Y., et al.: In-situ temperature measurement in lithium ion battery by transferable flexible thin film thermocouples. J. Power Sources 260, 43-49 (2014). https ://doi.org/10.1016/j.jpowsour.2014.03.004

242. Forgez, C., Vinh Do, D., Friedrich, G., et al.: Thermal modeling of a cylindrical $\mathrm{LiFePO}_{4}$ /graphite lithium-ion battery. J. Power Sources 195, 2961-2968 (2010). https://doi.org/10.1016/j.jpows our.2009.10.105

243. Zhu, J.G., Sun, Z.C., Wei, X.Z., et al.: Battery internal temperature estimation for $\mathrm{LiFePO}_{4}$ battery based on impedance phase shift under operating conditions. Energies 10, 60 (2017). https ://doi.org/10.3390/en10010060

244. Lee, C.Y., Chuang, S.M., Lee, S.J., et al.: Flexible micro sensor for in situ monitoring temperature and voltage of coin cells. Sens. Actuat. A Phys. 232, 214-222 (2015). https://doi.org/10.1016/j. sna.2015.06.004

245. Lee, C.Y., Lee, S.J., Hung, Y.M., et al.: Integrated microsensor for real-time microscopic monitoring of local temperature, voltage and current inside lithium ion battery. Sens. Actuat. A Phys. 253, 59-68 (2017). https://doi.org/10.1016/j.sna.2016.10.011

246. Ghannoum, A., Nieva, P., Yu, A.P., et al.: Development of embedded fiber-optic evanescent wave sensors for optical characterization of graphite anodes in lithium-ion batteries. ACS Appl. Mater. Interfaces. 9, 41284-41290 (2017). https://doi. org/10.1021/acsami.7b13464

247. Nascimento, M., Ferreira, M.S., Pinto, J.L.: Real time thermal monitoring of lithium batteries with fiber sensors and thermocouples: a comparative study. Measurement 111, 260-263 (2017). https://doi.org/10.1016/j.measurement.2017.07.049

248. Nascimento, M., Novais, S., Ding, M.S., et al.: Internal strain and temperature discrimination with optical fiber hybrid sensors in Li-ion batteries. J. Power Sources 410(411), 1-9 (2019). https:// doi.org/10.1016/j.jpowsour.2018.10.096

249. Sommer, L.W., Kiesel, P., Ganguli, A., et al.: Fast and slow ion diffusion processes in lithium ion pouch cells during cycling observed with fiber optic strain sensors. J. Power Sources 296, 46-52 (2015). https://doi.org/10.1016/j.jpowsour.2015.07.025

250. Novais, S., Nascimento, M., Grande, L., et al.: Internal and external temperature monitoring of a Li-ion battery with fiber Bragg grating sensors. Sensors 16, 1394 (2016). https://doi. org/10.3390/s16091394

251. Suresh, P., Shukla, A.K., Munichandraiah, N.: Temperature dependence studies of a.c. impedance of lithium-ion cells. J. Appl. Electrochem. 32, 267-273 (2002)

252. Zhu, J.G., Sun, Z.C., Wei, X.Z., et al.: A new lithium-ion battery internal temperature on-line estimate method based on electrochemical impedance spectroscopy measurement. J. Power Sources 274, 990-1004 (2015). https://doi.org/10.1016/j.jpows our.2014.10.182

253. Srinivasan, R., Demirev, P.A., Carkhuff, B.G.: Rapid monitoring of impedance phase shifts in lithium-ion batteries for hazard prevention. J. Power Sources 405, 30-36 (2018). https://doi. org/10.1016/j.jpowsour.2018.10.014

254. Wu, M.S., Chiang, P.C.J., Lin, J.C.: Electrochemical investigations on advanced lithium-ion batteries by three-electrode measurements. J. Electrochem. Soc. 152, A47 (2005). https:// doi.org/10.1149/1.1825385

255. Srinivasan, R., Carkhuff, B.G., Butler, M.H., et al.: Instantaneous measurement of the internal temperature in lithium-ion rechargeable cells. Electrochim. Acta 56, 6198-6204 (2011). https://doi. org/10.1016/j.electacta.2011.03.136

256. An, S.J., Li, J.L., Daniel, C., et al.: Design and demonstration of three-electrode pouch cells for lithium-ion batteries. J. Electrochem. Soc. 164, A1755-A1764 (2017). https://doi. org/10.1149/2.0031709jes

257. Yang, X.G., Ge, S.H., Liu, T., et al.: A look into the voltage plateau signal for detection and quantification of lithium plating in lithium-ion cells. J. Power Sources 395, 251-261 (2018). https ://doi.org/10.1016/j.jpowsour.2018.05.073

258. Jansen, A.N., Dees, D.W., Abraham, D.P., et al.: Low-temperature study of lithium-ion cells using a $\mathrm{Li}_{y} \mathrm{~S}_{n}$ micro-reference electrode. J. Power Sources 174, 373-379 (2007). https://doi. org/10.1016/j.jpowsour.2007.06.235

259. La Mantia, F., Wessells, C.D., Deshazer, H.D., et al.: Reliable reference electrodes for lithium-ion batteries. Electrochem. 
Commun. 31, 141-144 (2013). https://doi.org/10.1016/j.eleco m.2013.03.015

260. Liu, Q.Q., Du, C.Y., Shen, B., et al.: Understanding undesirable anode lithium plating issues in lithium-ion batteries. RSC Adv. 6, 88683-88700 (2016). https://doi.org/10.1039/c6ra19482f

261. Wu, H., Zhuo, D., Kong, D.S., et al.: Improving battery safety by early detection of internal shorting with a bifunctional separator. Nat. Commun. 5, 5193 (2014). https://doi.org/10.1038/ncomm s6193

262. Burns, J.C., Stevens, D.A., Dahn, J.R.: In-situ detection of lithium plating using high precision coulometry. J. Electrochem. Soc. 162, A959-A964 (2015). https://doi.org/10.1149/2.06215 06jes

263. Bitzer, B., Gruhle, A.: A new method for detecting lithium plating by measuring the cell thickness. J. Power Sources 262, 297-302 (2014). https://doi.org/10.1016/j.jpowsour.2014.03.142

264. Rieger, B., Schuster, S.F., Erhard, S.V., et al.: Multi-directional laser scanning as innovative method to detect local cell damage during fast charging of lithium-ion cells. J. Energy Storage 8, 1-5 (2016). https://doi.org/10.1016/j.est.2016.09.002

265. Grimsmann, F., Gerbert, T., Brauchle, F., et al.: Determining the maximum charging currents of lithium-ion cells for small charge quantities. J. Power Sources 365, 12-16 (2017). https:// doi.org/10.1016/j.jpowsour.2017.08.044

266. Uhlmann, C., Illig, J., Ender, M., et al.: In situ detection of lithium metal plating on graphite in experimental cells. J. Power Sources 279, 428-438 (2015). https://doi.org/10.1016/j.jpows our.2015.01.046

267. Smart, M.C., Ratnakumar, B.V.: Effects of electrolyte composition on lithium plating in lithium-ion cells. J. Electrochem. Soc. 158, A379 (2011). https://doi.org/10.1149/1.3544439

268. Petzl, M., Danzer, M.A.: Nondestructive detection, characterization, and quantification of lithium plating in commercial lithiumion batteries. J. Power Sources 254, 80-87 (2014). https://doi. org/10.1016/j.jpowsour.2013.12.060

269. von Lüders, C., Zinth, V., Erhard, S.V., et al.: Lithium plating in lithium-ion batteries investigated by voltage relaxation and in situ neutron diffraction. J. Power Sources 342, 17-23 (2017). https:// doi.org/10.1016/j.jpowsour.2016.12.032

270. Schindler, S., Bauer, M., Petzl, M., et al.: Voltage relaxation and impedance spectroscopy as in-operando methods for the detection of lithium plating on graphitic anodes in commercial lithium-ion cells. J. Power Sources 304, 170-180 (2016). https ://doi.org/10.1016/j.jpowsour.2015.11.044

271. Guo, Z.S., Zhu, J.Y., Feng, J.M., et al.: Direct in situ observation and explanation of lithium dendrite of commercial graphite electrodes. RSC Adv. 5, 69514-69521 (2015). https://doi. org/10.1039/c5ra13289d

272. Mehdi, B.L., Qian, J., Nasybulin, E., et al.: Observation and quantification of nanoscale processes in lithium batteries by operando electrochemical (S)TEM. Nano Lett. 15, 2168-2173 (2015). https://doi.org/10.1021/acs.nanolett.5b00175

273. Sagane, F., Shimokawa, R., Sano, H., et al.: In-situ scanning electron microscopy observations of Li plating and stripping reactions at the lithium phosphorus oxynitride glass electrolyte/ $\mathrm{Cu}$ interface. J. Power Sources 225, 245-250 (2013). https://doi. org/10.1016/j.jpowsour.2012.10.026

274. Wandt, J., Jakes, P., Granwehr, J., et al.: Quantitative and timeresolved detection of lithium plating on graphite anodes in lithium ion batteries. Mater. Today 21, 231-240 (2018). https://doi. org/10.1016/j.mattod.2017.11.001

275. Gotoh, K., Izuka, M., Arai, J., et al.: In situ 7Li nuclear magnetic resonance study of the relaxation effect in practical lithium ion batteries. Carbon 79, 380-387 (2014). https://doi.org/10.1016/j. carbon.2014.07.080
276. Finegan, D.P., Darcy, E., Keyser, M., et al.: Thermal runaway: identifying the cause of rupture of $\mathrm{Li}$-ion batteries during thermal runaway. Adv. Sci. 5, 1870003 (2018). https://doi.org/10.1002/ advs.201870003

277. Sun, J., Li, J.G., Zhou, T., et al.: Toxicity, a serious concern of thermal runaway from commercial Li-ion battery. Nano Energy 27, 313-319 (2016). https://doi.org/10.1016/j.nanoe n.2016.06.031

278. Fernandes, Y., Bry, A., de Persis, S.: Identification and quantification of gases emitted during abuse tests by overcharge of a commercial Li-ion battery. J. Power Sources 389, 106-119 (2018). https://doi.org/10.1016/j.jpowsour.2018.03.034

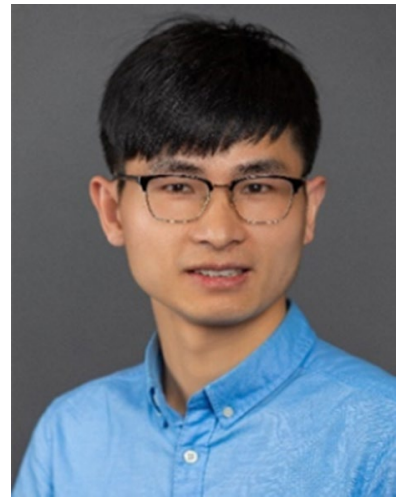

Jian Duan is currently a $\mathrm{Ph} . \mathrm{D}$. candidate in the School of Materials Science and Engineering, Tongji University. He received his B.S. and M.S. degrees from Huazhong University of Science and Technology (HUST) in 2012 and in 2015, respectively. In July 2015, he joined the Contemporary Amperex Technology Co. Limited (CATL) as a battery engineer and focused on the design of high-performance lithium-ion batteries (LIBs) for electric vehicles (EVs) and had worked for 2 years until he came back to study in Tongji University. Now he focuses on building LIBs with high energy density, safety issues of LIBs and all solid-state batteries.

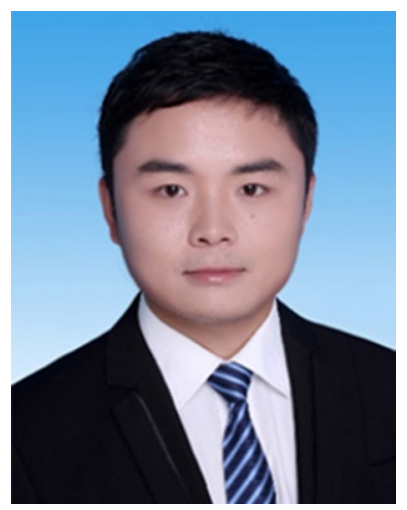

Xuan Tang is a Ph.D. candidate under the supervision of Prof. Xuezhe Wei at the Clean Energy Automotive Engineering Center, School of Automotive Studies, at Tongji University. He received his M.S. degree from Hunan University, China, in 2016. His current research is focusing on the safety issues and corresponding solutions of the energy storage system for new energy vehicles (NEVs).

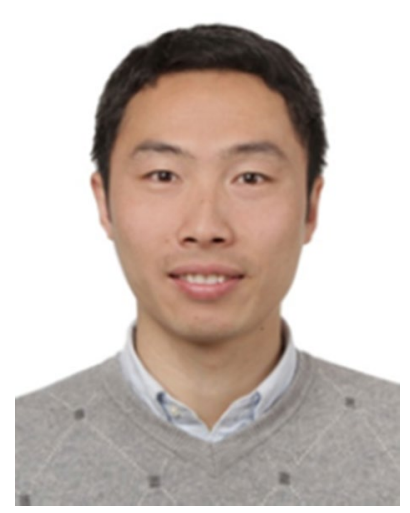

Haifeng Dai is currently a full professor at Tongji University. He received his Ph.D. in vehicular engineering in 2008 from Tongji University. His current research interest mainly focuses on the topics of characteristic modeling, state estimation, aging and safety issues of lithium-ion batteries and fuel cell systems for vehicular applications. Professor Dai has co-authored more than 40 research papers published in refereed journals and has been authorized more than 15 patents. 


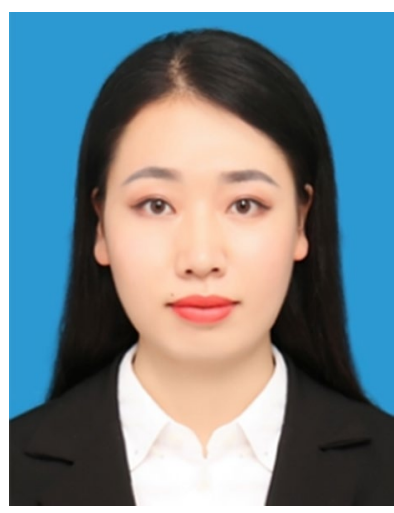

Ying Yang is now working as a postdoctoral fellow in the group of Prof. Yunhui Huang at the Clean Energy Automotive Engineering Center of Tongji University. She received her Ph.D. degree in physical chemistry from Dalian University of Technology (DUT), China, in 2018. Currently, her research interest mainly focuses on the advanced alloytype anode materials, especially tin-based materials for $\mathrm{Li}$-ion batteries and Na-ion batteries, and cathode materials of $\mathrm{Al}$ ion batteries such as carbon materials.

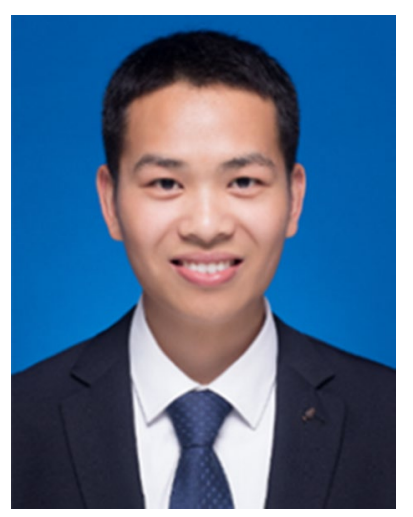

Wangyan Wu is currently a senior student of Tongji University, majoring in materials science and engineering. He started his $\mathrm{Ph} . \mathrm{D}$. career from September 2019 under the supervision of Prof. Wei Luo at the Institute of New Energy for Vehicles, Tongji University. He has previously joined in programs on solid-state batteries.

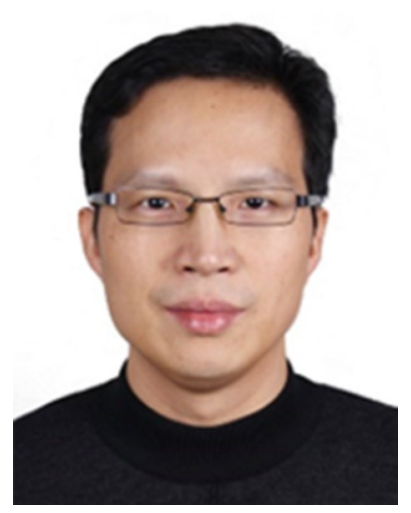

XuezheWei is a professor of automotive engineering at Tongji University. He received his Ph.D. in automotive engineering from Tongji University in 2005. He works as the director of the Clean Energy Automotive Engineering Center and the vice dean of the School of Automotive Studies in Tongji University. His current research is focusing on power systems for new energy vehicles (NEVs), which includes the battery management system (BMS) for battery electric vehicles (BEVs), the fuel cell control system for fuel cell vehicles (FCVs), etc.

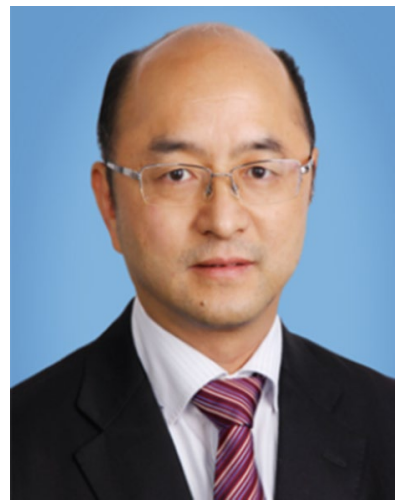

Yunhui Huang received his Ph.D. from Peking University in 2000. From 2004 to 2007, he worked with Prof. John Goodenough in the University of Texas at Austin. In 2008, he became a Chair Professor of materials science in Huazhong University of Science and Technology. He is now the Director of the Institute of New Energy for Vehicles in Tongji University. His research group works on rechargeable batteries for energy storage and their electrode materials. 